Supporting Information

\title{
How to Constrain Metal-Oxyl Bonds on a Solid Surface? Lesson from Isovalent Zn(II)-Oxyl and Ga(III)-Oxyl Bonds Isolated in Zeolite Matrix
}

\author{
Akira Oda, ${ }^{*}$, a, b Tomoyasu Tanaka, ${ }^{a}$ Kyoichi Sawabe, ${ }^{a}$ Atsushi Satsuma ${ }^{\text {a, b }}$ \\ aDepartment of Materials Chemistry, Graduate School of Engineering, Nagoya University, Nagoya 464-8603, Japan. \\ bElements Strategy Initiative for Catalysts and Batteries (ESICB), Kyoto University, Kyoto 615-8520, Japan.
}

Corresponding Author

*Email: akira@ chembio.nagoya-u.ac.jp (A. O.) 


\section{Table of Contents}

1. Methods

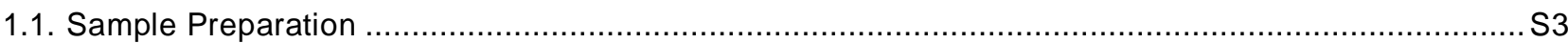

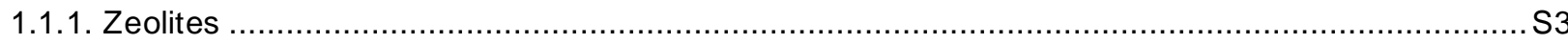

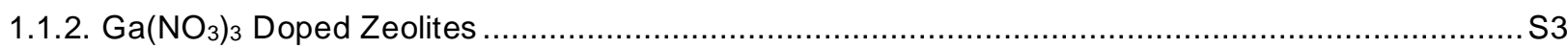

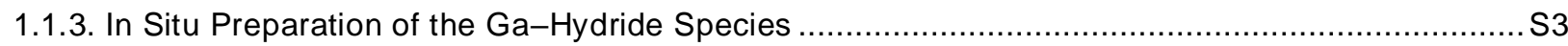

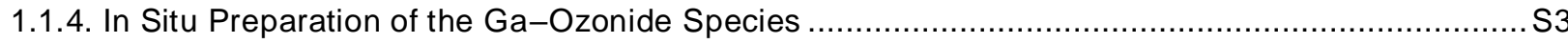

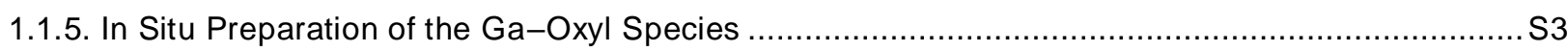

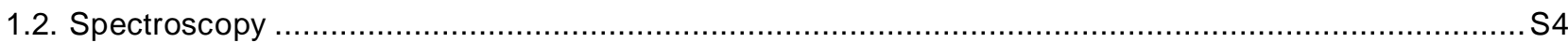

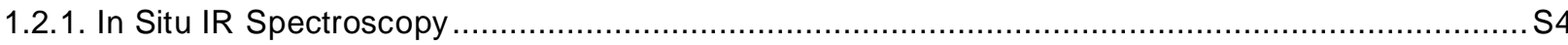

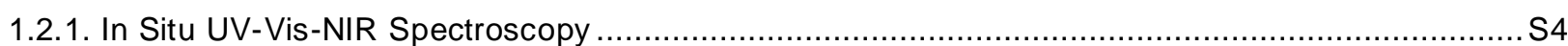

1.2.3. In Situ Electron Spin Resonance (ESR) Spectroscopy ............................................................. 4

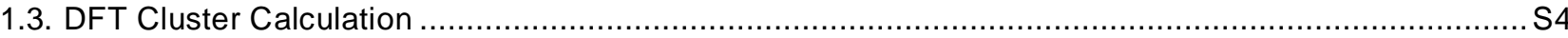

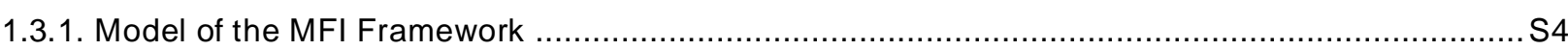

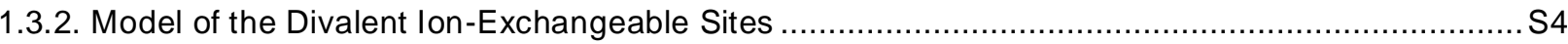

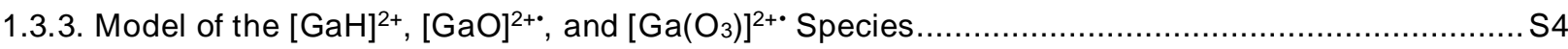

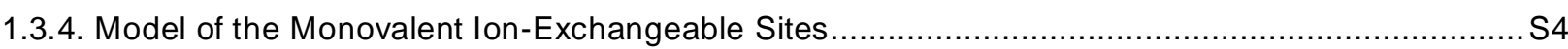

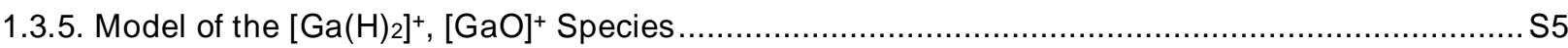

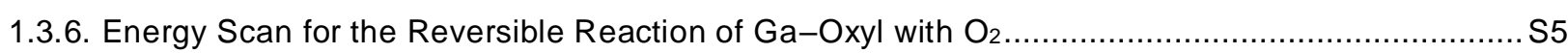

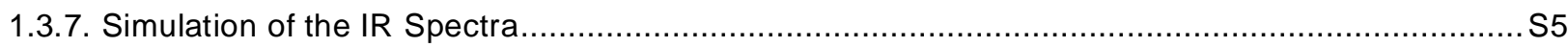

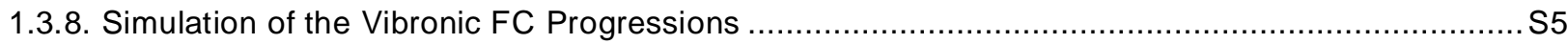

1.3.9. Computational Prediction of the UV-Vis-NIR Spectrum of the $\left[\mathrm{Ga} \mathrm{a}^{\prime \prime \prime}=\mathrm{O}\right]^{+}$Species ..........................S6

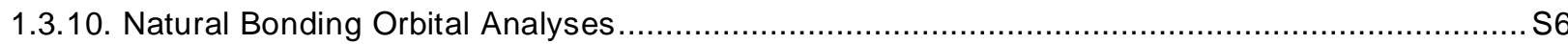

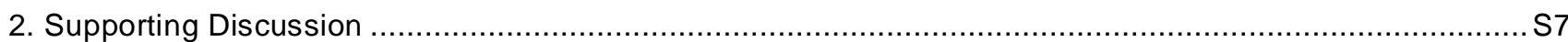

2.1. IR Evidence for the $[\mathrm{GaH}]^{2+}$ Species as the Precursor of the $\mathrm{Ga}-\mathrm{O}$ Radicals .................................S7

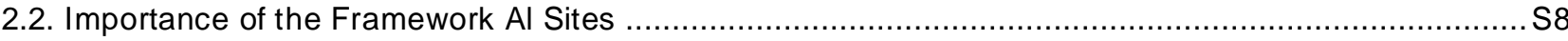

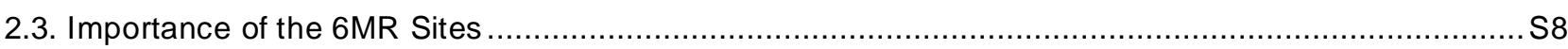

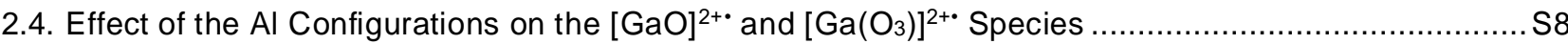

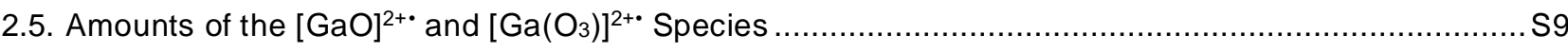

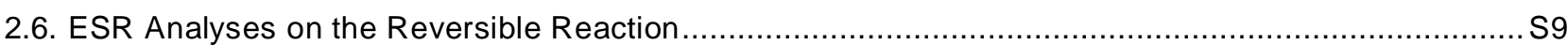

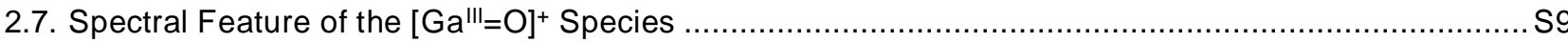

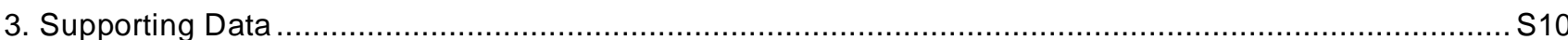

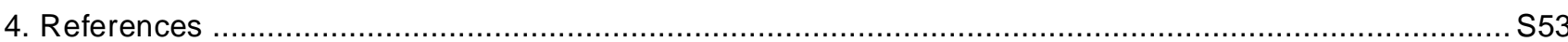




\section{Methods}

\subsection{Sample Preparation}

1.1.1. Zeolites. $\mathrm{NH}_{4}{ }^{+}$ion-exchanged MFI with $\mathrm{Si} / \mathrm{Al}=20$ (TOSO Co. Ltd.) was pre-calcined at $873 \mathrm{~K}$ under vacuum $(<$ $10^{-6}$ Torr), by which $\mathrm{H}^{+}$ion-exchanged MFI was obtained. Al-free MFI zeolite, i.e., silicate, was synthesized by the following procedure. First, $0.83 \mathrm{~g} \mathrm{NaOH}$ and $52.06 \mathrm{~g}$ of $22.5 \mathrm{wt} \%$ tetrapropylammonium hydroxide (TPAOH) aqueous solution were added to $72.39 \mathrm{ml}$ of distilled water in a $300-\mathrm{ml}$ Teflon beaker, and the mixture was well stirred for $10 \mathrm{~min}$ at ambient condition. Next, $31.7 \mathrm{~g}$ colloidal silica was loaded into the mixture with vigorous stirring for $1 \mathrm{~h}$. The synthesis solution was then transferred to a 300-ml Teflon-line stainless steel autoclave, and placed in a convection oven at $443 \mathrm{~K}$ and rotated at $15 \mathrm{rpm}$ for $1 \mathrm{~d}$. The sample was cooled to room temperature (RT) and collected by filtration. The sample was well rinsed and subsequently dried overnight at $353 \mathrm{~K}$. To remove the structure-directing agent, the as-synthesized zeolite was calcined in air at $823 \mathrm{~K}$ overnight. The obtained sample was identified by XRD as having the MFI-type structure.

1.1.2. $\mathrm{Ga}\left(\mathrm{NO}_{3}\right)_{3}$-Doped Zeolites. $1 \mathrm{~g} \mathrm{H}^{+}$-zeolites were dispersed in a $\mathrm{Ga}\left(\mathrm{NO}_{3}\right)_{3}$ aqueous solution at $\mathrm{RT}$ for $1 \mathrm{~h}$. The amount of the $\mathrm{Ga}$ ion was set to $\mathrm{Ga} / \mathrm{Al}=0.5$, where $\mathrm{Ga} / \mathrm{Al}$ means the ratio between $\mathrm{Ga}$ and the framework $\mathrm{Al}$ atoms. Next, the water was evaporated at $343 \mathrm{~K}$ and subsequently dried at RT under vacuum. For the preparation of the $\mathrm{Ga}\left(\mathrm{NO}_{3}\right)_{3}$-doped MFI silicate, the amount of $\mathrm{Ga}$ ion was set to the same amount for the $\mathrm{Ga}\left(\mathrm{NO}_{3}\right)_{3}$-doped $\mathrm{H}^{+}$- $\mathrm{MFI}$ zeolite having $\mathrm{Si} / \mathrm{Al}=20$ and $\mathrm{Ga} / \mathrm{Al}=0.5$.

1.1.3. In Situ Preparation of the Ga-Hydride Species. The $\mathrm{Ga}\left(\mathrm{NO}_{3}\right)_{3}$-modified zeolites were evacuated at $873 \mathrm{~K}$ and subsequently treated under $\mathrm{H}_{2}$ atmosphere $\left(P_{\mathrm{e}}=100\right.$ Torr $)$ at $873 \mathrm{~K}$, through which the Ga ion was reduced to the zerovalent state. This mobile $\mathrm{Ga}^{0}$ species is easily incorporated into the zeolite pore and ion-exchanged with a proton, as demonstrated in numerous studies. ${ }^{[\mathrm{S} 1]}$ The reduction process of the $\mathrm{Ga}$ ion generates a large amount of $\mathrm{H}_{2} \mathrm{O}$. The generated $\mathrm{H}_{2} \mathrm{O}$ was trapped by a cooled trap placed in a glass vacuum line at $77 \mathrm{~K}$ using liquid $\mathrm{N}$. After the reduction, the sample was cooled to RT and subsequently irradiated with UV light $(\lambda<300 \mathrm{~nm})$ for $1 \mathrm{~h}$ in the presence of $\mathrm{H}_{2}$ gas with the aim of producing as much Ga-hydride as possible. Spectroscopic evidence for the efficient generation of the Ga-hydride species is discussed in the Supporting Discussion (2.1). The amount of the ion-exchanged $\mathrm{H}^{+}$was evaluated by intensities of the IR band at $3613 \mathrm{~cm}^{-1}$ attributed to the $\mathrm{O}-\mathrm{H}$ vibrational mode of the Brønsted acid site (Figure S1). From this result, it was found that $32 \%$ of $\mathrm{H}^{+}$was ion-exchanged with $\mathrm{Ga}$ ions. This ion-exchange degree is consistent well with the report of Bell et al. ${ }^{[\mathrm{S} 1 \mathrm{~g}]}$

1.1.4. In Situ Preparation of the Ga-Ozonide Species. After the preparation of the Ga-hydride species, the sample was exposed to $\mathrm{O}_{2}$ gas $\left(P_{\mathrm{e}}=100\right.$ Torr $)$ at $\mathrm{RT}$, and subsequently irradiated with UV light for $1 \mathrm{~h}$ in the presence of $\mathrm{O}_{2}$ gas. In this process, the Ga-ozonide species was generated via the photoreaction of the Ga-hydride site with $\mathrm{O}_{2}$, as described in the manuscript.

1.1.5. In Situ Preparation of the Ga-Oxyl Species. After the generation of the Ga-ozonide species, the $\mathrm{O}_{2}$ gas was evacuated at RT. Upon this evacuation, the Ga-oxyl species was generated via decomposition of the Ga-ozonide species with the liberation of $\mathrm{O}_{2}$, as described in the manuscript. 


\subsection{Spectroscopy}

1.2.1. In Situ IR Spectroscopy. $8 \mathrm{mg}$ of the sample was pressed under a pressure of $120 \mathrm{~kg} \mathrm{~cm}^{-2}$ into a disk of $10 \mathrm{~mm}$ diameter and loaded into an in situ cell equipped with KRS-5 windows. IR spectra were recorded in the transmission mode at RT using a Fourier transform IR (FT/IR) 6600 spectrophotometer equipped with a Hg-Cd-Te detector (JASCO Co. Ltd.). Accumulation times of 128 and a nominal resolution of $2 \mathrm{~cm}^{-1}$ were applied in the measurements.

1.2.2. In Situ UV-Vis-NIR Spectroscopy. $100 \mathrm{mg}$ of the sample was placed in an in situ reflectance cell made of fused silica. UV-Vis-NIR diffuse reflectance spectra were recorded using a JASCO V-570 spectrophotometer equipped with an integrating sphere attachment. All the measurements were carried out at RT. $\mathrm{BaSO}_{4}$ was used as the reference material. The resolution was set to $0.5 \mathrm{~nm}$ for all measurements.

1.2.3. In Situ Electron Spin Resonance (ESR) Spectroscopy. $5 \mathrm{mg}$ of the sample was loaded into an in situ ESR sample tube with a diameter of $5 \mathrm{~mm}$. The X-band ESR spectra (ca. $9.0 \mathrm{GHz}$ ) were recorded at $4 \mathrm{~K}$ with a JEOL JESFA200 spectrometer equipped with lower temperature variable apparatus (ES-CT470).

\subsection{DFT Cluster Calculation}

We performed DFT calculations using the Gaussian G16 software. Computational details are summarized below.

1.3.1. Model of the MFI Framework. From the crystallographic data of the dehydrated MFI zeolite, ${ }^{[\mathrm{S} 2]}$ the coordinate of the MFI pore was extracted. The terminated parts were capped with $\mathrm{H}$ atoms, by which the DFT cluster model of the pore of the MFI silicate, i.e., $\mathrm{Si}_{152} \mathrm{O}_{263} \mathrm{H}_{82}$, was constructed (Figure S10).

1.3.2. Model of the Divalent lon-Exchangeable Site. The 6MR site containing T7, T11, T12, T19, T23, and T24 framework $\mathrm{T}$ atoms was considered as the potential anchor site for the $[\mathrm{GaH}]^{2+},[\mathrm{GaO}]^{2+\bullet}$, and $\left[\mathrm{Ga}\left(\mathrm{O}_{3}\right)\right]^{2+\bullet}$ species. Its surrounding is shown in Figure S11A. For reproducing the divalent ion-exchangeable site, two framework Si atoms were substituted for two $\mathrm{Al}$ atoms. To examine the Al distribution effect on the state of the ion-exchanged Ga species, six types of the Al configurations i.e., T11/T23, T7/T11, T12/T19, T7/T12, T5/T23, and T20/T23, were constructed. These Al configurations are schematically illustrated in Figure S12. The T11/T23, T7/T11, T12/T19, and T7/T12 configurations feature the presence of two framework $\mathrm{Al}$ atoms within a 6MR site. By contrast, the T5/T23 and T20/T23 configurations feature the presence of two framework $\mathrm{Al}$ atoms incorporated into the different 6MR sites.

1.3.3. Model of the $[\mathrm{GaH}]^{2+},[\mathrm{GaO}]^{2+\bullet}$, and $\left[\mathrm{Ga}\left(\mathrm{O}_{3}\right)\right]^{2+\bullet}$ Species. The $[\mathrm{GaH}]^{2+},[\mathrm{GaO}]^{2+\bullet}$, or $\left[\mathrm{Ga}\left(\mathrm{O}_{3}\right)\right]^{2+\bullet}$ motifs were placed in the vicinity of the divalent ion-exchangeable sites as counter cations. Geometrical optimizations were conducted on all coordinates of the $[\mathrm{GaH}]-\mathrm{Al}_{2} \mathrm{Si}_{150} \mathrm{O}_{263} \mathrm{H} 82,[\mathrm{GaO}]-\mathrm{Al}_{2} \mathrm{Si}_{150} \mathrm{O}_{263} \mathrm{H}_{82}$, and $\left[\mathrm{Ga}\left(\mathrm{O}_{3}\right)\right]-\mathrm{Al}_{2} \mathrm{Si}_{150} \mathrm{O}_{263} \mathrm{H}_{82}$ geometries, except for the terminated hydrogen atoms, using a B3LYP functional with a 6-311G(d,p) basis set for Ga, terminal $\mathrm{H}$ or O atoms and a $6-31 \mathrm{G}(\mathrm{d})$ basis set for the remaining atoms (zeolite framework and capping $\mathrm{H}$ atoms). The optimized geometries are summarized in Figures S14-S20, S22-S28, S30-S36.

1.3.4. Model of the Monovalent Ion-Exchangeable Site. The 10MR site containing T5, T6, T11, T12, T13, T14, T15, T19, T20, and T21 was considered as the potential anchor site for the $\left[\mathrm{Ga}(\mathrm{H})_{2}\right]^{+}$, and $[\mathrm{GaO}]^{+}$species (Figure S11B). For 
the reproduction of the monovalent ion-exchangeable site, one framework Si atom at the T5 position was substituted for one $\mathrm{Al}$ atom (Figure S13).

1.3.5. Model of the $\left[\mathrm{Ga}(\mathrm{H})_{2}\right]^{+},[\mathrm{GaO}]^{+}$Species. The $\left[\mathrm{Ga}(\mathrm{H})_{2}\right]^{+}$or $[\mathrm{GaO}]^{+}$motifs were placed in the vicinity of the monovalent ion-exchangeable sites as counter cations. Geometrical optimizations were conducted on all coordinates of the $\left[\mathrm{Ga}(\mathrm{H})_{2}\right]-\mathrm{Al}_{1} \mathrm{Si}_{151} \mathrm{O}_{263} \mathrm{H}_{82}$ and $[\mathrm{GaO}]-\mathrm{Al}_{1} \mathrm{Si}_{151} \mathrm{O}_{263} \mathrm{H}_{82}$ geometries, except for the terminated $\mathrm{H}$ atoms, using a B3LYP functional with a 6-311G(d,p) basis set for $\mathrm{Ga}$, terminal $\mathrm{H}$ or $\mathrm{O}$ atoms and a 6-31G(d) basis set for the remaining atoms (zeolite framework and capping H atoms). The optimized geometries are summarized in Figures S38 and S39.

1.3.6. Energy Scan for the Reversible Reaction of $\mathrm{Ga}-\mathrm{Oxyl}$ with $\mathrm{O}_{2}$. The reversible reaction includes two steps: (i) $\mathrm{O}-\mathrm{O}$ radical coupling/decoupling, and (ii) isomerization between end-on $\left[\mathrm{Ga}\left(\mathrm{O}_{3}\right)\right]^{2+\bullet}$ and side-on $\left[\mathrm{Ga}\left(\mathrm{O}_{3}\right)\right]^{2+\bullet}$ species. For the $\mathrm{O}-\mathrm{O}$ radical coupling/decoupling processes, $S=1 / 2$ potential energy surface along the $\mathrm{O}_{2}-\mathrm{Oxyl}$ distance was computed, where spin multiplicities of the $\mathrm{O}_{2}$ and the $[\mathrm{GaO}]^{2+\bullet}$ grafted MFI zeolite were specified as $S=1$ and $S=-1 / 2$, respectively, using the guess=fragment keyword and option (Figure S40). ${ }^{[\mathrm{S} 3]}$ By contrast, for the isomerization processes, an energy scan was performed along the Ga-O-O-O dihedral angle (Figure S41). The respective geometries were fully optimized except for the $\mathrm{O}-\mathrm{O}$ distance or $\mathrm{Ga}-\mathrm{O}-\mathrm{O}-\mathrm{O}$ dihedral angle. Optimizations were carried out at the B3LYP/6-311G(d,p), 6$31 \mathrm{G}(\mathrm{d})$ level. The self-consistent field (SCF) energies of the respective optimized geometries were calculated using a B3LYP functional including an empirical dispersion gd3 (B3LYP-D3) with a 6-311++G(3df,3pd) basis set for Ga, O2, oxyl, and ozonide, and a 6-31G(d) basis set for the remaining atoms. The relative SCF energies were calculated based on the total SCF energies of the free $\mathrm{O}_{2}$ molecule $(S=1)$ and $\mathrm{Ga}^{\mathrm{III}}-$ oxyl model $(S=1 / 2)$ shown in Figure S22. Due to the high computational cost of the transition state and frequency calculations on the large cluster $\left(\left[\mathrm{GaO}_{2} \mathrm{O}_{2}\right]-\mathrm{Al}_{2} \mathrm{Si}_{150} \mathrm{O}_{263} \mathrm{H}_{82}\right.$ geometry), the transition states could not be computed directly. Therefore, the activation energies were estimated from the computed potential energy surfaces shown in Figures S40 and S41.

1.3.7. Simulation of the IR Spectra. Vibrational frequency calculations were conducted on the local environment of the $\mathrm{Ga}$ ion on the optimized DFT cluster models, i.e., [GaH]- $\mathrm{Al}_{2} \mathrm{Si}_{150} \mathrm{O}_{263} \mathrm{H} 82$ and $\left[\mathrm{Ga}(\mathrm{H})_{2}\right]-\mathrm{Al}_{1} \mathrm{Si}_{150} \mathrm{O}_{263} \mathrm{H}_{82}$ geometries (Figures S14-S19, and S38), where terminated H atoms were kept frozen. Computed IR spectra of the DFT cluster models of the Ga-hydride species were scaled with 0.975, and compared with the experimental data (Figure S5). All calculations were performed at the B3LYP/6-311G(d,p), 6-31G(d) level.

1.3.8. Simulations of Vibronic FC Progression. The vibronic progressions of the $[\mathrm{GaO}]^{2+\bullet}$ and side-on $\left[\mathrm{Ga}\left(\mathrm{O}_{3}\right)\right]^{2+\bullet}$ species were computed by procedures developed in our previous works where the successful simulations of the recondite vibronically resolved spectra of the $\mathrm{Zn}^{\mathrm{II}}$-oxyl $(S=1 / 2),{ }^{\left[{ }^{[3}, \mathrm{S} 4\right]}$ side-on $\mathrm{Ni}^{\mathrm{II}}$-superoxo $(S=1 / 2),{ }^{[\mathrm{S} 5]}$ side-on $\mathrm{Co}^{\mathrm{III}}$-peroxo $(S=$ $1),{ }^{[\mathrm{S} 6]}$ and side-on $\mathrm{Zn}^{\mathrm{II}}$-ozonide $(S=1 / 2) \operatorname{species}^{[\mathrm{S} 3]}$ were reported. This procedure requires high-cost calculations on the excited state. To reduce the computational cost as much as possible, the smallest cluster models, i.e., $\left[\mathrm{Ga}\left(\mathrm{O}_{3}\right)\right]-\mathrm{Al}_{2} \mathrm{Si}_{4} \mathrm{O}_{6} \mathrm{H}_{12}$ and $[\mathrm{GaO}]-\mathrm{Al}_{2} \mathrm{Si}_{4} \mathrm{O}_{6} \mathrm{H}_{12}$ having T11/T23 configuration (Figures $\mathbf{S 4 3}$ and $\mathbf{S 4 4}$ ), were used as the candidate models. These geometries were constructed by cutting from the optimized coordinates of the $\left[\mathrm{Ga}\left(\mathrm{O}_{3}\right)\right]-\mathrm{Al}_{2} \mathrm{Si}_{150} \mathrm{O}_{263} \mathrm{H}_{82}$ and $\left.[\mathrm{GaO})\right]-$ $\mathrm{Al}_{2} \mathrm{Si}_{150} \mathrm{O}_{263} \mathrm{H}_{82}$ geometries shown in Figures S22 and S30. The coordinates of the electronic ground states were fully optimized except for terminated $\mathrm{H}$ atoms. The electronic excited states, which are associated with the vibronic progressions (vide infra), were determined by the TD method (Figures S45 and S46). The coordinates of the electronic excited states were optimized, where terminated H atoms were kept frozen (Figures $\mathbf{S 4 3}$ and S44). The local minima of the ground and 
electronic excited states were confirmed by vibrational frequency calculations where no imaginary frequency was computed; thus, we considered the optimizations to be correct. The overlap levels of the vibrational wave functions of the electronic ground and excited states were evaluated using the $f r e q=f c$ keyword and option with consideration of the isotope natural abundance of $\mathrm{Ga}\left(60.1 \%{ }^{69} \mathrm{Ga}, 39.9 \%{ }^{71} \mathrm{Ga}\right)$, by which we simulated the vibronic FC progressions. Half widths at half maximum of the bands were set to $450 \mathrm{~cm}^{-1}$ for the Ga-ozonide model and $250 \mathrm{~cm}^{-1}$ for the Ga-oxyl model. All the calculations were performed at the B3LYP/6-311G(d,p) level.

1.3.9. Computational Prediction of the UV-Vis-NIR Spectrum of the $\left[\mathrm{Ga}^{\prime \prime \prime}=\mathrm{O}\right]^{+}$Species. The excited states of the $\left[\mathrm{Ga}^{\mathrm{III}}=\mathrm{O}\right]^{+}$species at the single framework $\mathrm{Al}$ site were analyzed by the TD method. In this calculation, we used the smallest cluster model of the $\left[\mathrm{Ga}^{\mathrm{III}}=\mathrm{O}\right]^{+}$species, i.e., a fully optimized $[\mathrm{GaO}]-\mathrm{Al}_{1} \mathrm{Si}_{2} \mathrm{O}_{4} \mathrm{H}_{8}$ cluster (Figure S47). All the calculations were performed at the B3LYP/6-311G(d,p) level.

1.3.10. Natural Bonding Orbital Analyses. The smallest cluster model, i.e., [GaO]- $\mathrm{Al}_{2} \mathrm{Si}_{4} \mathrm{O}_{6} \mathrm{H}_{12}$ having $\mathrm{T} 11 / \mathrm{T} 23$ configuration, was constructed by cutting from the optimized coordinate of the $[\mathrm{GaO}]-\mathrm{Al}_{2} \mathrm{Si}_{150} \mathrm{O}_{263} \mathrm{H}_{82}$ geometry shown in Figure S22. The coordinate of the electronic ground state was fully optimized except for terminated H atoms. The coordinate except for the terminated $\mathrm{H}$ atoms was optimized. The obtained smallest geometry was used for NBO analyses. NBOs related to the Ga-oxyl bond and their electron occupancies were computed, through which schematic molecular orbital diagrams are depicted (Figure 4 in the manuscript). All the calculations were performed at B3LYP-D3/6$311++\mathrm{G}(3 \mathrm{df}, 3 \mathrm{pd})$ level. Similarly, the NBO analyses were performed for the optimized $\mathrm{Zn}-$ oxyl bond, i.e., [ZnO]$\mathrm{Al}_{1} \mathrm{Si}_{9} \mathrm{O}_{10} \mathrm{H}_{20}$ geometry, in which the monovalent ion-exchangeable $\mathrm{T} 5$ site was used for the anchor site. 


\section{Supporting Discussion}

\subsection{IR Evidence for the $[\mathrm{GaH}]^{2+}$ Species as the Precursor of the Ga-O Radicals}

First, we tried to prepare the Ga-hydride-containing MFI zeolite through the RSSIE method developed previously. ${ }^{[S 1]}$ Briefly, the $\mathrm{Ga}\left(\mathrm{NO}_{3}\right)_{3}$-modified $\mathrm{H}^{+}$-MFI zeolite was evacuated at $873 \mathrm{~K}$ and subsequently treated under $\mathrm{H}_{2}$ atmosphere $\left(P_{\mathrm{e}}=100\right.$ Torr $)$ at $873 \mathrm{~K}$. Upon this process, the Ga ion was reduced to the zero-valent state. This mobile $\mathrm{Ga}^{0}$ species is easily incorporated into the zeolite pore and ion-exchanged with protons, as demonstrated in numerous studies. ${ }^{[\mathrm{S} 1]}$ As an analogous reaction, the ion-exchanging behavior of $\mathrm{Zn}^{0}$ vapor with $\mathrm{H}^{+}$(Brønsted acid site) is well known in zeolite chemistry. ${ }^{[\mathrm{S} 7]}$

It has been suggested that the RSSIE method effectively generates the Ga-hydride species ion-exchanged in the zeolite. ${ }^{[\mathrm{S} 1 \mathrm{a}-\mathrm{d}, \mathrm{g}-\mathrm{i}]}$ To confirm the generation of the Ga-hydride species in the present sample, we performed in situ IR measurements (Figure S2A). The weak IR bands were observed at 2064 and $2041 \mathrm{~cm}^{-1}$ that are assignable to $\tilde{v}_{\mathrm{Ga}-\mathrm{H}}$ of the $[\mathrm{Ga}-\mathrm{H}]^{2+}$ species stabilized at divalent ion-exchangeable MFI sites. ${ }^{[S 1 a-d, \mathrm{~g}-\mathrm{i}]}$ This result suggests that the following reaction proceeds upon the solid-state ion-exchange of $\mathrm{Ga}$ :

$$
\mathrm{Ga}^{0}+2 \mathrm{H}^{+}-\mathrm{OL}-Z \rightarrow Z-\mathrm{OL}_{\mathrm{L}}-[\mathrm{GaH}]^{2+}-\mathrm{O}_{\mathrm{L}}-Z+1 / 2 \mathrm{H}_{2}
$$

where $Z$ means the local structure of the framework $\mathrm{Al}$ atom and $\mathrm{O}_{\mathrm{L}}$ means the lattice oxygen atom.

The intensities of the $\tilde{v}_{\mathrm{Ga}-\mathrm{H}}$ bands were found to be significantly small, which indicates the small fraction of the Ga-hydride species. To further increase the amount of Ga-hydride species, we decided to modify the sample preparation procedure. In our protocol, we used the abnormal photoresponsivity of the Ga ion dispersed within the zeolite pore. Serykh recently reported that the Ga ion-exchange within the zeolite pore exhibits strong UV photoluminescence emission. ${ }^{[\mathrm{S} 8]}$ In the present system, such an abnormal photoresponsivity was also confirmed in the UV-Vis spectrum (Figure S2B) where the luminescence signature, i.e., the larger than $500 \% \mathrm{R}$ reflectance band, was observed in the UV region. ${ }^{[\mathrm{S} 8]}$ In the cryogenic inert-element matrix systems, it is well known that a photoreaction of the atomically dispersed Ga atoms with $\mathrm{H}_{2}$ generates the Ga-hydride species. ${ }^{\left[{ }^{[9]}\right]}$ With these in mind, the sample was irradiated with UV light in the presence of $\mathrm{H}_{2}$, through which we tried to positively induce the photo-cleavage of $\mathrm{H}_{2}$ and efficiently generate the Ga-hydride species. Upon the photoreaction of the sample with $\mathrm{H}_{2}$, the developments of the IR bands due to the Ga-hydride species were distinctly observed in the $2200-1900 \mathrm{~cm}^{-1}$ region (Figure S3), which indicates that $\mathrm{H}_{2}$-splitting effectively takes place in the excited state of the Ga ions atomically dispersed within the zeolite matrix. Subsequent irradiation of the sample under $\mathrm{O}_{2}$ gas $\left(P_{\mathrm{e}}=100\right.$ Torr) led to the disappearance of $\tilde{v}_{\mathrm{Ga}-\mathrm{H}}$ bands (Figure S4). The observation of the decays of multiple $\tilde{v}_{\mathrm{Ga}}$ $\mathrm{H}$ bands suggests the involvement of the distinguishable $\mathrm{Ga}$-hydride species in the photoreaction with $\mathrm{O}_{2}$. $\mathrm{Based}_{\text {on }}$ the computational results, the 2006 and $1985 \mathrm{~cm}^{-1}$ bands were assigned to symmetric and asymmetric $\tilde{v}_{\mathrm{Ga}-\mathrm{H}}$ bands of the $\left[\mathrm{Ga}(\mathrm{H})_{2}\right]^{+}$species stabilized at the monovalent ion-exchangeable site, whereas the bands of the $2075-2032 \mathrm{~cm}^{-1} \mathrm{region}$ were assigned to $\tilde{v}_{\mathrm{Ga}-\mathrm{H}}$ of the $[\mathrm{GaH}]^{2+}$ species stabilized at the $6 \mathrm{MR}$ sites having different $\mathrm{Al}$ configurations (Figure S5, S14-S20, and S38). 


\subsection{Importance of the Framework Al Sites}

The importance of the framework Al sites was confirmed by an experiment regarding the Ga-doped Al-free MFI zeolite (silicate), where the vibronic progression of the Ga-ozonide species was not observed (Figure S7).

\subsection{Importance of the 6MR Sites}

Using the distinct vibronic progression of the $\mathrm{Ga}$-ozonide species as a site-selective spectroscopic probe, we investigated the local structure of the zeolite, which is indispensable for creating the $\left[\mathrm{Ga}\left(\mathrm{O}_{3}\right)\right]^{2+}$ and $[\mathrm{GaO}]^{2+}$ species. As a result of examining CHA, MFI, and BEA zeolites, the vibronic progression was observed in all structures, although there were differences in strength (Figure S8). Since the spectral features of the vibronic progressions were very similar, it can be interpreted that the Ga-ozonide species having similar geometric and electronic structures were generated in all samples. The common zeolite local structure for CHA, MFI, and BEA zeolites is only the 6MR site (see the table in Figure S8). Therefore, the $6 \mathrm{MR}$ site is the most plausible site for creating the $\left[\mathrm{Ga}\left(\mathrm{O}_{3}\right)\right]^{2+\bullet}$ and $[\mathrm{GaO}]^{2+\bullet}$ species. Based on this fact, DFT calculation was performed using the 6MR site as the candidate anchor site in this study.

\subsection{Effect of the Al Configurations on the $[\mathrm{GaO}]^{2+\bullet}$ and $\left[\mathrm{Ga}\left(\mathrm{O}_{3}\right)\right]^{2+\cdot}$ Species}

The several $\tilde{v}_{\mathrm{Ga}-\mathrm{H}}$ bands of the $[\mathrm{Ga}-\mathrm{H}]^{2+}$ species decayed upon photoreaction with $\mathrm{O}_{2}$ (Figure S2), from which involvements of the several types of the divalent ion-exchangeable 6MR sites were suggested for the present system. The vibronic progressions of the Ga-ozonide and Ga-oxyl species are broad compared with the vibronic progressions of the associated $\mathrm{Zn}$ species (Figure 1B, C). The relatively low resolutions of the vibrational structures are probably derived from the heterogeneous distribution of the divalent ion-exchangeable 6MR sites. Then, in addition to the T11/T23 site discussed in the manuscript, several types of the divalent ion-exchangeable 6MR sites were also computationally examined as potential sites for stabilizing the Ga-oxyl bond. DFT cluster models of the $[\mathrm{Ga}-\mathrm{O}]^{2+\bullet}$ species anchored on the $6 \mathrm{MR}$ sites having different Al configurations are summarized in Figure S22-S27. The Ga-oxyl bonds having a hole localized at a terminal $\mathrm{O}$ atom were confirmed in all $\mathrm{Al}$ configurations. These results are indicative that the $6 \mathrm{MR}$ sites containing two framework $\mathrm{Al}$ atoms have the potential to create the $\mathrm{Ga}-\mathrm{oxyl}$ species. We also examined the $\mathrm{Al}$ configuration effect on the $\left[\mathrm{Ga}-\left(\mathrm{O}_{3}\right)\right]^{2+\bullet}$ species and confirmed the local minima of the side-on $\left[\mathrm{Ga}-\left(\mathrm{O}_{3}\right)\right]^{2+\bullet}$ species (Figures S30-S35). The determination of the $\mathrm{Al}$ distribution within the zeolite framework is an experimental challenge. Then, the geometric feature suitable to stabilize the $[\mathrm{Ga}-\mathrm{O}]^{2+\bullet}$ species was computationally examined by comparison of the relative energies of the $[\mathrm{Ga}-\mathrm{O}]^{2+\cdot}$ models having different $\mathrm{Al}$ configurations (Figure S29). The most stable was the T11/T23 site. This site has the geometric features enabling the stabilization of the square pyramidal $\mathrm{GaO}_{5}$ structure via interactions between $\mathrm{Ga}$ and lattice $\mathrm{O}$ atoms connected to framework $\mathrm{Al}$ atoms. Therefore, the nearest $\mathrm{Al}$-pair site, i.e., T11/T23 site, is the most plausible site for stabilizing the $[\mathrm{Ga}-\mathrm{O}]^{2+\bullet}$ species. The presence of this type of nearest $\mathrm{Al}$ site was suggested for several types of zeolites on the basis of the spectroscopically supported DFT cluster calculations, ${ }^{[\mathrm{S} 11]}$ which is consistent with our results. Although we are unable to determine the actual $\mathrm{Al}$ configuration due to the analytical difficulty, we discuss the bonding nature, spectroscopy, and reactivity of the Ga-oxyl species in this manuscript based on the computational result obtained using the most plausible model, i.e., the T11/T23 model.

\subsection{Amounts of the $[\mathrm{GaO}]^{2+\cdot}$ and $\left[\mathrm{Ga}\left(\mathrm{O}_{3}\right)\right]^{2+\cdot}$ Species}

In the previous work, the amount of the precursor for the $[\mathrm{ZnO}]^{+\cdot}$ and $\left[\mathrm{Zn}\left(\mathrm{O}_{3}\right)\right]^{+^{+}}$species, i.e., $[\mathrm{ZnH}]^{+}$species that is formed through the heterolytic cleavage of $\mathrm{H}_{2}$ at single $\mathrm{Zn}^{\mathrm{II}}$ site in dehydrated $\mathrm{Zn}$-MFI zeolite, has been quantified by $\mathrm{H}_{2}$-adsorption 
isotherm at around room temperature. ${ }^{[\mathrm{S} 12]}$ From this procedure, the $[\mathrm{ZnH}]^{+}$species was estimated as $100 \mu \mathrm{mol} \mathrm{g}^{-1}$; thus, $100 \mu \mathrm{mol} \mathrm{g}{ }^{-1}$ equiv of the $\mathrm{Zn}$-ozonide and $\mathrm{Zn}$-oxyl species would be generated in the Zn-MFI sample. ${ }^{[\mathrm{S} 3, \mathrm{S4}]}$ For the GaMFI system, $\mathrm{H}_{2}$-adsorption isotherms is not available for quantification of the precursor, i.e., the $[\mathrm{GaH}]^{2+}$ species, because the formation of the $\left[\mathrm{Ga}(\mathrm{H})_{2}\right]^{+}$species does not require $\mathrm{H}_{2}$-adsorption process. However, we can claim at least that Gaozonide is expected to be generated at about $>66 \mu \mathrm{mol} \mathrm{g}{ }^{-1}$, because the vibronic progression having an intensity about $2 / 3$ of that of $\mathrm{Zn}$-ozonide was observed for the Ga-MFI sample (Figure 1B in the main text), despite the lower vibronic coupling efficiency.

It should be noted that the amount of oxyl cannot be estimated from the intensity of the vibronic progression of oxyl. Since the vibronic progression of oxyl originates from the forbidden transition (see Figure S46), the strength of the vibronic progression is dominantly determined by vibronic coupling efficiency. As shown in Figure 1C in the text, the vibronic coupling efficiency of Ga-oxyl is much smaller than that of $\mathrm{Zn}-$ oxyl. As a result, the vibronic transition of Gaoxyl was observed to be much smaller than that of $\mathrm{Zn}$-oxyl without reflecting the precise stoichiometric ratio.

\subsection{ESR Analyses on the Reversible Reaction}

To detect the Ga-O radicals, i.e., Ga-oxyl and -ozonide species, we performed in situ ERR measurements (Figure S9). Two types of ESR signals were observed under $\mathrm{O}_{2}$ gas. Almost all these signals disappeared by evacuation of the $\mathrm{O}_{2}$ gas. No new ESR signal was observed in the vacuum process. When the sample was re-exposed to the $\mathrm{O}_{2}$ gas, the original ESR spectrum was obtained again. Considering the reversible reaction (Scheme 2 in the main text), the ESR signals observed under $\mathrm{O}_{2}$ gas were assignable to the $\mathrm{Ga}$-ozonide species. Based on the literature regarding the side-on metal-ozonide complexes, the axial $g$-tensor should be assigned as the side-on Ga-ozonide species. ${ }^{[S 13]}$ By contrast, the rhombic $g$-tensor cannot be interpreted by considering the side-on Ga-ozonide species. As shown in Figure 3 in the main text, the isomerization of end-on ozonide into side-on ozonide requires activation energy of only $6 \mathrm{~kJ} \mathrm{~mol}^{-1}$. The relative energies of the end-on ozonide are higher than that for the side-on ozonide only by $8 \mathrm{~kJ} \mathrm{~mol}^{-1}$. These are indicative that an equilibrium mixture of both complexes on the MFI pore; thus, the rhombic $g$-tensor is assignable to end-on Ga-ozonide species. Unfortunately, we were unable to detect the Ga-oxyl species due to the fast relaxation behavior of surface oxyl.

\subsection{Spectral Feature of the $\left[\mathrm{Ga}^{\mathrm{III}}=0\right]^{+}$Species}

The NIR vibronic progression observed experimentally (Figure 1) was attributed to the Ga GII-oxyl species. We also computationally examined the spectroscopy of the $[\mathrm{Ga}=\mathrm{O}]^{+}$species at the single framework $\mathrm{Al}$ site. The time-dependent DFT calculation predicted no NIR band; the lowest excited state was predicted in the UV region $\left(27,780 \mathrm{~cm}^{-1}\right)$. Thus, the $[\mathrm{Ga}=\mathrm{O}]^{+}$model should be excluded from consideration as the potential model that exhibits the NIR vibronic progression. 


\section{Supporting data}

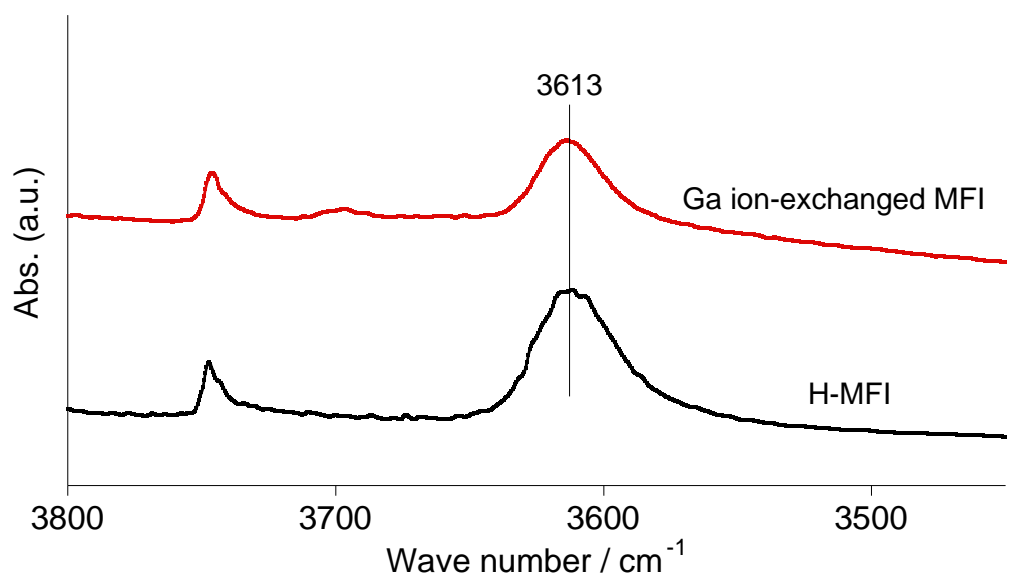

Figure S1. IR spectra of the H-MFI sample before and after the Ga ion-exchange.

A)

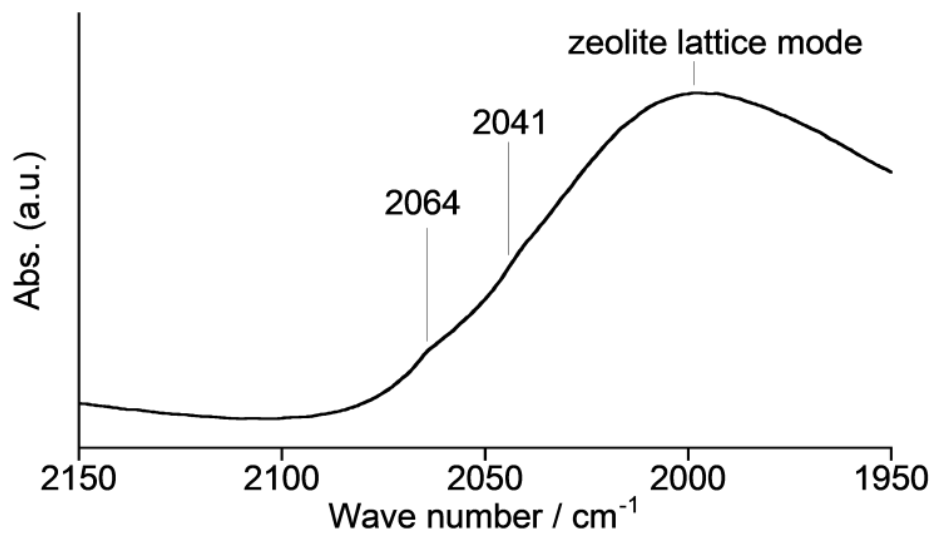

B)

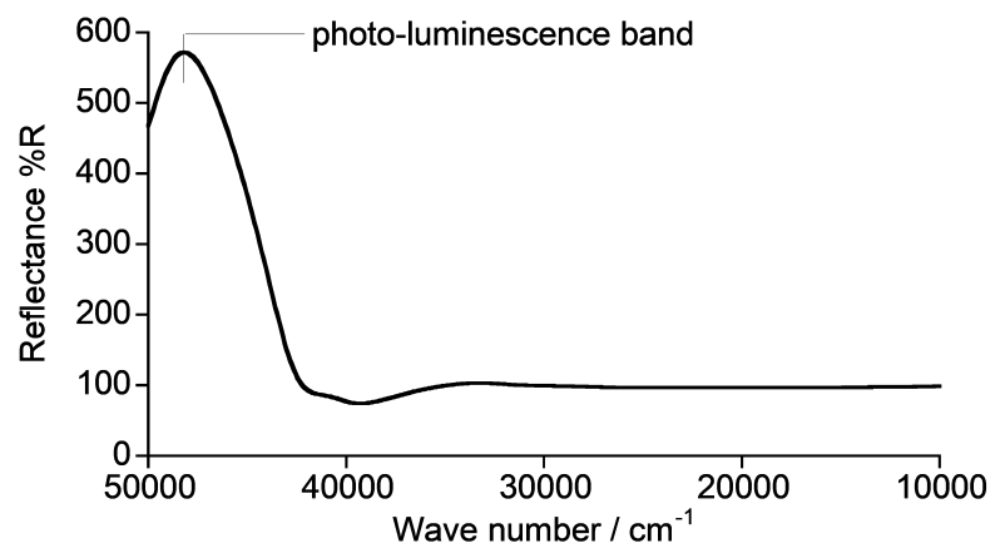

Figure S2. (A) In situ IR spectrum of the sample synthesized by RSSIE. (B) UV-Vis-NIR spectrum of the sample synthesized by RSSIE. 

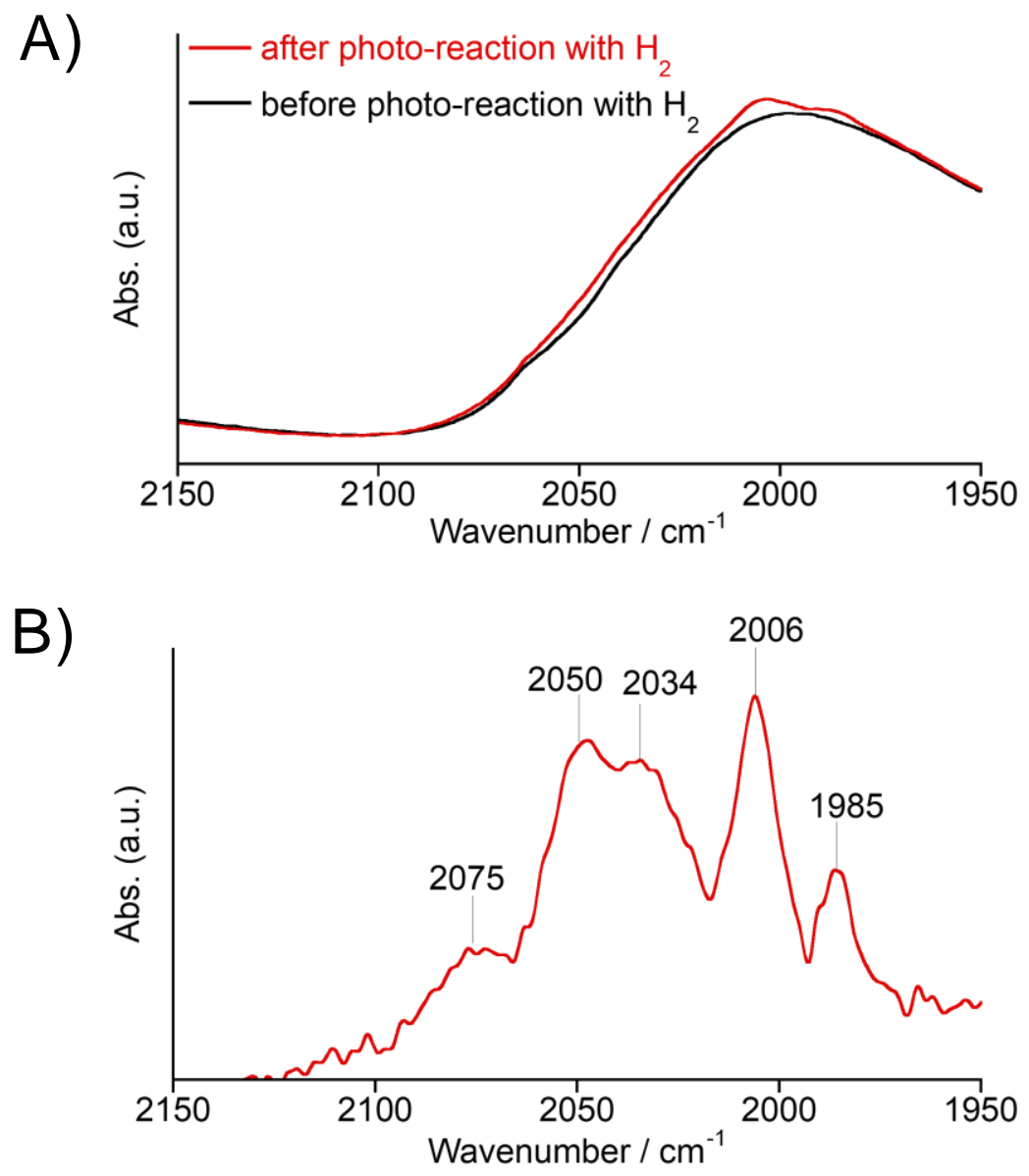

Figure S3. (A) In situ IR spectra of the sample before and after the photo-reaction with $\mathrm{H}_{2}\left(P_{\mathrm{e}}=100\right.$ Torr). (B) Difference IR spectrum upon the photo-reaction, which was obtained by subtracting the black spectrum from the red spectrum shown Figure S3A. This difference spectrum represents the IR bands of the gallium hydride species generated upon the photo-reaction with $\mathrm{H}_{2}$. 

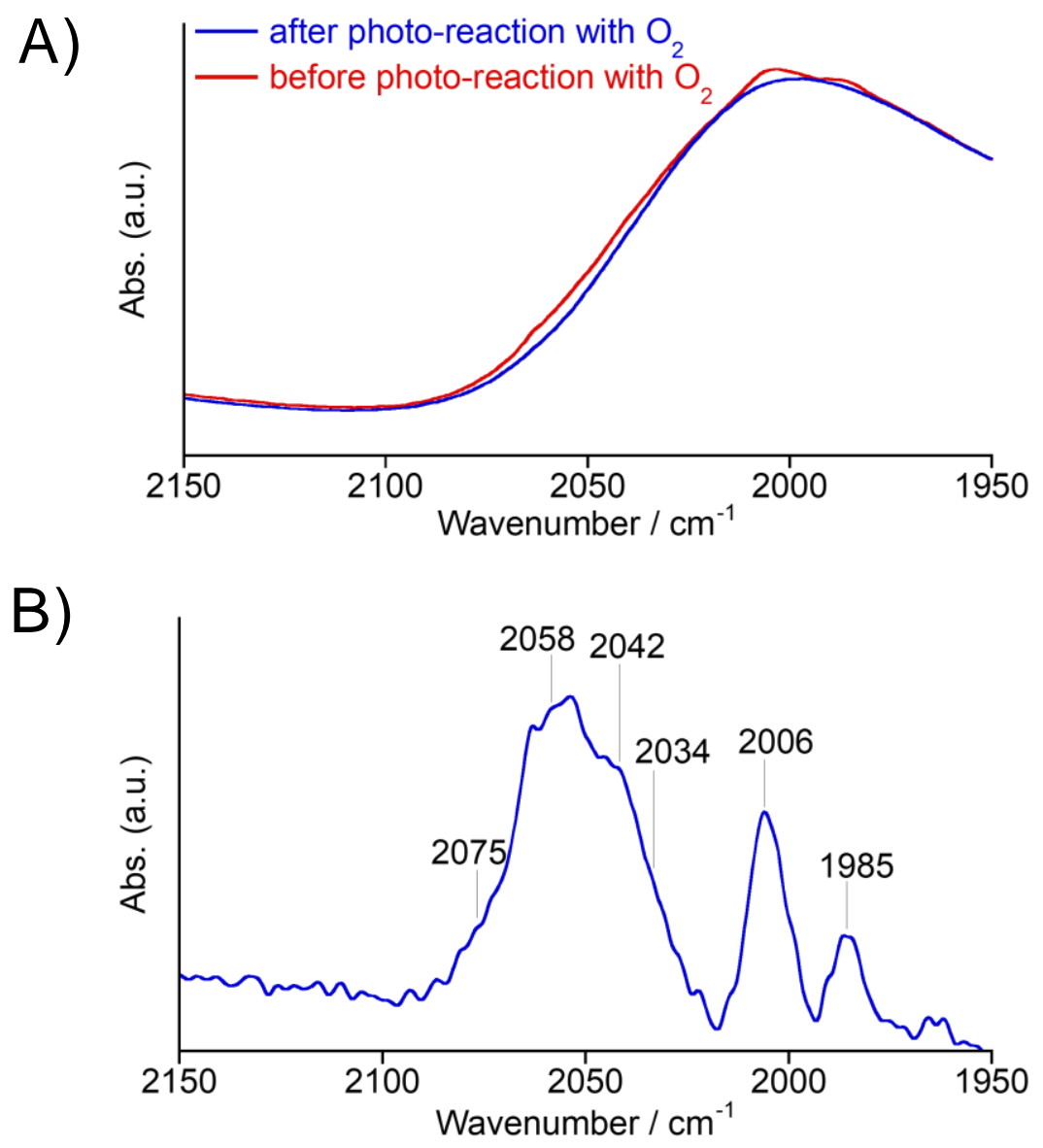

Figure S4. (A) In situ IR spectra of the sample before and after the photo-reaction with $\mathrm{O}_{2}\left(P_{\mathrm{e}}=100\right.$ Torr). (B) Difference IR spectrum upon the photo-reaction, which was obtained by subtracting the blue spectrum from the red spectrum shown Figure S4A. This difference spectrum represents the IR band of the gallium hydride species involving in the photo-reaction with $\mathrm{O}_{2}$. 


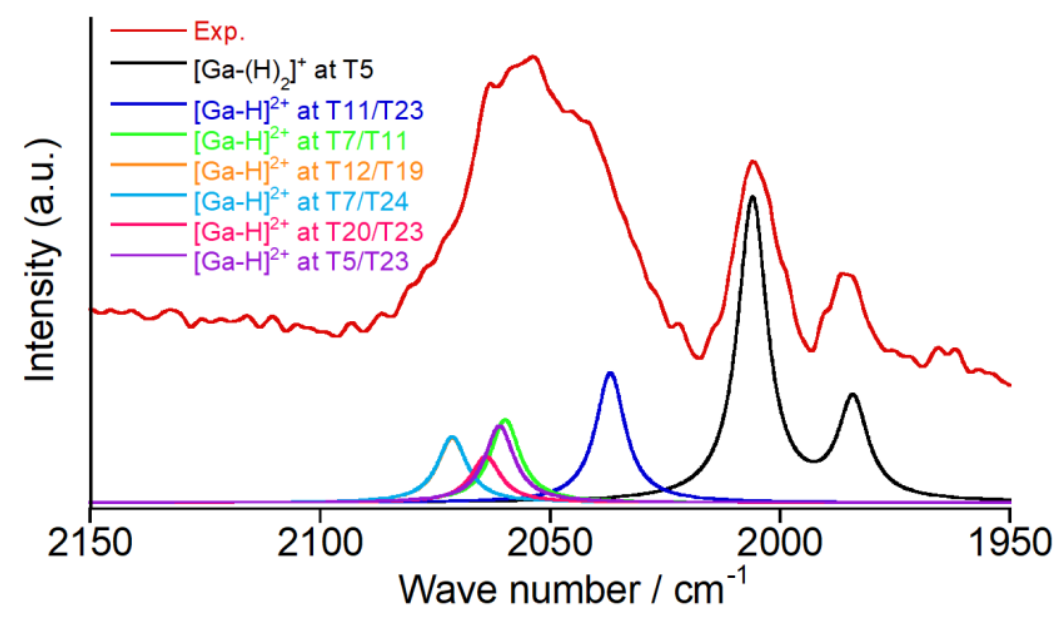

Figure S5. DFT predicted IR spectra of the $[\mathrm{Ga}-\mathrm{H}]^{2+}$ and $[\mathrm{Ga}-\mathrm{H}]^{+}$models shown in Figures S14-S20, S38. For comparison, experimental data, i.e., difference spectrum shown in Figure S4B, was also given.

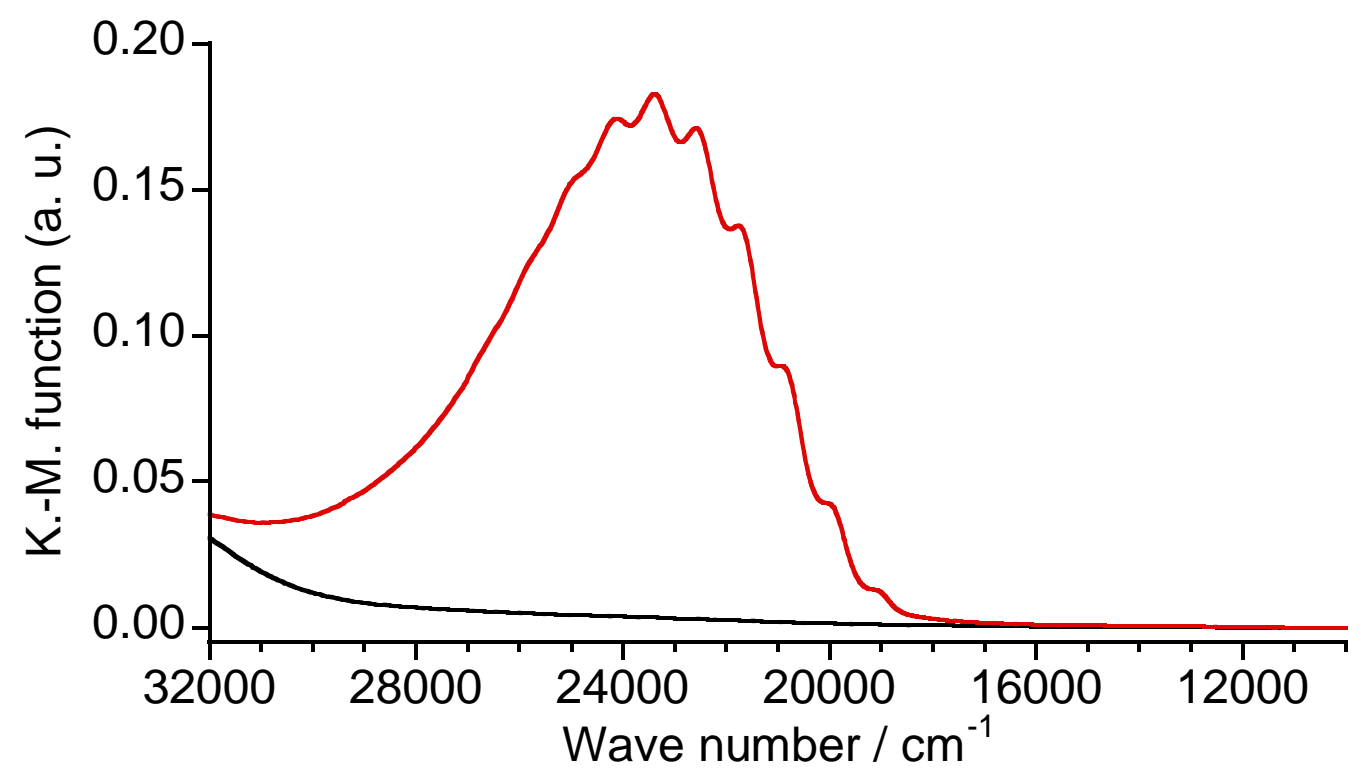

Figure S6. In situ UV-Vis-NIR spectra of the sample containing gallium hydride species (black) before and (red) after the UV-irradiation in the presence of $\mathrm{O}_{2}$. 


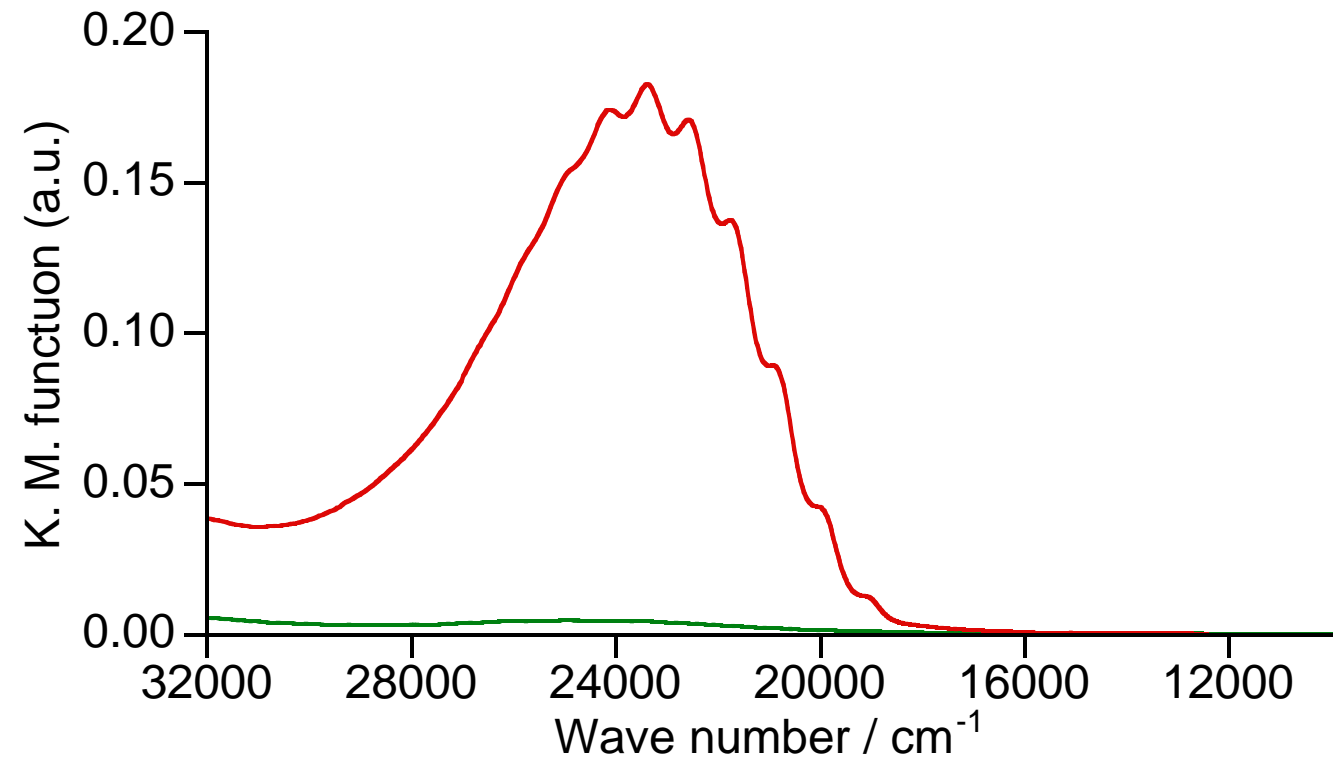

Figure S7. UV-Vis-NIR spectra of the Ga doped MFI silicate after the photo-activation by $\mathrm{H}_{2}$ and $\mathrm{O}_{2}$. For comparison, the result of the $\mathrm{GaMFI}$ zeolite $(\mathrm{Ga} / \mathrm{Al}=0.5, \mathrm{Si} / \mathrm{Al}=20)$, that was shown in Figure 1 in the manuscript, is also given. 


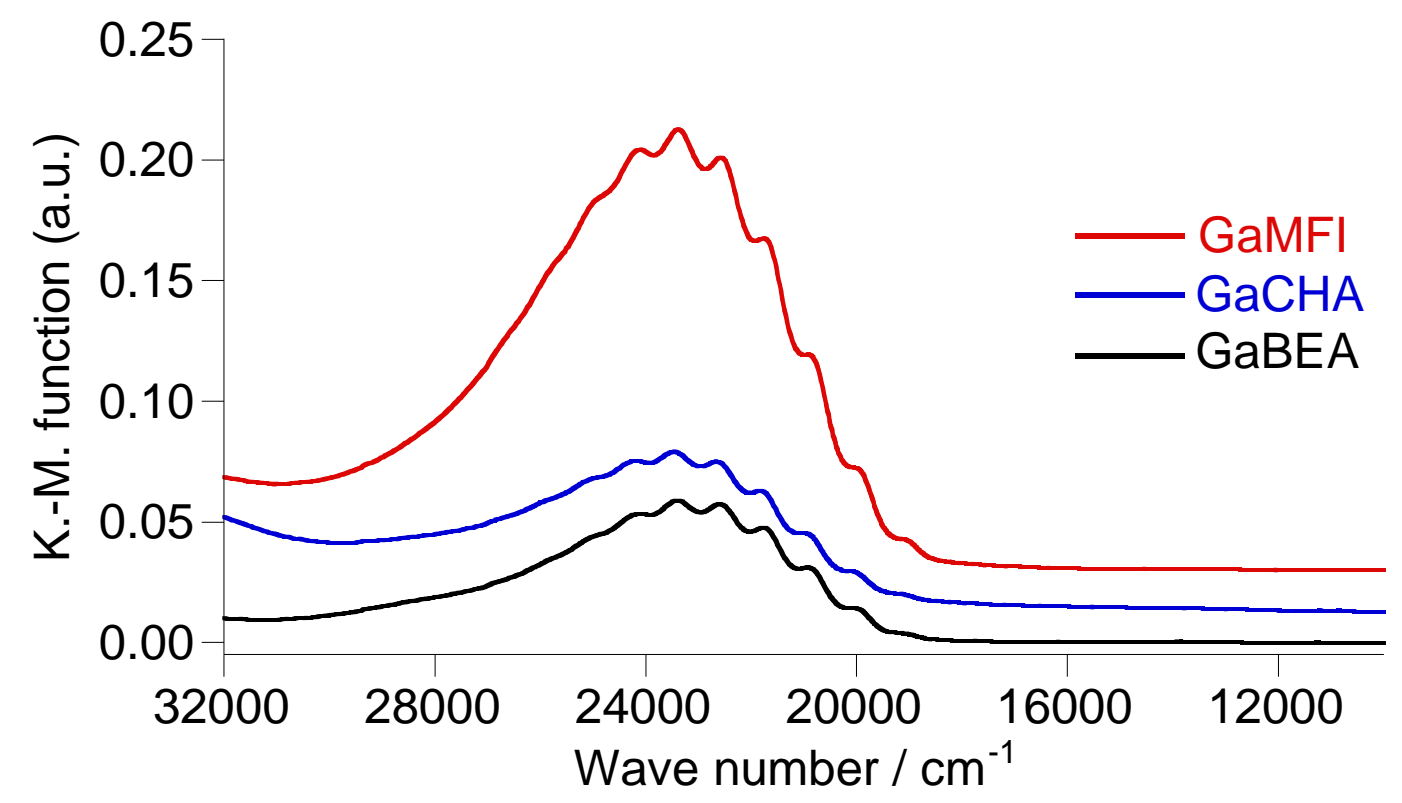

$\begin{array}{lccc} & \text { CHA } & \text { MFI } & \text { BEA } \\ 4 \mathrm{MR} & \checkmark & \checkmark & \checkmark \\ 5 \mathrm{MR} & \checkmark & \checkmark \\ 6 \mathrm{MR} & \checkmark & \checkmark & \\ 8 \mathrm{MR} & \checkmark & \checkmark & \\ 10 \mathrm{MR} & & \\ 12 \mathrm{MR} & & \\ \checkmark=\text { ring present in zeolites } & & \end{array}$

Figure S8. Comparison of the vibronic progressions observed in the Ga doped CHA, MFI, and BEA zeolites upon the photo-reaction with $\mathrm{O}_{2}$. $\mathrm{H}^{+}$ion-exchanged $\mathrm{CHA}$ with $\mathrm{Si} / \mathrm{Al}=14$ (TOSO Co. Ltd.) and $\mathrm{BEA}$ with $\mathrm{Si} / \mathrm{Al}=$ 12 (TOSO Co. Ltd.) were used as the CHA and BEA zeolite supports. The same sample preparation methods were applied in all samples. Typical sites for CHA, MFI, and BEA zeolites were summarized in a table. 


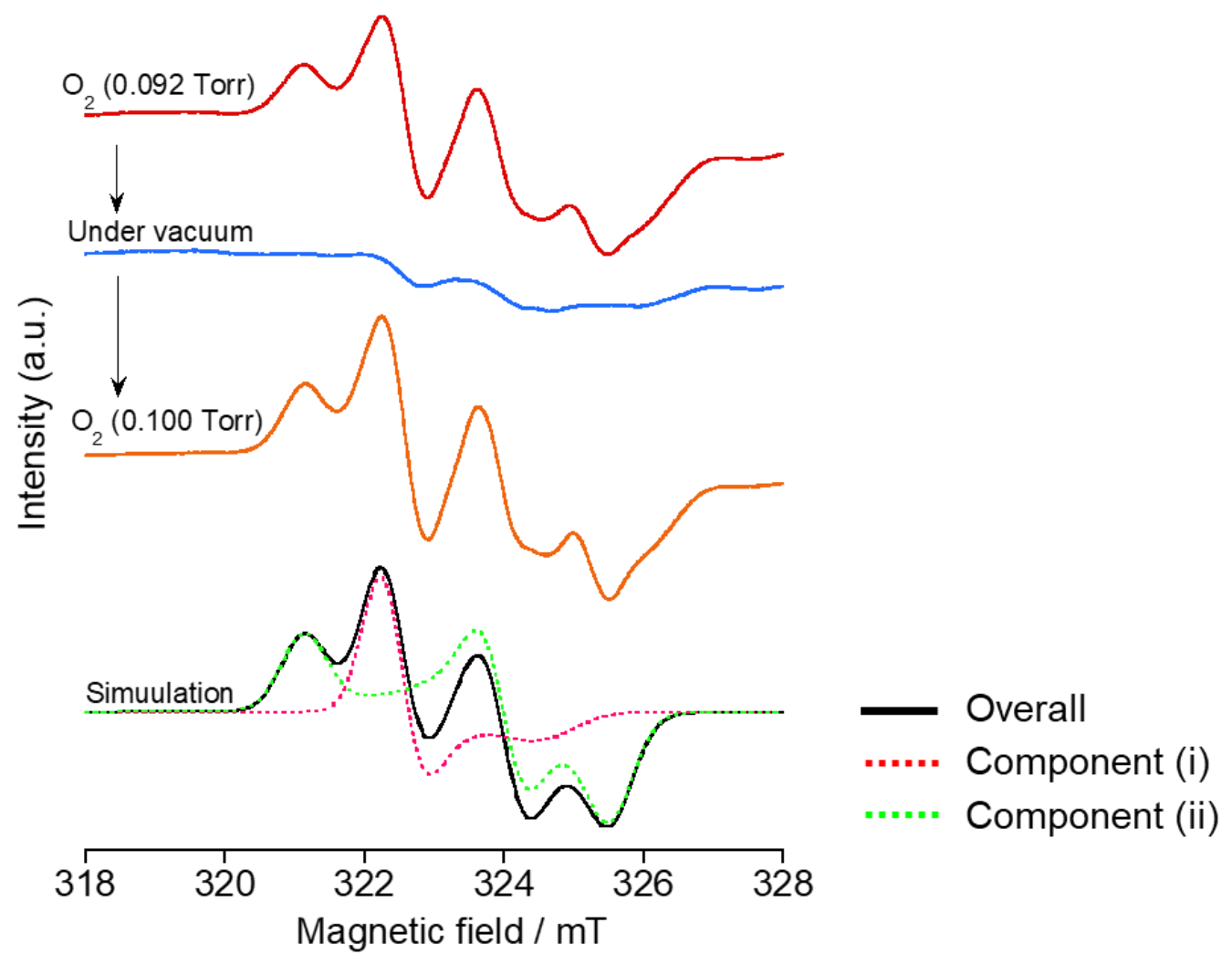

Figure S9. In situ ESR spectra of the sample upon the reversible reaction. Simulated spectrum was also shown, which was obtained by assuming the presence of two types of $g$-tensors: (i) $g_{\perp}=2.0132, g_{/ /=} .0000$; (ii) $g_{x x}=$ 2.0213, $g_{\mathrm{y}}=2.0035, g_{z z}=1.9940$. 


\section{Straight channel view}

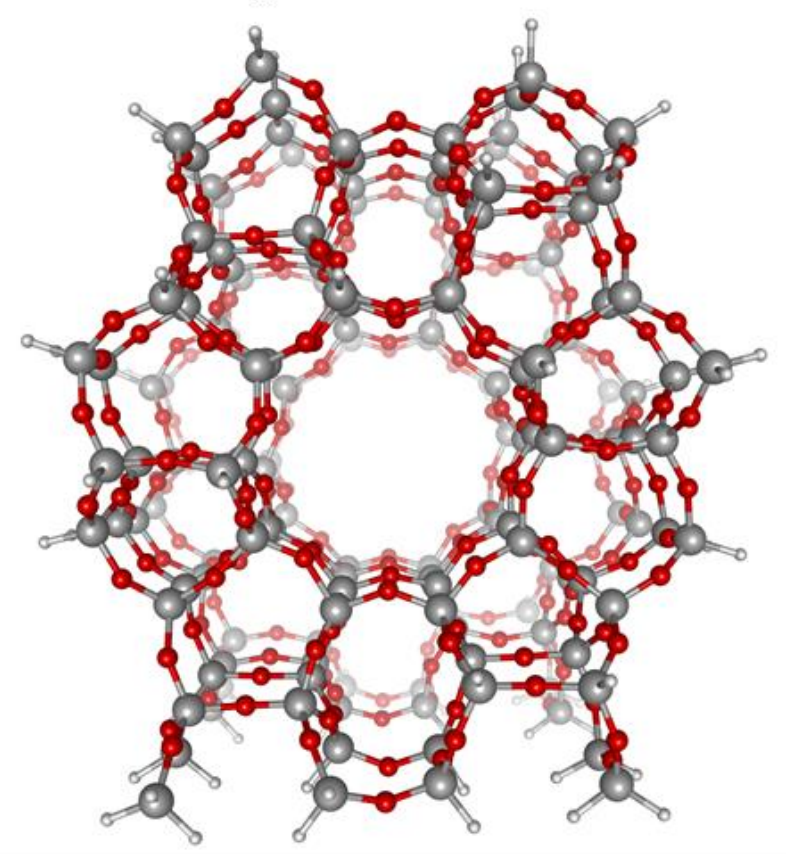

\section{Sinusoidal channel view}

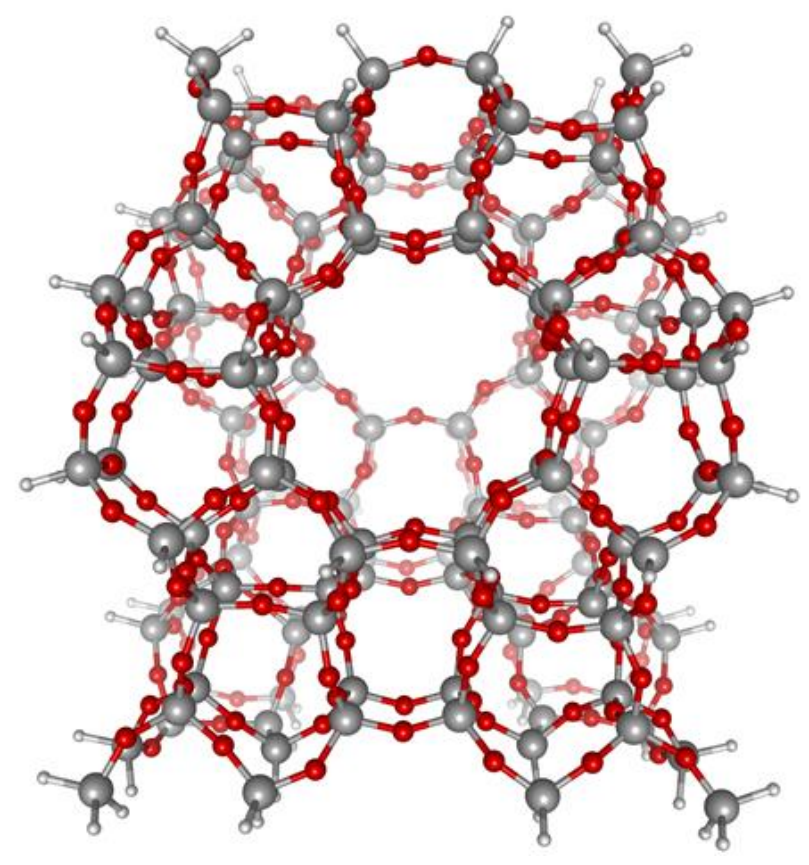

Figure S10. DFT cluster model of the MFI pore, i.e., $\mathrm{Si}_{152} \mathrm{O}_{263} \mathrm{H}_{82}$, constructed based on the crystallographic data. ${ }^{[2]}$ Terminated Si atoms were capped with hydrogen atoms. Legend: grey, Si; red, O. 

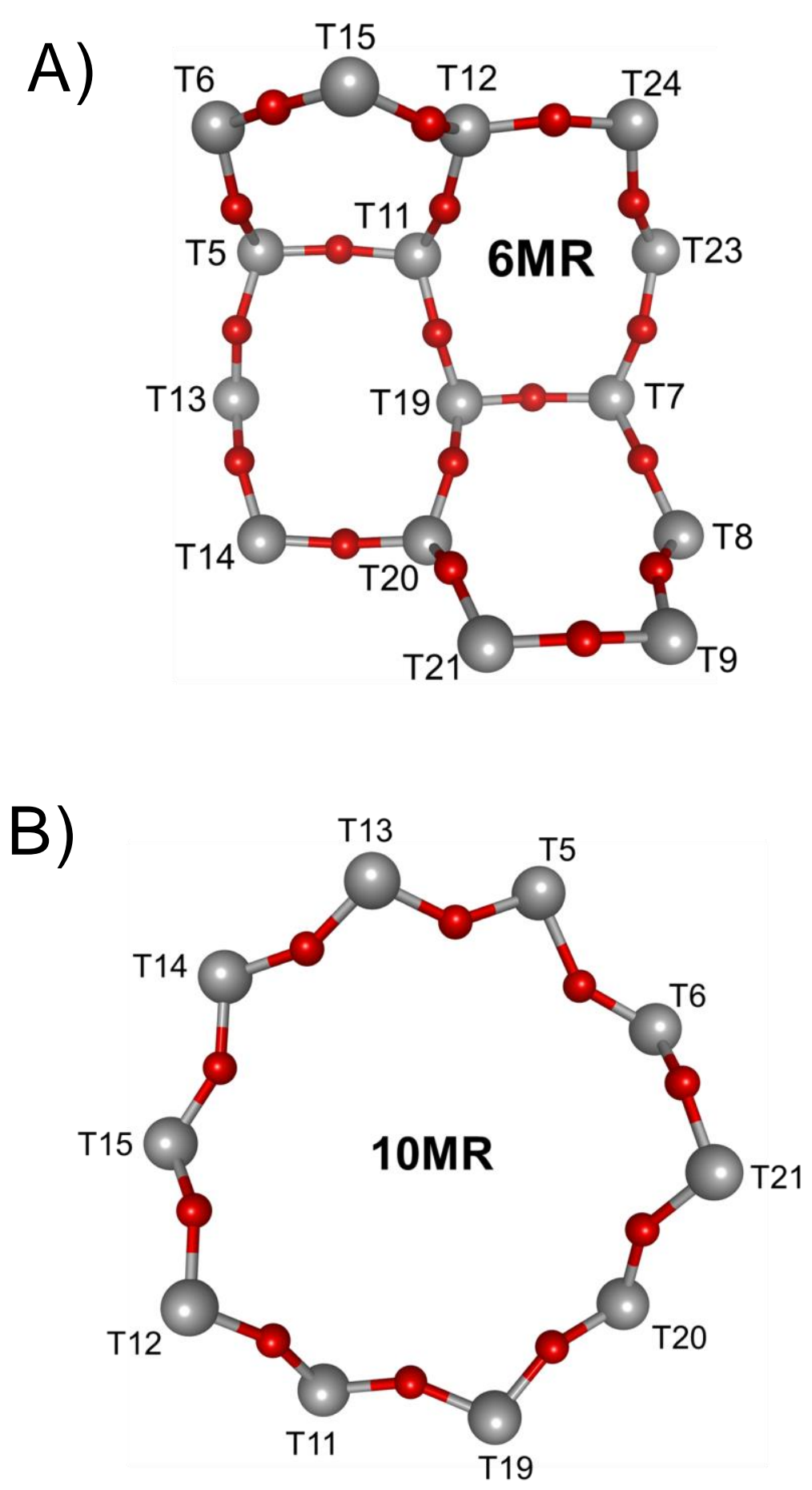

Figure S11. (A) The surrounding of the 6MR site that is considered in the present study as the potential anchor site for the divalent cations. This site locates at the straight channel of MFI zeolite. (B) The 10MR site that is considered in the present study as the potential anchor site for the monovalent ions. This site locates at the straight channel of MFI zeolite. For an explanation on the crystallographically distinguishable $T$ sites, $T$ site numbers were also given in the figure. ${ }^{[\mathrm{S} 2]}$ Legend: grey, $\mathrm{Si}$; red, $\mathrm{O}$. 

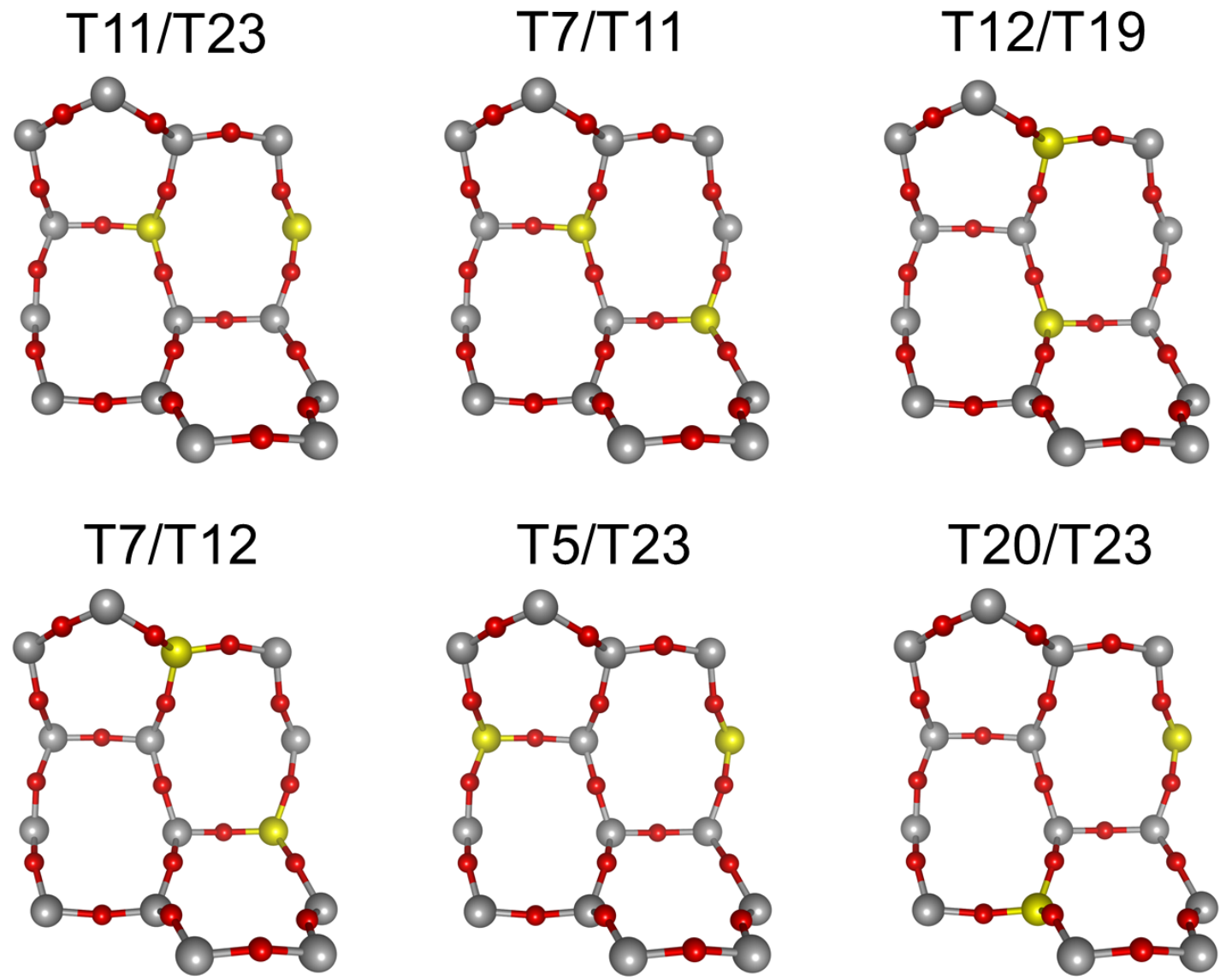

Figure S12. Divalent ion-exchangeable MFI sites that were considered in the present study. Legend: yellow, Al; grey, Si; red, $\mathrm{O}$.

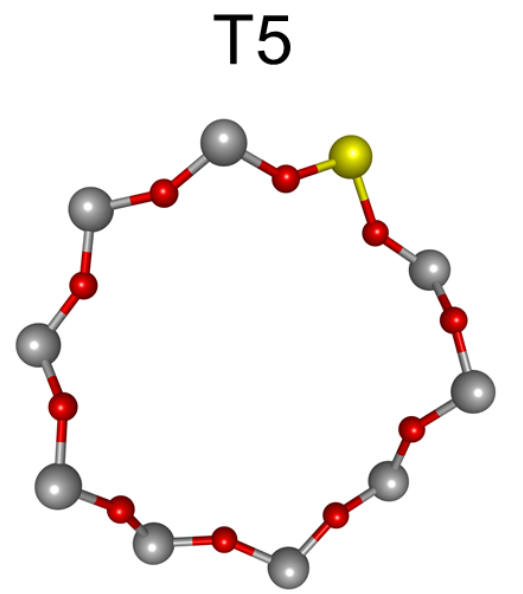

Figure S13. Monovalent ion-exchangeable MFI site that was considered in the present study. Legend: yellow, Al; grey, Si; red, O. 


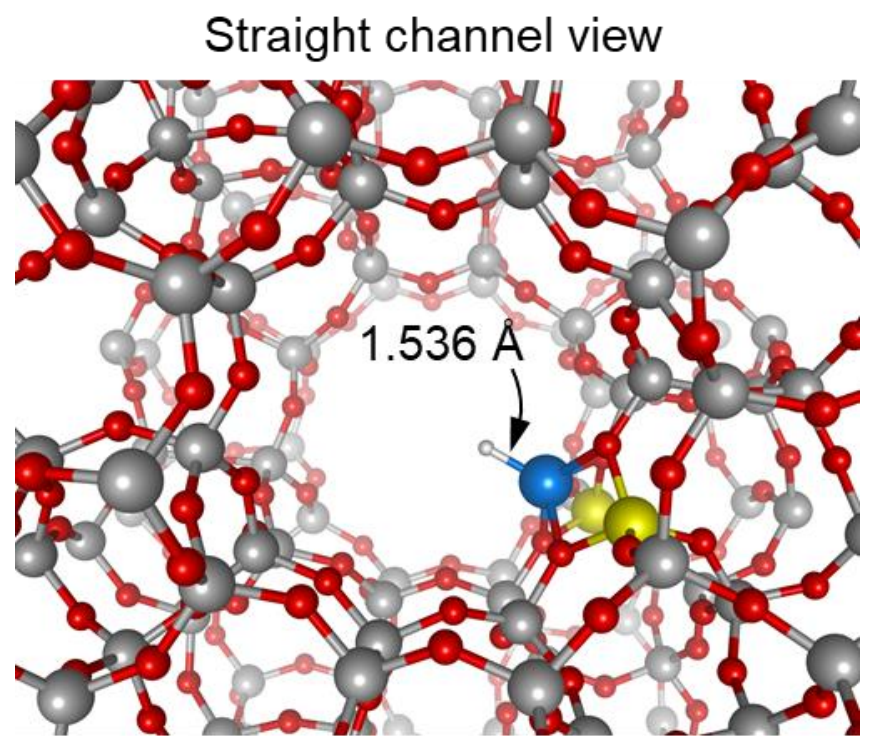

Sinusoidal channel view

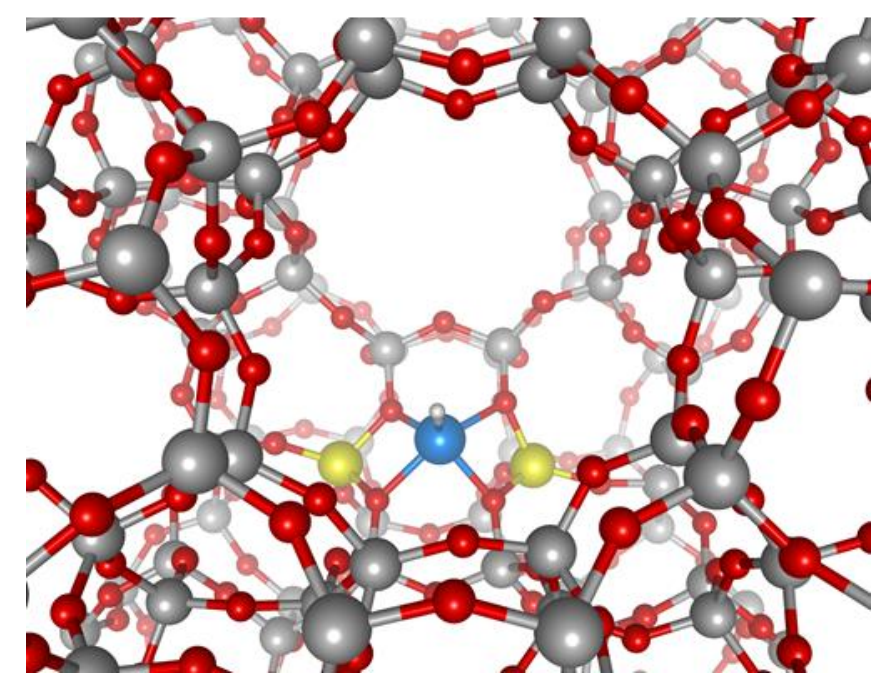

Figure S14. Optimized $[\mathrm{GaH}]-\mathrm{Al}_{2} \mathrm{Si}_{150} \mathrm{O}_{263} \mathrm{H}_{82}$ geometry representing the $[\mathrm{Ga}-\mathrm{H}]^{2+}$ species anchored on the 6MR site containing two framework $\mathrm{Al}$ atoms at T11/T23 crystallographic positions: (top) straight channel view; (bottom) sinusoidal channel view. Legend: blue, Ga; yellow, Al; grey, Si; red, O. 


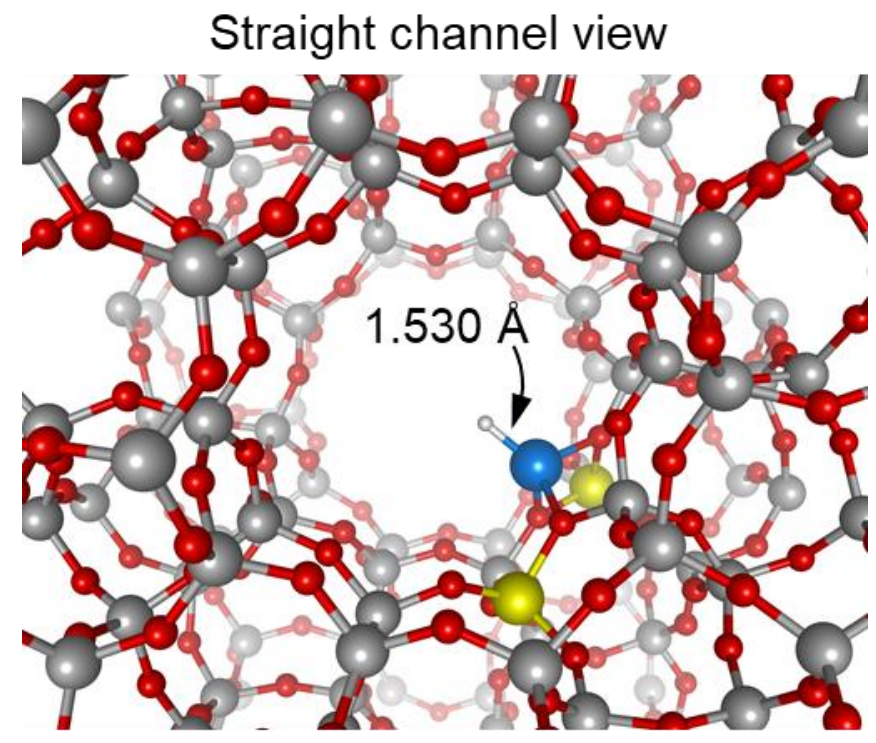

Sinusoidal channel view

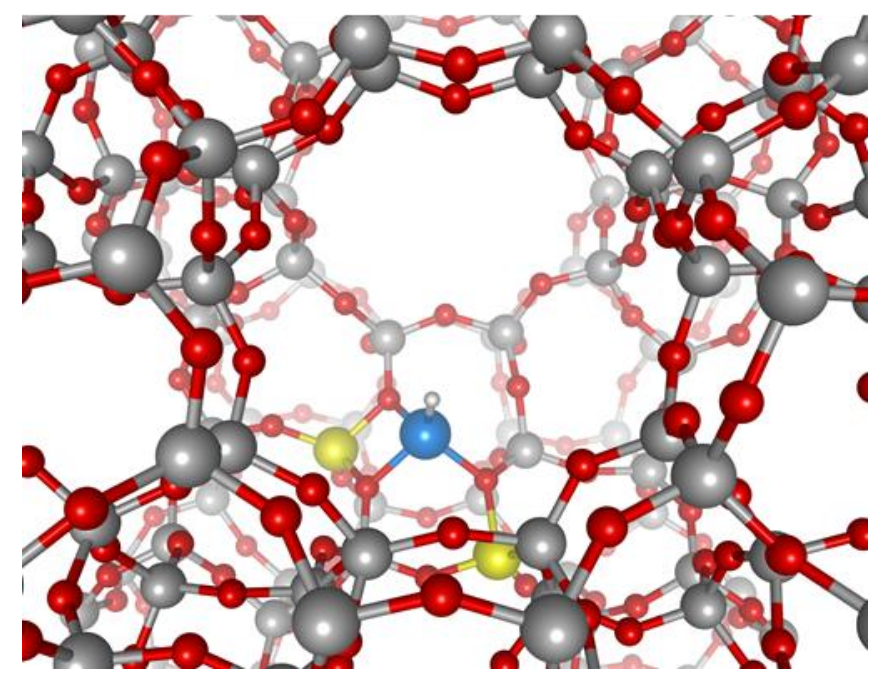

Figure S15. Optimized $[\mathrm{GaH}]-\mathrm{Al}_{2} \mathrm{Si}_{150} \mathrm{O}_{263} \mathrm{H}_{82}$ geometry representing the $[\mathrm{Ga}-\mathrm{H}]^{2+}$ species anchored on the $6 \mathrm{MR}$ site containing two framework $\mathrm{Al}$ atoms at T7/T11 crystallographic positions: (top) straight channel view; (bottom) sinusoidal channel view. Legend: blue, Ga; yellow, Al; grey, Si; red, O. 


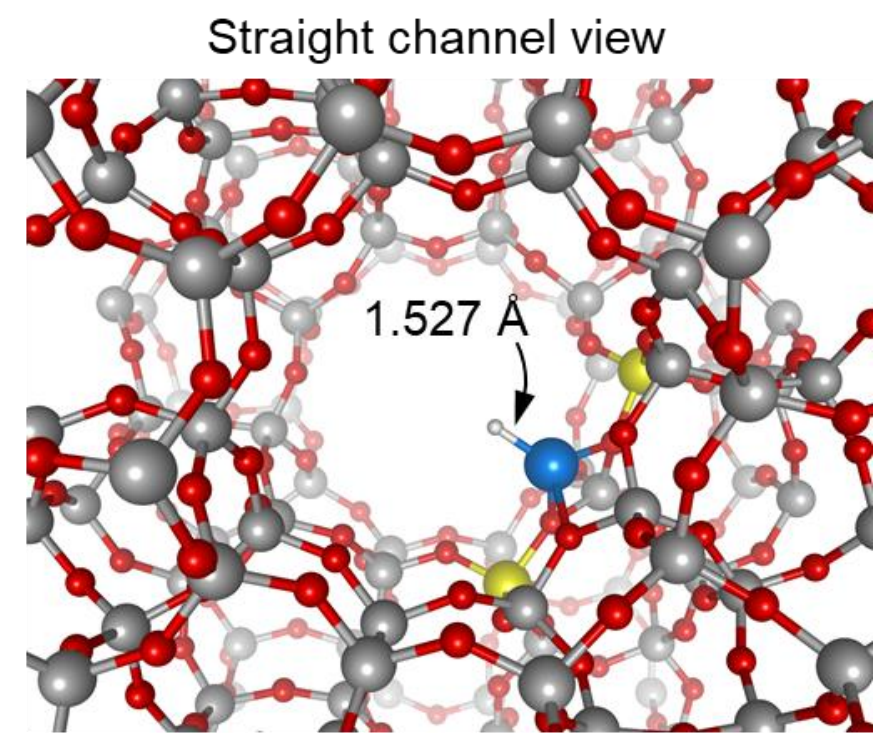

Sinusoidal channel view

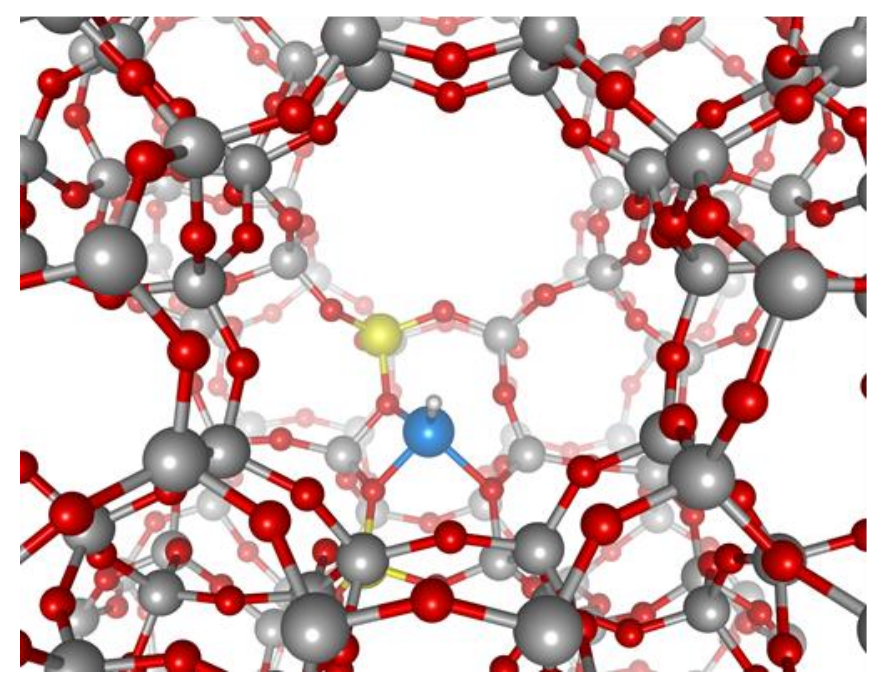

Figure S16. Optimized $[\mathrm{GaH}]-\mathrm{Al}_{2} \mathrm{Si}_{150} \mathrm{O}_{263} \mathrm{H}_{82}$ geometry representing the $[\mathrm{Ga}-\mathrm{H}]^{2+}$ species anchored on the $6 \mathrm{MR}$ site containing two framework Al atoms at T12/T19 crystallographic positions: (top) straight channel view; (bottom) sinusoidal channel view. Legend: blue, Ga; yellow, Al; grey, Si; red, O. 

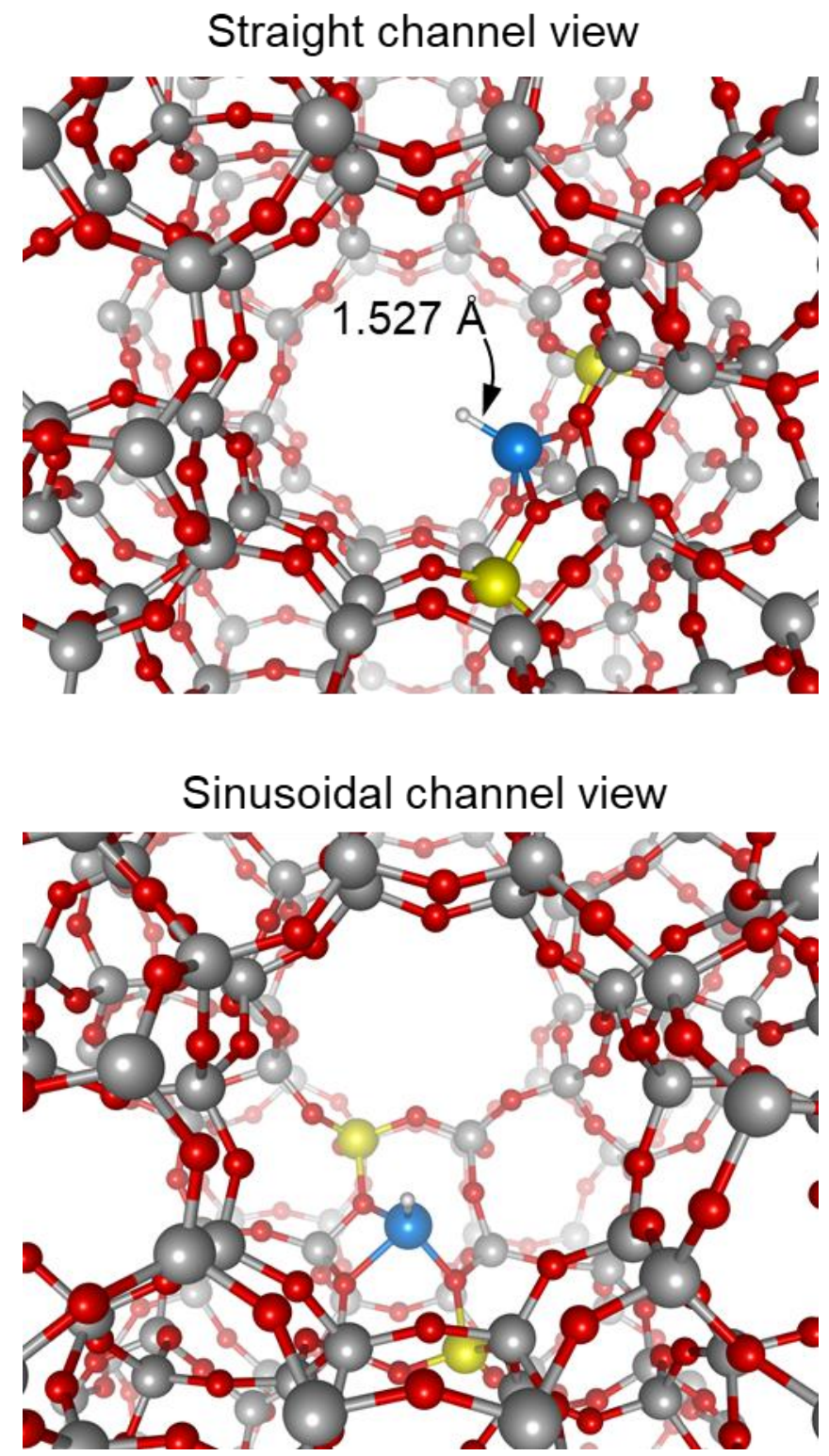

Figure S17. Optimized $[\mathrm{GaH}]-\mathrm{Al}_{2} \mathrm{Si}_{150} \mathrm{O}_{263} \mathrm{H}_{82}$ geometry representing the $[\mathrm{Ga}-\mathrm{H}]^{2+}$ species anchored on the $6 \mathrm{MR}$ site containing two framework $\mathrm{Al}$ atoms at T7/T12 crystallographic positions: (top) straight channel view; (bottom) sinusoidal channel view. Legend: blue, Ga; yellow, Al; grey, Si; red, O. 


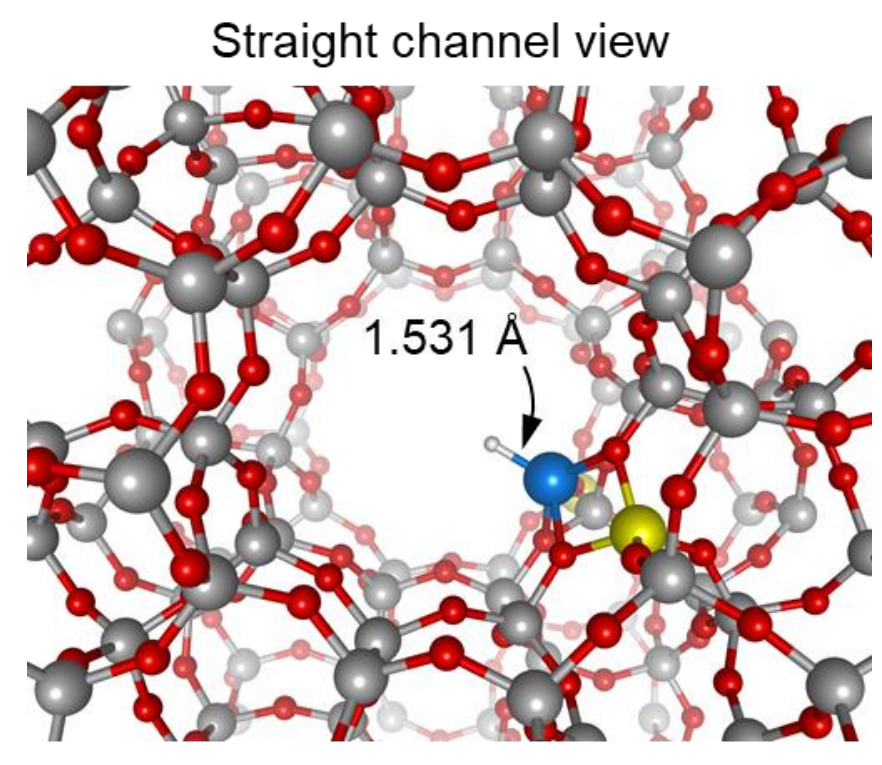

\section{Sinusoidal channel view}

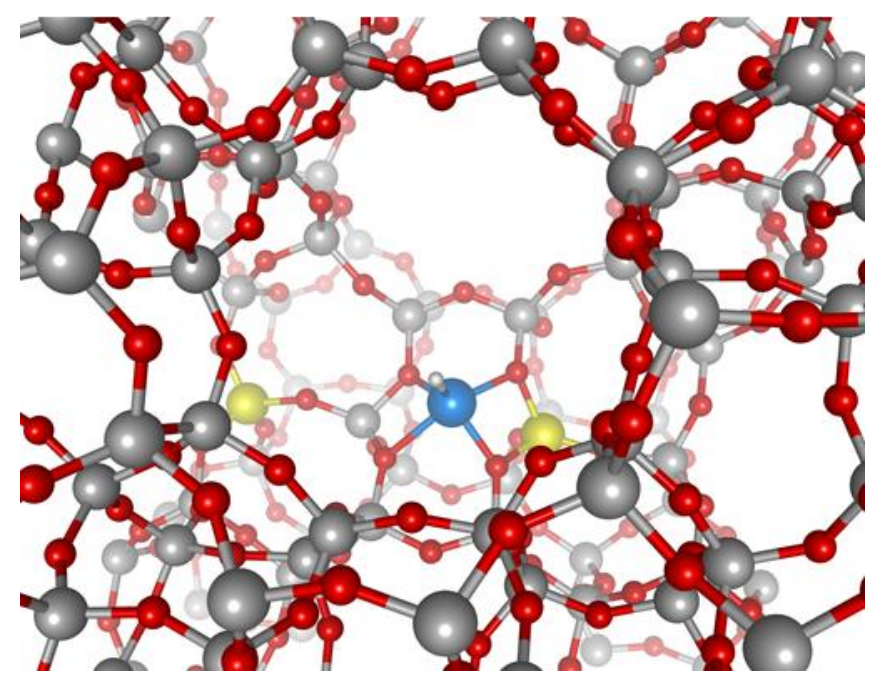

Figure S18. Optimized $[\mathrm{GaH}]-\mathrm{Al}_{2} \mathrm{Si}_{150} \mathrm{O}_{263} \mathrm{H}_{82}$ geometry representing the $[\mathrm{Ga}-\mathrm{H}]^{2+}$ species anchored on the $6 \mathrm{MR}$ site containing two framework $\mathrm{Al}$ atoms at T5/T23 crystallographic positions: (top) straight channel view; (bottom) sinusoidal channel view. Legend: blue, Ga; yellow, Al; grey, Si; red, O. 

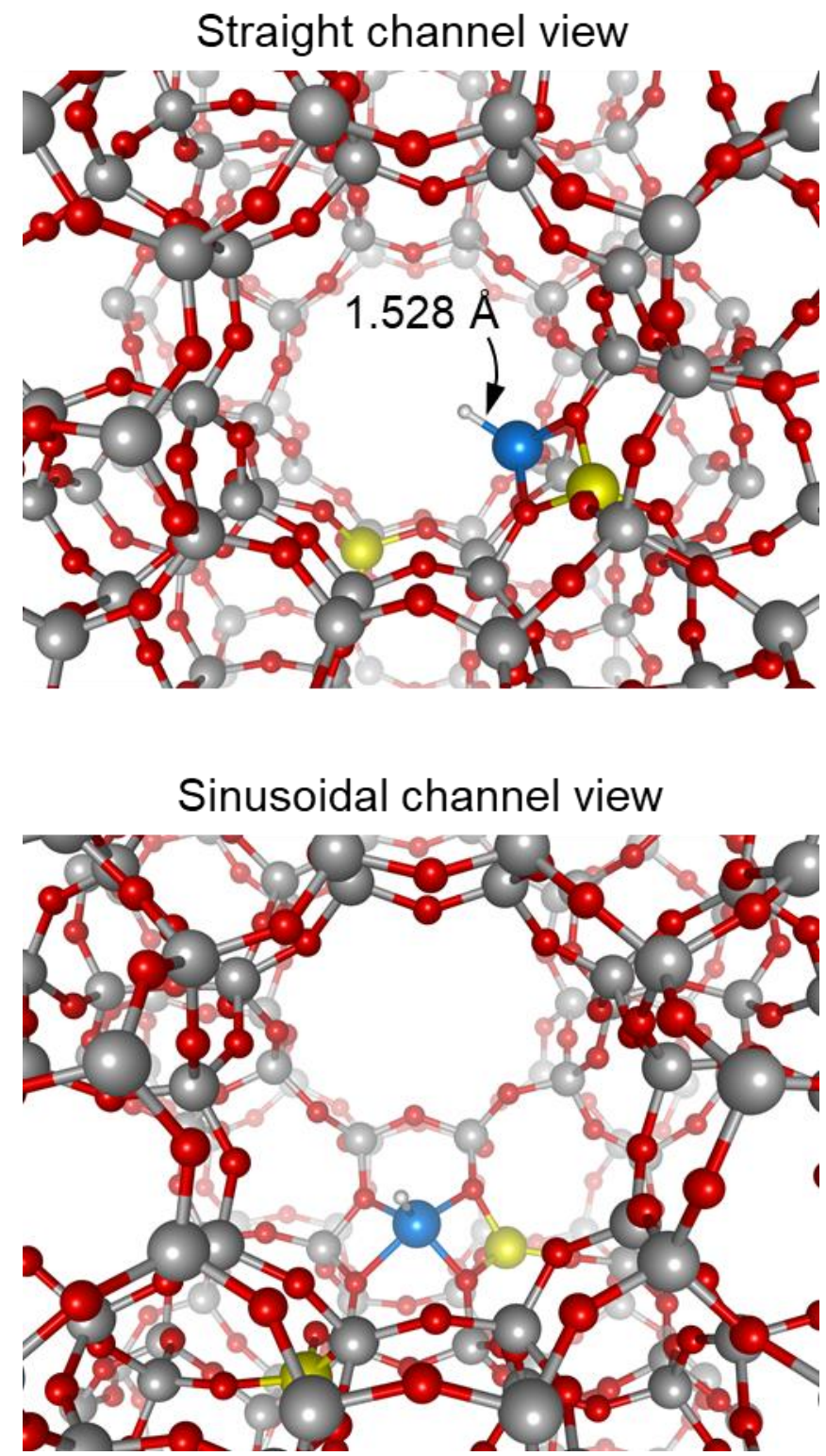

Figure S19. Optimized $[\mathrm{GaH}]-\mathrm{Al}_{2} \mathrm{Si}_{150} \mathrm{O}_{263} \mathrm{H}_{82}$ geometry representing the $[\mathrm{Ga}-\mathrm{H}]^{2+}$ species anchored on the 6MR site containing two framework $\mathrm{Al}$ atoms at T20/T23 crystallographic positions: (top) straight channel view; (bottom) sinusoidal channel view. Legend: blue, Ga; yellow, Al; grey, Si; red, O. 
$\mathrm{T} 11 / \mathrm{T} 23$

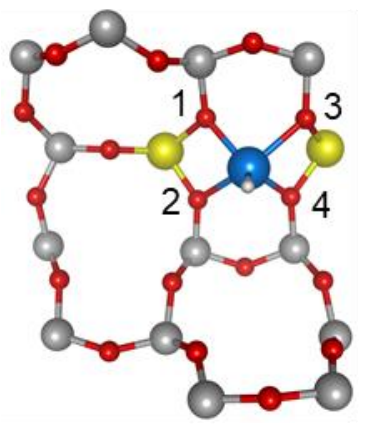

$\mathrm{T} 7 / \mathrm{T} 12$

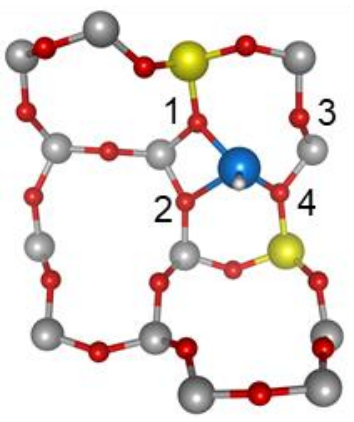

T7/T11

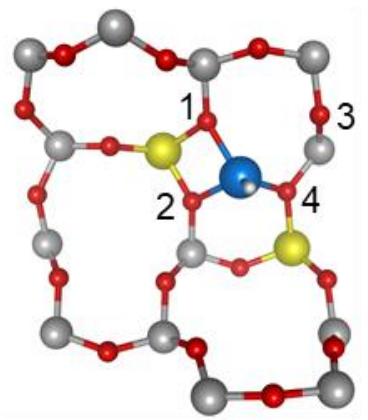

T5/T23

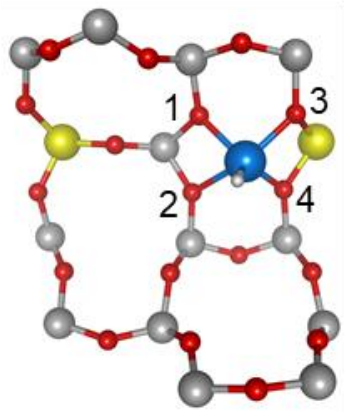

$\mathrm{T} 12 / \mathrm{T} 19$

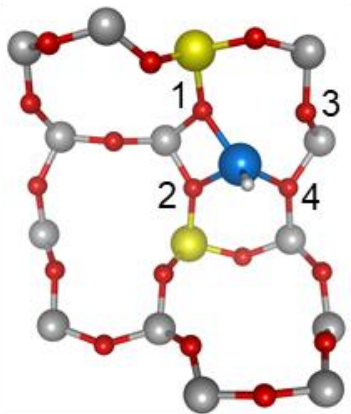

T20/T23

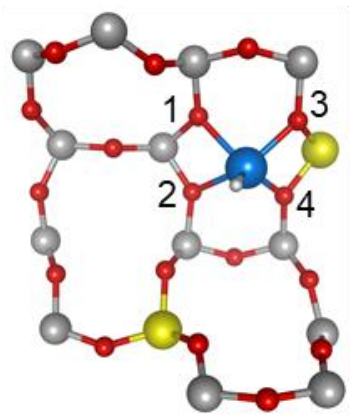

$\begin{array}{ccccccc}\begin{array}{c}\text { Distance }(\AA) \\ \text { and natural } \\ \text { charge }\end{array} & \text { T11/T23 } & \text { T7/T11 } & \text { T12/T19 } & \text { T7/T12 } & \text { T5/T23 } & \text { T20/T23 } \\ \text { Ga-H } & 1.536 & 1.530 & 1.527 & 1.527 & 1.531 & 1.528 \\ \text { Ga-1OL } & 1.984 & 1.970 & 1.956 & 1.943 & 2.038 & 2.144 \\ \text { Ga-2OL } & 2.092 & 1.928 & 1.975 & 2.203 & 2.246 & 2.208 \\ \text { Ga-3OL } & 2.129 & 2.909 & 2.357 & 2.263 & 2.025 & 2.025 \\ \text { Ga-4OL } & 1.972 & 1.929 & 2.069 & 1.928 & 1.946 & 1.925 \\ \text { Al1-Al2 } & 4.831 & 5.003 & 5.985 & 6.502 & 7.910 & 7.330 \\ \text { Charge (Ga) } & 1.49 & 1.53 & 1.50 & 1.50 & 1.50 & 1.49 \\ \text { Charge (H) } & -0.24 & -0.23 & -0.22 & -0.22 & -0.22 & -0.21 \\ \text { Charge (1OL) } & -1.30 & -1.31 & -1.29 & -1.29 & -1.29 & -1.26 \\ \text { Charge (2OL) } & -1.31 & -1.31 & -1.30 & -1.27 & -1.27 & -1.26 \\ \text { Charge (3OL) } & -1.30 & -1.27 & -1.26 & -1.26 & -1.26 & -1.30 \\ \text { Charge (4OL }) & -1.31 & -1.29 & -1.26 & -1.29 & -1.29 & -1.31\end{array}$

${ }^{a} \mathrm{O}_{\mathrm{L}}$ means the lattice oxygen atoms.

Figure S20. Summary of the geometric features of the $[\mathrm{Ga}-\mathrm{H}]^{2+}$ sites shown in Figures S14-S19. 


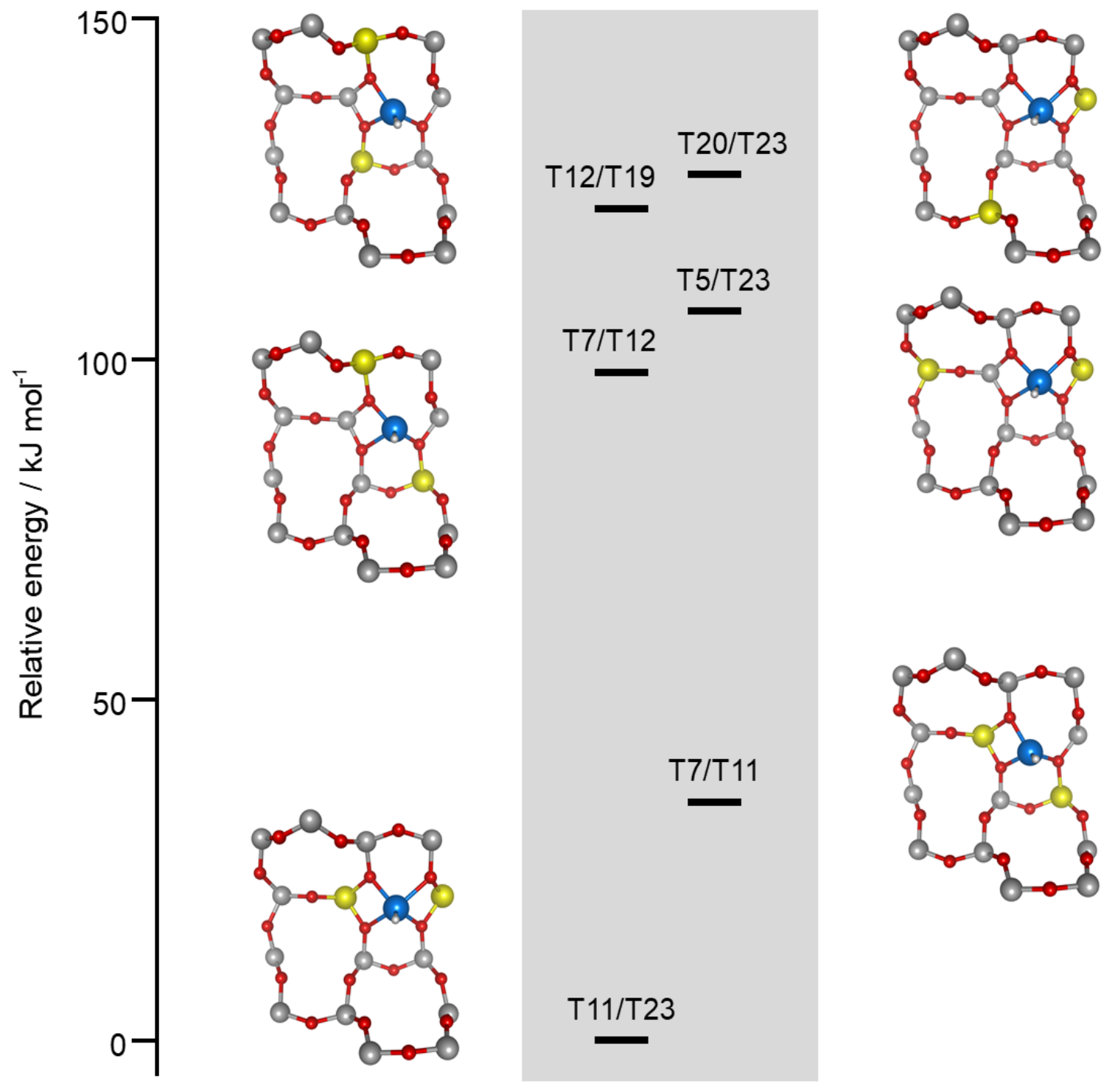

Figure S21. Relative energies of the $[\mathrm{GaH}]-\mathrm{Al}_{2} \mathrm{Si}_{150} \mathrm{O}_{263} \mathrm{H}_{82}$ geometries Figures S14-S19. For clarity, the local geometries of the $[\mathrm{Ga}-\mathrm{H}]^{2+}$ species were also shown. Legend: blue, Ga; yellow, Al; grey, Si; red, O. 

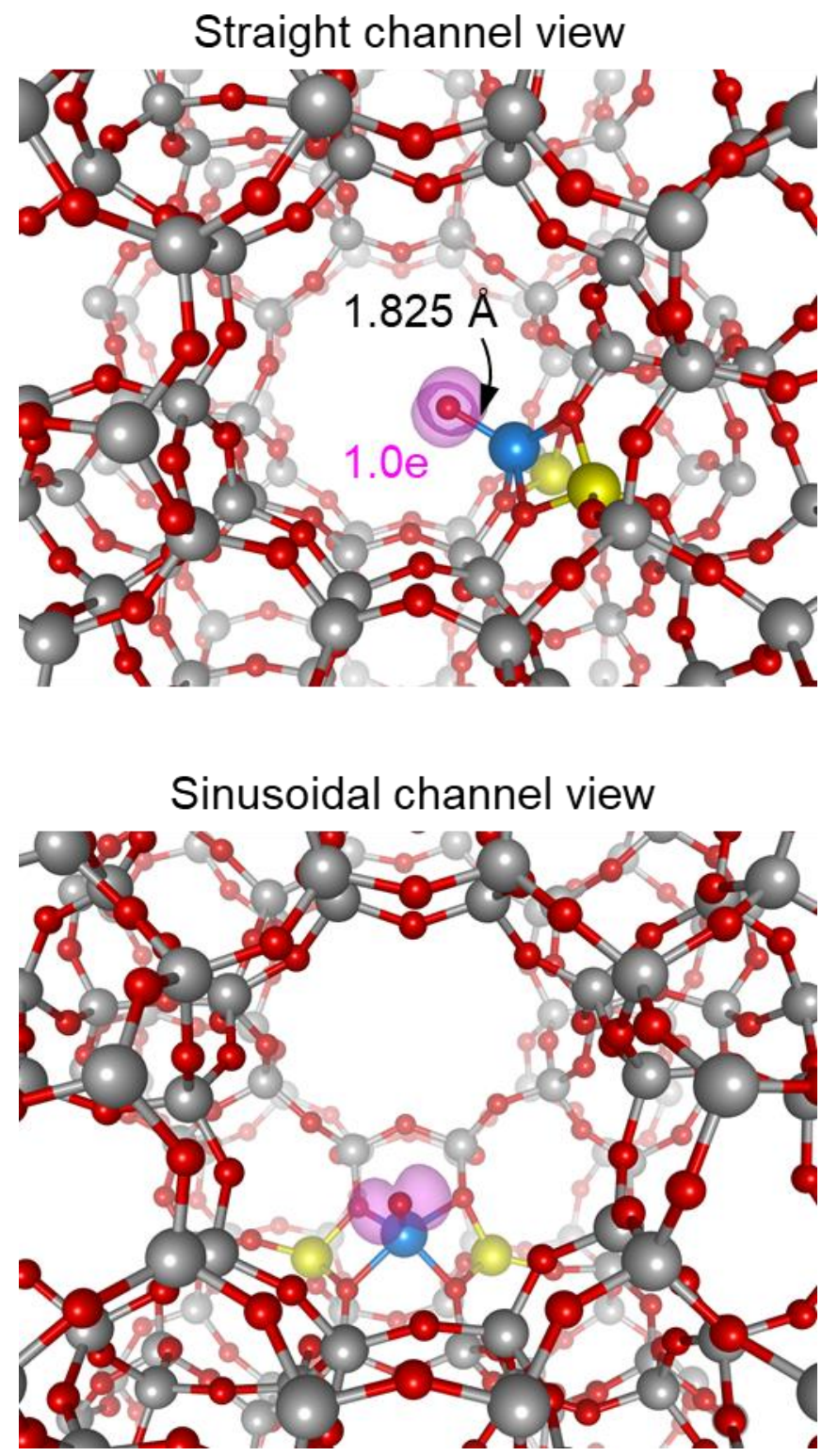

Figure S22. Optimized [GaO]- $\mathrm{Al}_{2} \mathrm{Si}_{150} \mathrm{O}_{263} \mathrm{H}_{82}$ geometry representing the $[\mathrm{Ga}-\mathrm{O}]^{2+\cdot}$ species anchored on the 6MR site containing two framework $\mathrm{Al}$ atoms at T11/T23 crystallographic positions: (top) straight channel view; (bottom) sinusoidal channel view. This figure corresponds to the enlarged graph of Figure 2 in the manuscript. The Mulliken spin distribution was also shown as a pink surface. Legend: blue, Ga; yellow, Al; grey, Si; red, O. 


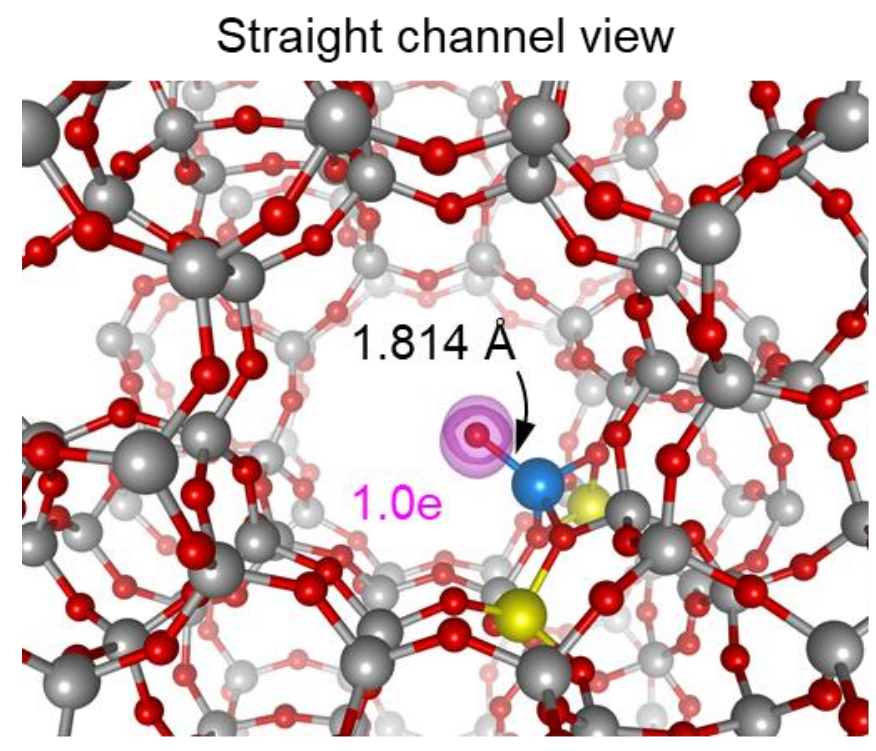

Sinusoidal channel view

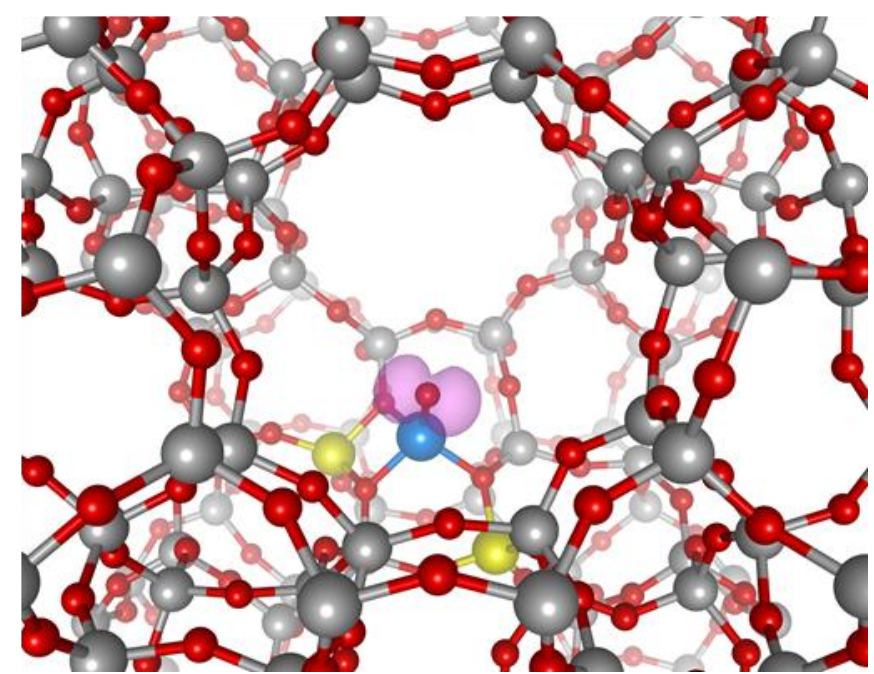

Figure S23. Optimized [GaO]- $\mathrm{Al}_{2} \mathrm{Si}_{150} \mathrm{O}_{263} \mathrm{H}_{82}$ geometry representing the $[\mathrm{Ga}-\mathrm{O}]^{2+\cdot}$ species anchored on the $6 \mathrm{MR}$ site containing two framework $\mathrm{Al}$ atoms at T7/T11 crystallographic positions: (top) straight channel view; (bottom) sinusoidal channel view. The Mulliken spin distribution was also shown as a pink surface. Legend: blue, Ga; yellow, Al; grey, Si; red, O. 

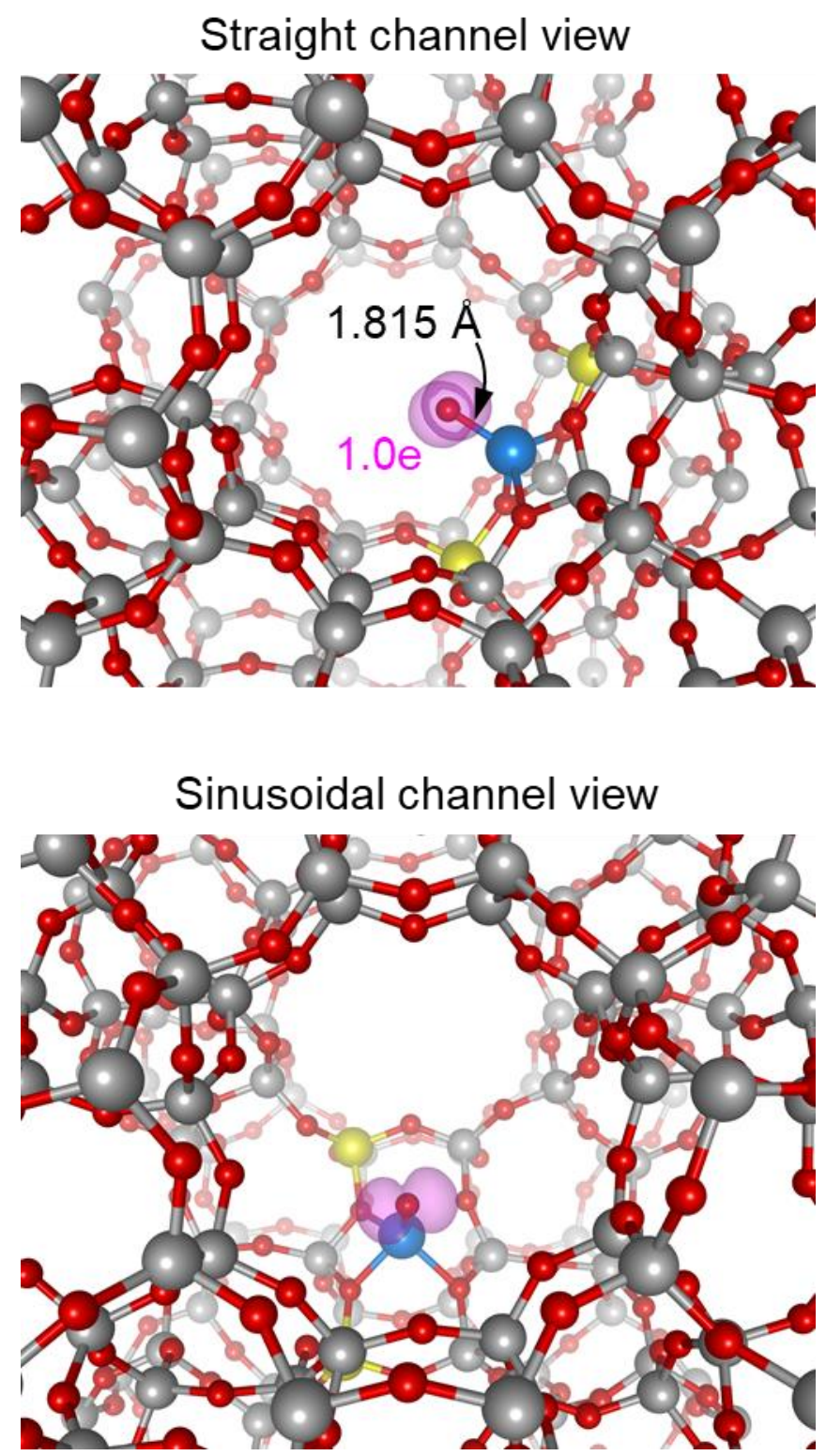

Figure S24. Optimized [GaO]- $\mathrm{Al}_{2} \mathrm{Si}_{150} \mathrm{O}_{263} \mathrm{H}_{82}$ geometry representing the $[\mathrm{Ga}-\mathrm{O}]^{2+\cdot}$ species anchored on the 6MR site containing two framework $\mathrm{Al}$ atoms at T12/T19 crystallographic positions: (top) straight channel view; (bottom) sinusoidal channel view. The Mulliken spin distribution was also shown as a pink surface. Legend: blue, Ga; yellow, Al; grey, Si; red, O. 


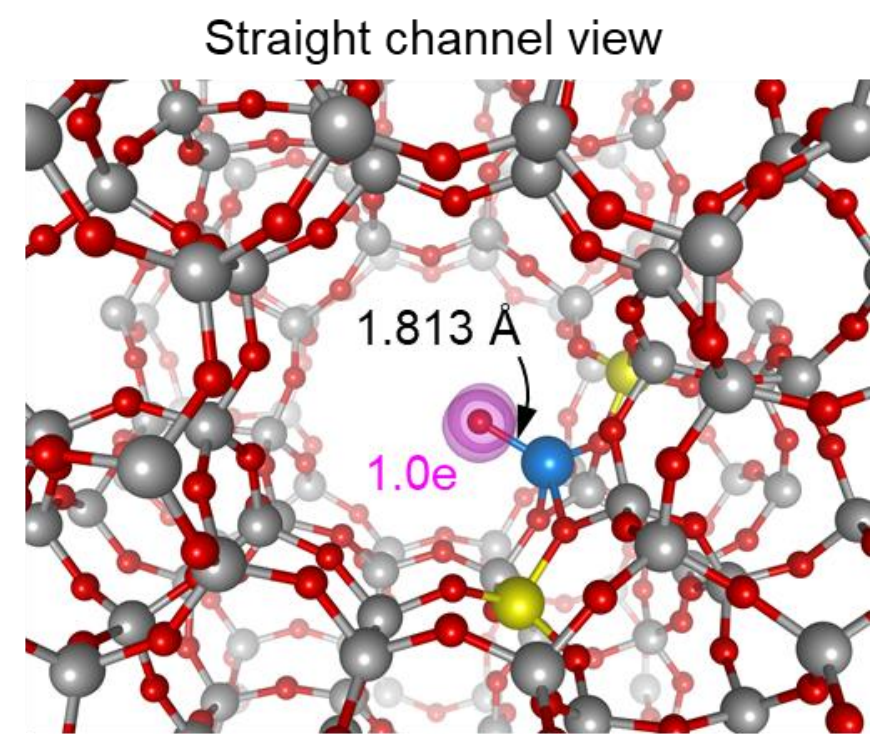

Sinusoidal channel view

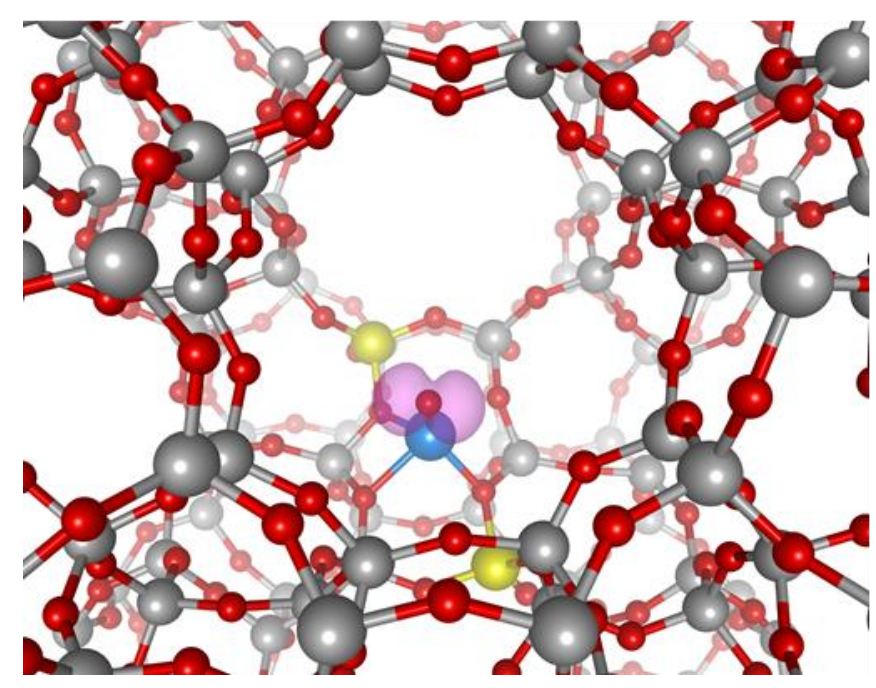

Figure S25. Optimized [GaO]- $\mathrm{Al}_{2} \mathrm{Si}_{150} \mathrm{O}_{263} \mathrm{H}_{82}$ geometry representing the $[\mathrm{Ga}-\mathrm{O}]^{2+\cdot}$ species anchored on the $6 \mathrm{MR}$ site containing two framework $\mathrm{Al}$ atoms at T7/T12 crystallographic positions: (top) straight channel view; (bottom) sinusoidal channel view. The Mulliken spin distribution was also shown as a pink surface. Legend: blue, Ga; yellow, Al; grey, Si; red, O. 
Straight channel view

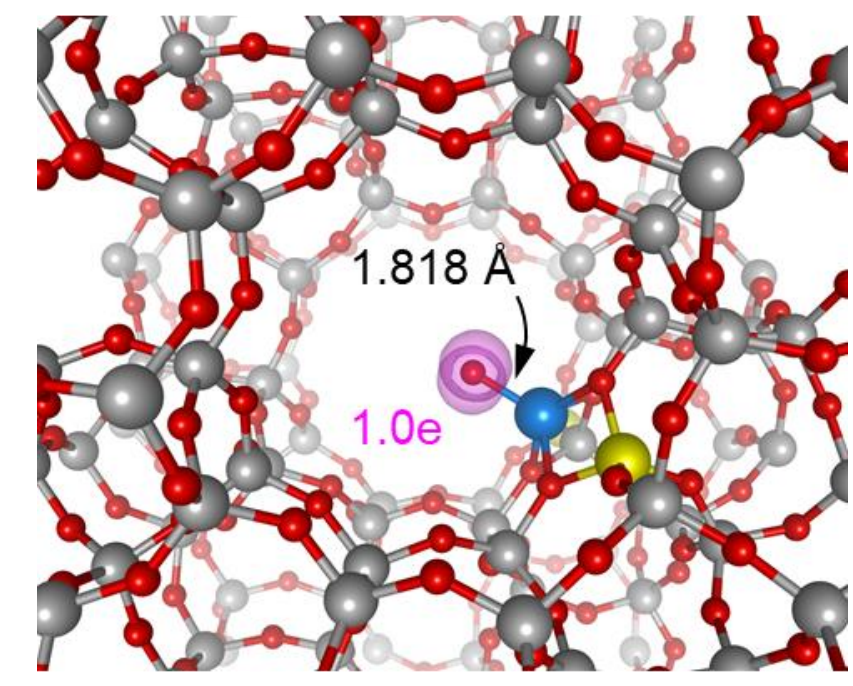

\section{Sinusoidal channel view}

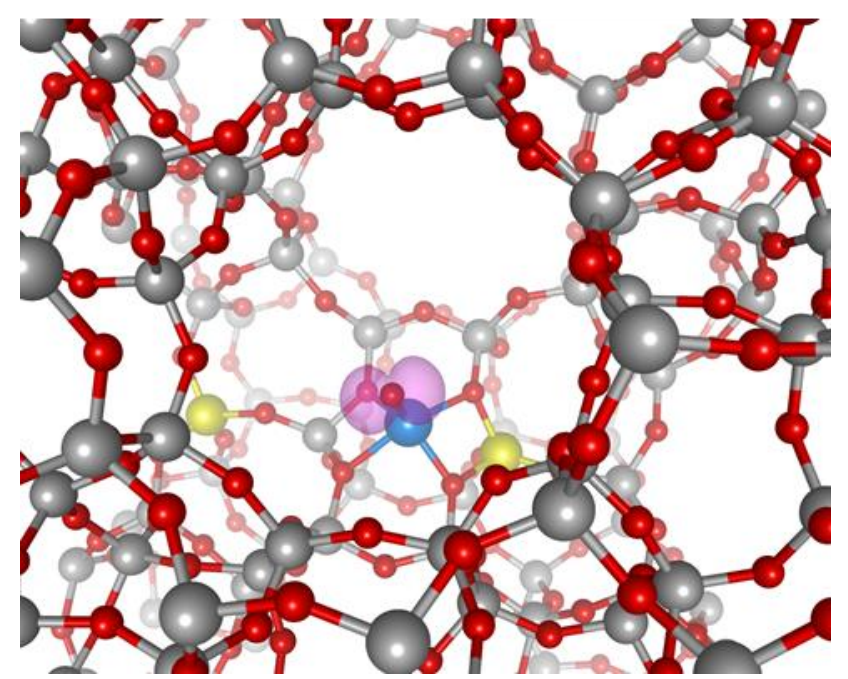

Figure S26. Optimized [ $\mathrm{GaO}]-\mathrm{Al}_{2} \mathrm{Si}_{150} \mathrm{O}_{263} \mathrm{H}_{82}$ geometry representing the $[\mathrm{Ga}-\mathrm{O}]^{2+\bullet}$ species anchored on the 6MR site containing two framework Al atoms at T5/T23 crystallographic positions: (top) straight channel view; (bottom) sinusoidal channel view. The Mulliken spin distribution was also shown as a pink surface. Legend: blue, Ga; yellow, Al; grey, Si; red, O. 

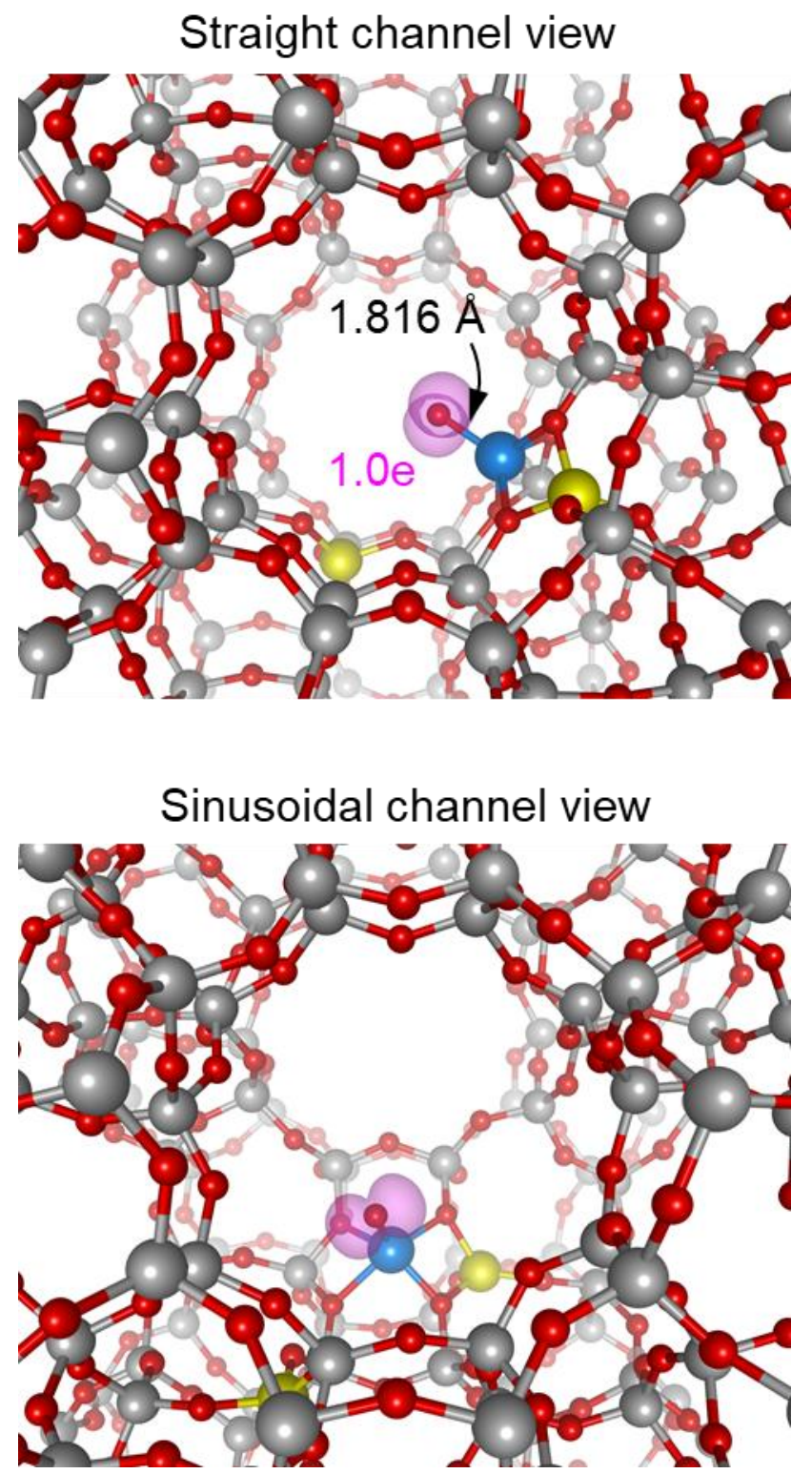

Figure S27. Optimized [GaO]- $\mathrm{Al}_{2} \mathrm{Si}_{150} \mathrm{O}_{263} \mathrm{H}_{82}$ geometry representing the $[\mathrm{Ga}-\mathrm{O}]^{2+\cdot}$ species anchored on the $6 \mathrm{MR}$ site containing two framework $\mathrm{Al}$ atoms at T20/T23 crystallographic positions: (top) straight channel view; (bottom) sinusoidal channel view. The Mulliken spin distribution was also shown as a pink surface. Legend: blue, Ga; yellow, Al; grey, Si; red, O. 
$\mathrm{T} 11 / \mathrm{T} 23$

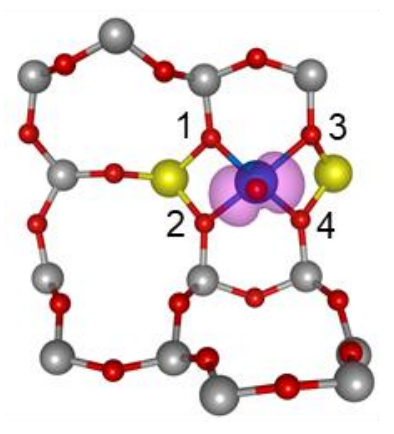

T7/T11

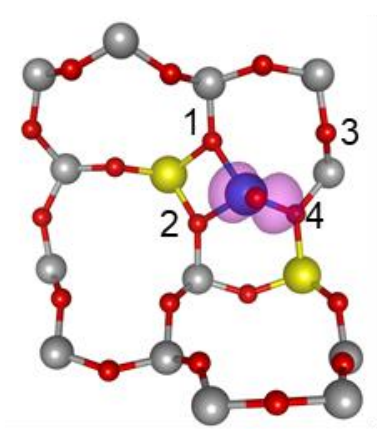

T12/T19

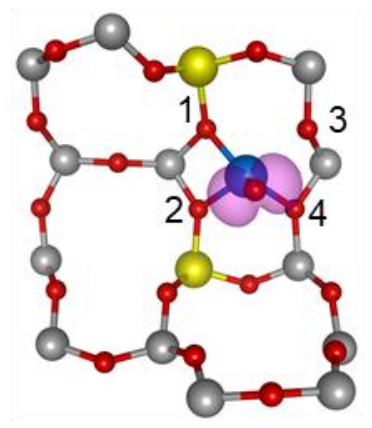

T7/T12

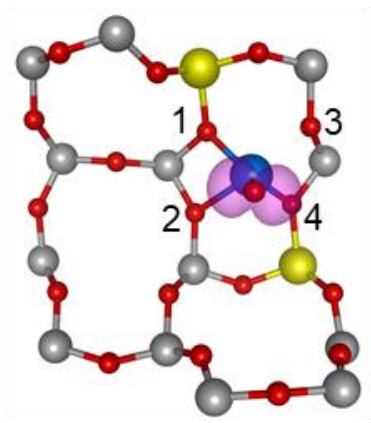

T5/T23

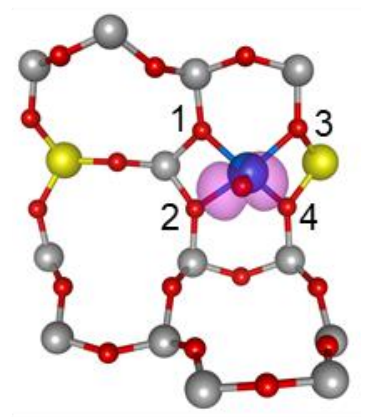

T20/T23

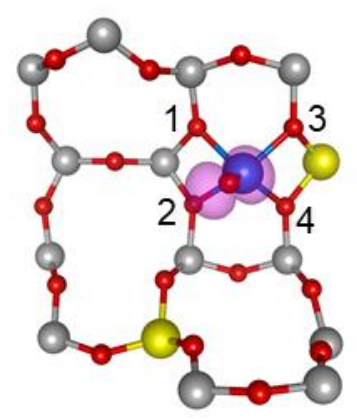

T5/T23

T20/T23

density and

T11/T23

T7/T11

T12/T19

T7/T12

\section{T5/T23}

1.815

1.813

1.818

1.816

Ga-1OL

1.959

1.940

1.941

1.919

2.004

2.099

Ga-2OL

2.046

1.910

1.962

2.157

2.145

2.110

Ga-3OL

2.078

2.881

2.208

2.212

2.003

2.004

$\mathrm{Ga}-4 \mathrm{OL}$

1.949

1.893

2.038

1.906

1.928

1.912

$$
\text { Al-Al }
$$

4.873

5.046

5.988

6.543

8.028

7.357

$\operatorname{Spin}(\mathrm{Ga})$

$-0.02$

$-0.02$

$-0.02$

$-0.02$

$-0.02$

$-0.02$

$\operatorname{Spin}\left(\mathrm{O}_{\mathrm{t}}\right)$

1.01

1.01

1.01

0.01

0.01

1.01

0.01

1.01

1.01

Spin (zeolite)

0.01

1.80

1.77

1.78

0.01

0.01

Charge (Ga)

$-0.55$

$-0.53$

$-0.53$

$-0.53$

1.78

1.78

Charge $\left(\mathrm{O}_{\mathrm{t}}\right)$

$-1.31$

$-1.31$

$-1.29$

$-1.26$

$-0.54$

$-0.53$

Charge (1O $\left.\mathrm{O}_{\mathrm{L}}\right)$

$-1.31$

$-1.32$

$-1.29$

$-1.27$

$-1.27$

$-1.26$

Charge (20L)

$-1.30$

$-1.27$

$-1.26$

$-1.26$

$-1.27$

$-1.27$

Charge (4OL

$-1.31$

$-1.29$

$-1.27$

$-1.29$

$-1.30$

$-1.30$

$-1.31$

$-1.32$

${ }^{a} \mathrm{O}_{\mathrm{t}}$ means the terminal oxyl; $\mathrm{O}_{\mathrm{L}}$ means the lattice oxygen atoms.

Figure S28. Summary of the geometric features of the $\left[\mathrm{Ga}-\mathrm{O}^{2+\cdot}\right.$ sites shown in Figures S22-S27. 

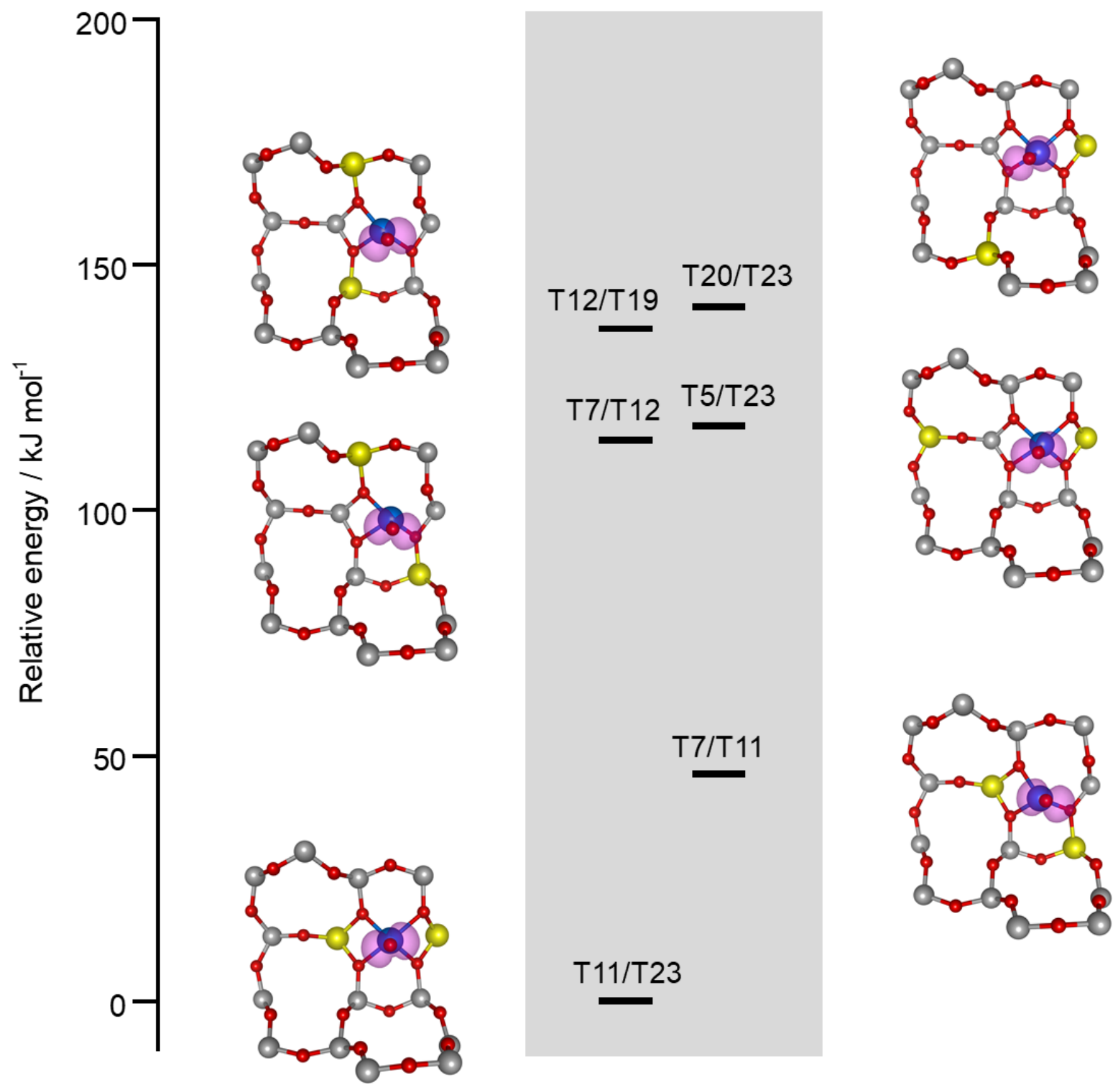

Figure S29. Relative energies of the $[\mathrm{GaO}]-\mathrm{Al}_{2} \mathrm{Si}_{150} \mathrm{O}_{263} \mathrm{H}_{82}$ geometries shown in Figures S22-S27. For clarity, the local geometries of the $[\mathrm{Ga}-\mathrm{O}]^{2+\cdot}$ species were also shown, where the Mulliken spin distributions were also shown as pink surfaces. Legend: blue, Ga; yellow, Al; grey, Si; red, O. 

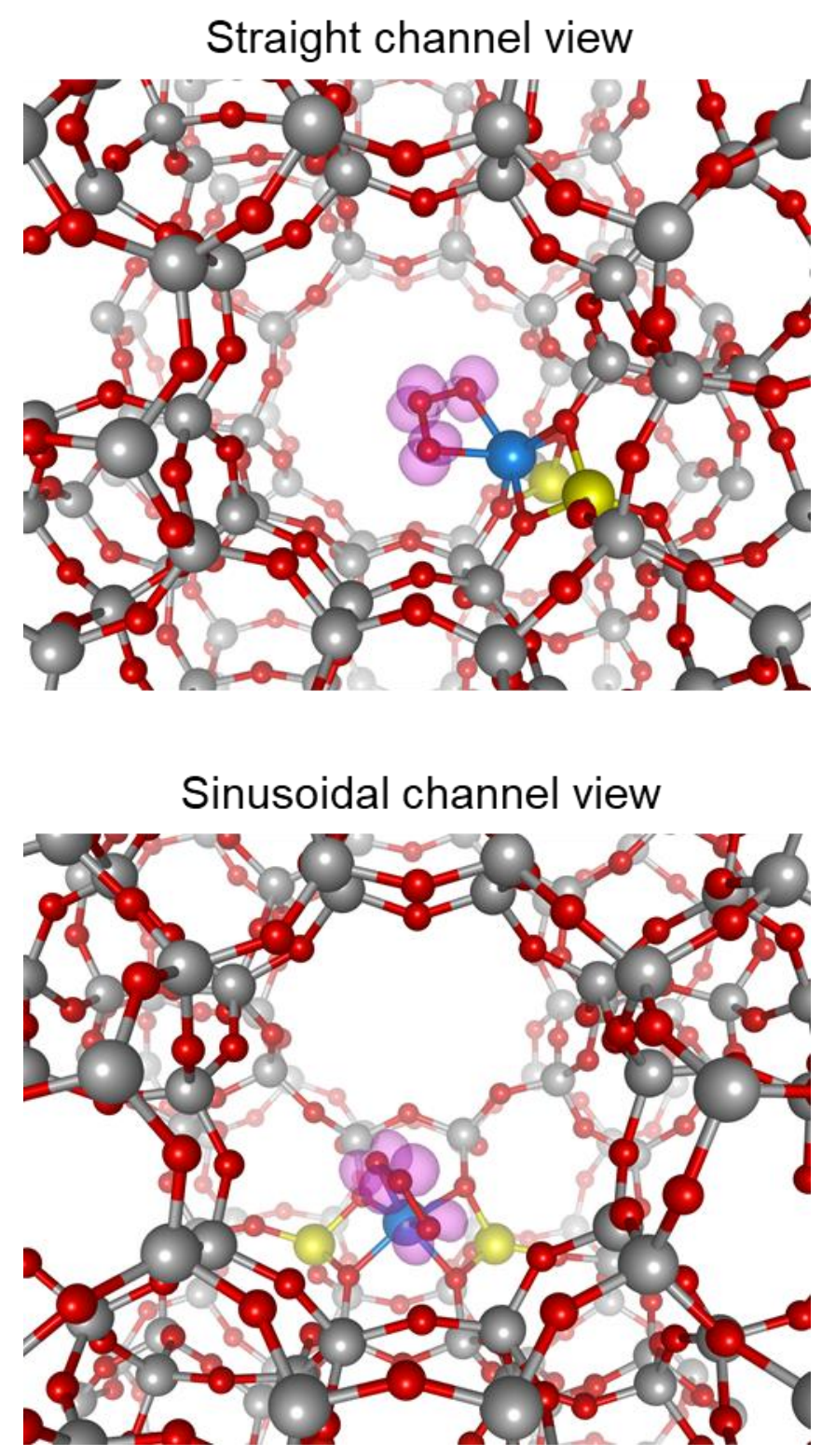

Figure S30. Optimized $\left[\mathrm{GaO}_{3}\right]-\mathrm{Al}_{2} \mathrm{Si}_{150} \mathrm{O}_{263} \mathrm{H}_{82}$ geometry representing the $\left[\mathrm{Ga}-\left(\mathrm{O}_{3}\right)\right]^{2+\cdot}$ species anchored on the 6MR site containing two framework Al atoms at T11/T23 crystallographic positions: (top) straight channel view; (bottom) sinusoidal channel view. The Mulliken spin distribution was also shown as a pink surface. Legend: blue, Ga; yellow, Al; grey, Si; red, O. 

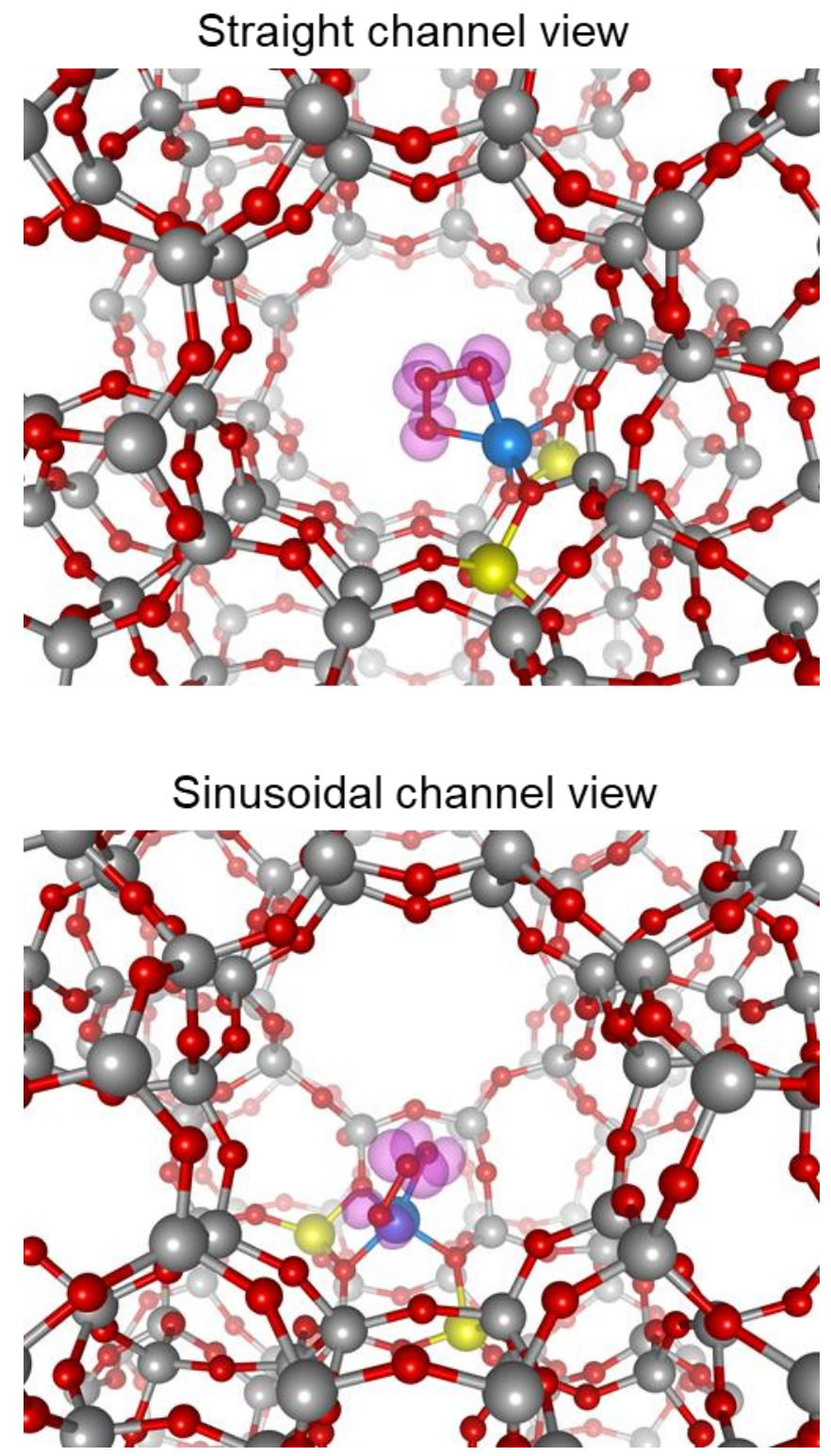

Figure S31. Optimized $\left[\mathrm{GaO}_{3}\right]-\mathrm{Al}_{2} \mathrm{Si}_{150} \mathrm{O}_{263} \mathrm{H}_{82}$ geometry representing the $\left[\mathrm{Ga}-\left(\mathrm{O}_{3}\right)\right]^{2+\cdot}$ species anchored on the $6 \mathrm{MR}$ site containing two framework $\mathrm{Al}$ atoms at T7/T11 crystallographic positions: (top) straight channel view; (bottom) sinusoidal channel view. The Mulliken spin distribution was also shown as a pink surface. Legend: blue, Ga; yellow, Al; grey, Si; red, O. 

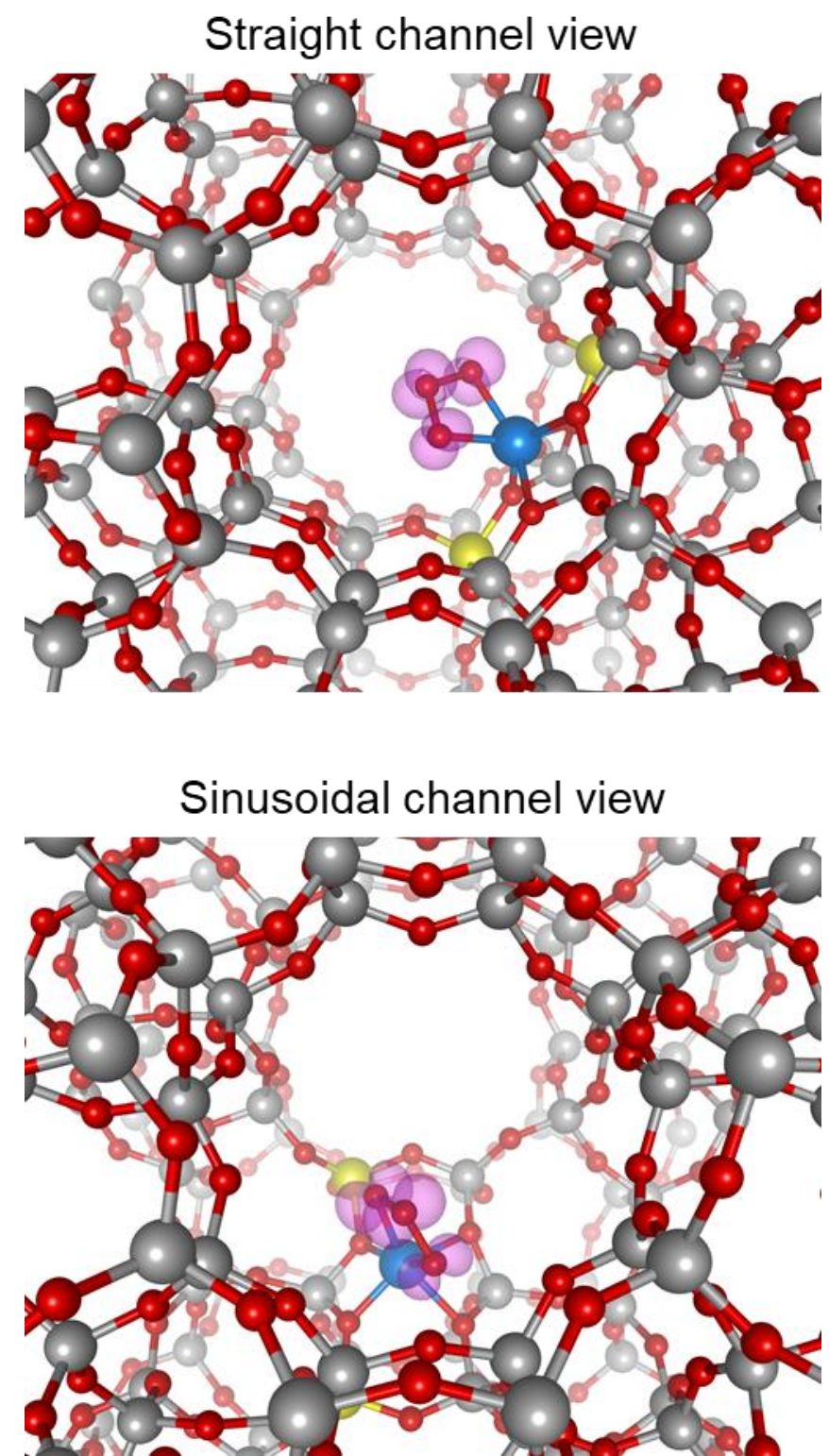

Figure S32. Optimized $\left[\mathrm{GaO}_{3}\right]-\mathrm{Al}_{2} \mathrm{Si}_{150} \mathrm{O}_{263} \mathrm{H}_{82}$ geometry representing the $\left[\mathrm{Ga}-\left(\mathrm{O}_{3}\right)\right]^{2+\cdot}$ species anchored on the 6MR site containing two framework Al atoms at T12/T19 crystallographic positions: (top) straight channel view; (bottom) sinusoidal channel view. The Mulliken spin distribution was also shown as a pink surface. Legend: blue, Ga; yellow, Al; grey, Si; red, O. 

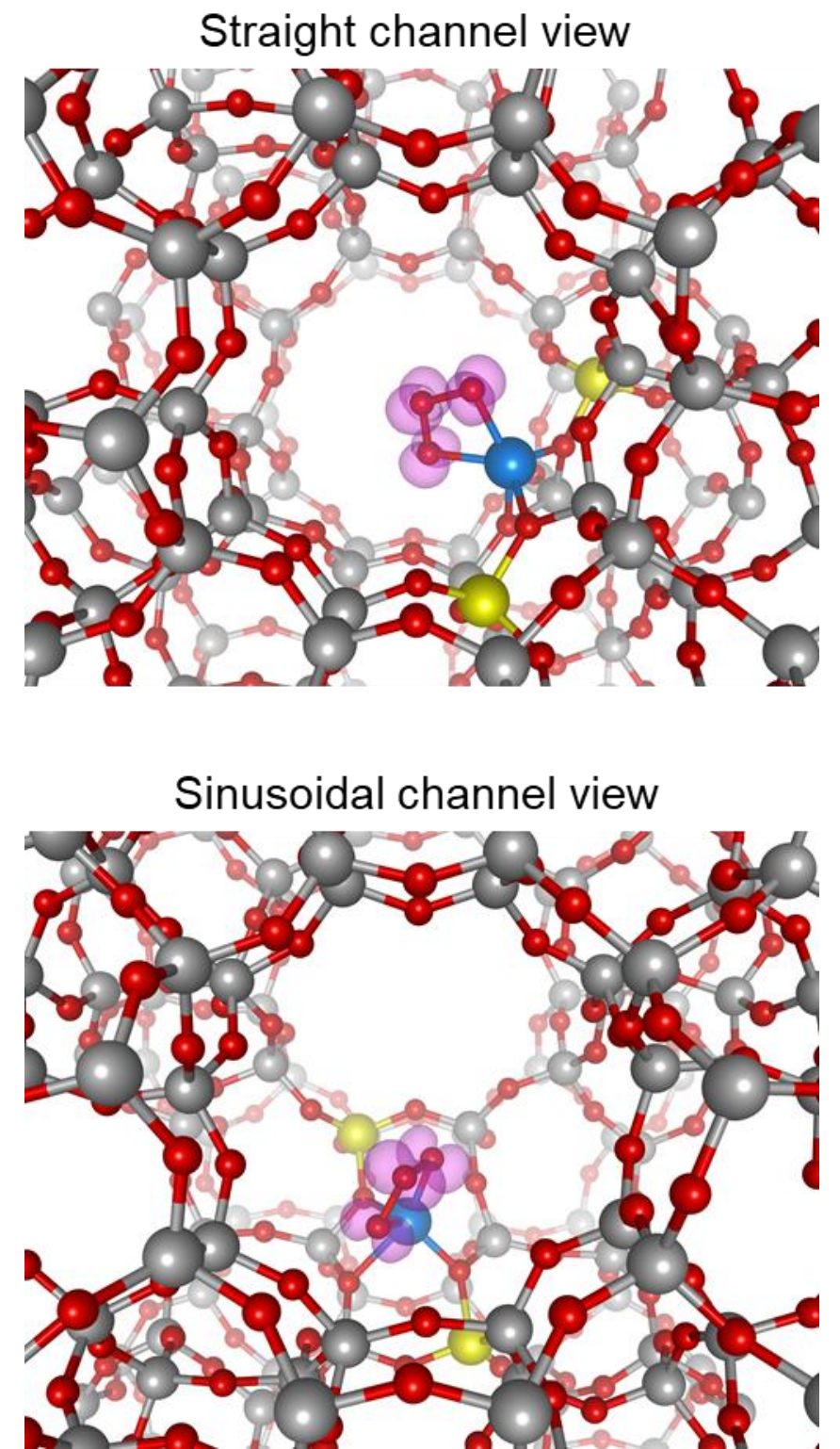

Figure S33. Optimized $\left[\mathrm{GaO}_{3}\right]-\mathrm{Al}_{2} \mathrm{Si}_{150} \mathrm{O}_{263} \mathrm{H}_{82}$ geometry representing the $\left[\mathrm{Ga}-\left(\mathrm{O}_{3}\right)\right]^{2+\cdot}$ species anchored on the $6 \mathrm{MR}$ site containing two framework $\mathrm{Al}$ atoms at T7/T12 crystallographic positions: (top) straight channel view; (bottom) sinusoidal channel view. The Mulliken spin distribution was also shown as a pink surface. Legend: blue, Ga; yellow, Al; grey, Si; red, O. 

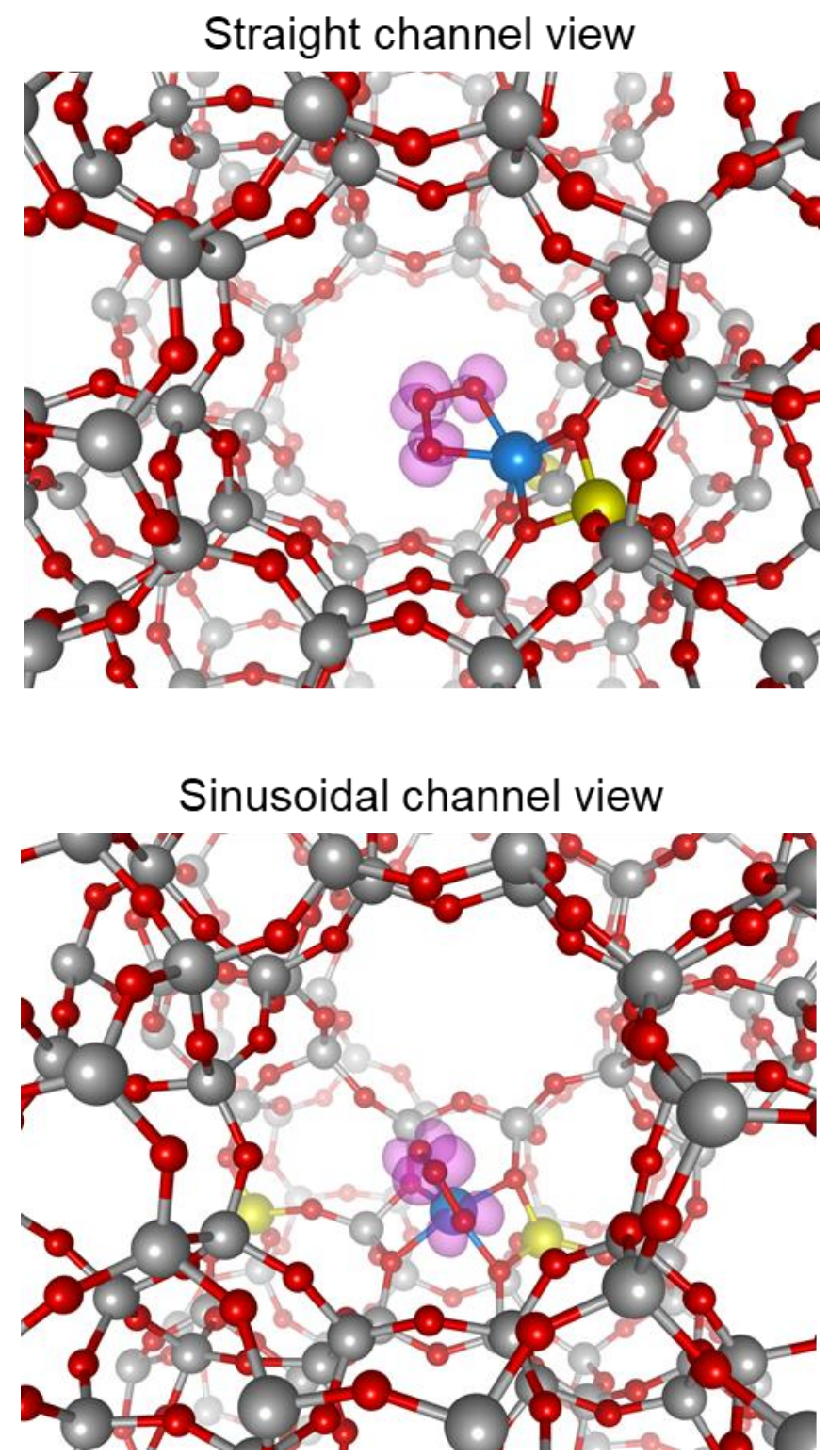

Figure S34. Optimized $\left[\mathrm{GaO}_{3}\right]-\mathrm{Al}_{2} \mathrm{Si}_{150} \mathrm{O}_{263} \mathrm{H}_{82}$ geometry representing the $\left[\mathrm{Ga}-\left(\mathrm{O}_{3}\right)\right]^{2+\cdot}$ species anchored on the 6MR site containing two framework Al atoms at T5/T23 crystallographic positions: (top) straight channel view; (bottom) sinusoidal channel view. The Mulliken spin distribution was also shown as a pink surface. Legend: blue, Ga; yellow, Al; grey, Si; red, O. 

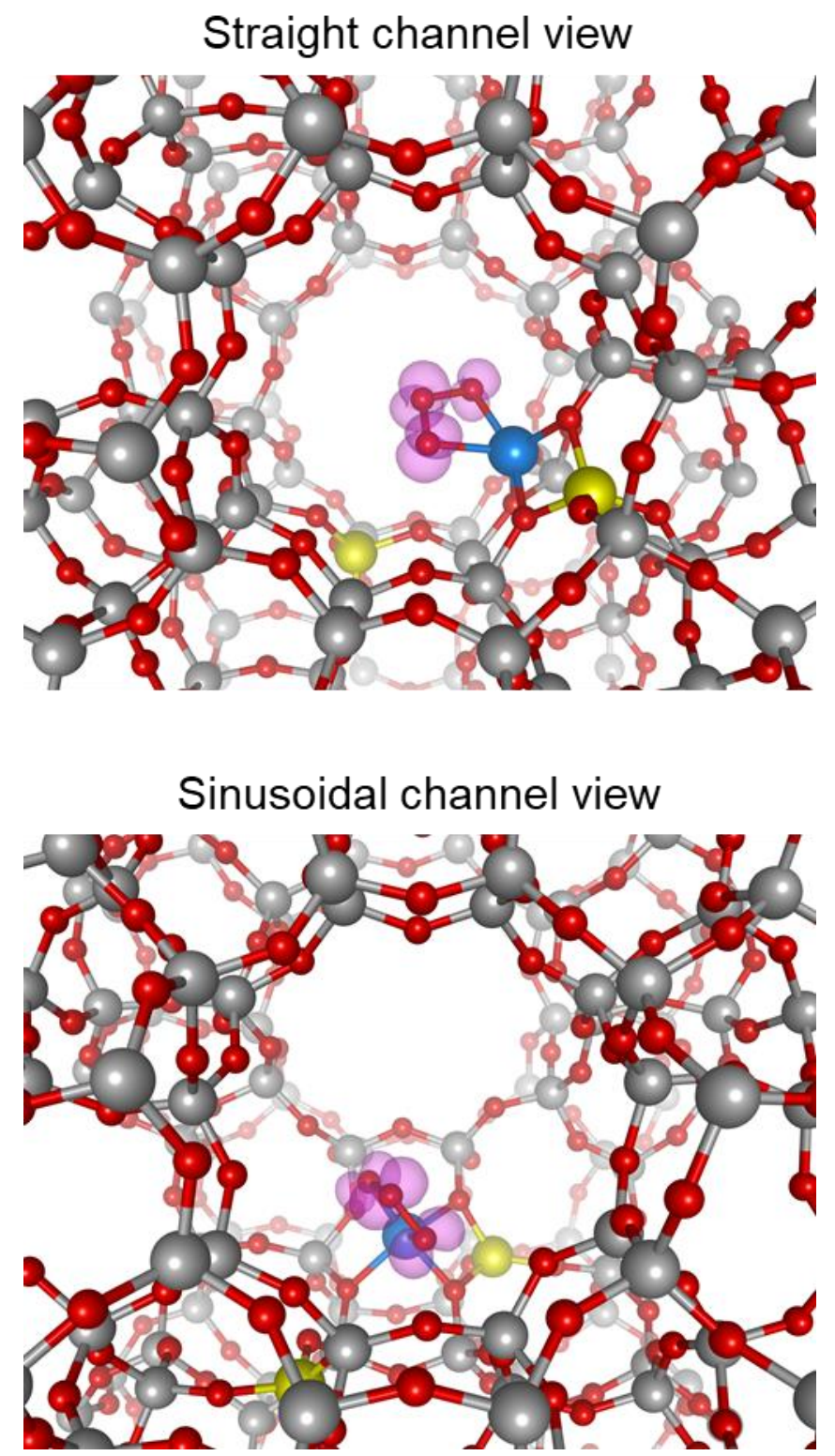

Figure S35. Optimized $\left[\mathrm{GaO}_{3}\right]-\mathrm{Al}_{2} \mathrm{Si}_{150} \mathrm{O}_{263} \mathrm{H}_{82}$ geometry representing the $\left[\mathrm{Ga}-\left(\mathrm{O}_{3}\right)\right]^{2+\bullet}$ species anchored on the $6 \mathrm{MR}$ site containing two framework $\mathrm{Al}$ atoms at T20/T23 crystallographic positions: (top) straight channel view; (bottom) sinusoidal channel view. The Mulliken spin distribution was also shown as a pink surface. Legend: blue, Ga; yellow, Al; grey, Si; red, O. 
$\mathrm{T} 11 / \mathrm{T} 23$

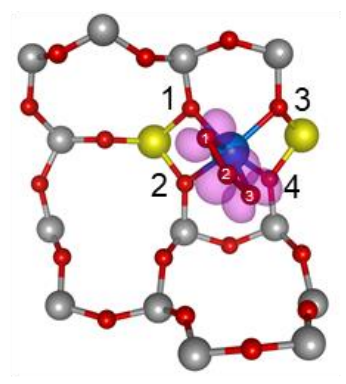

$\mathrm{T} 7 / \mathrm{T} 11$

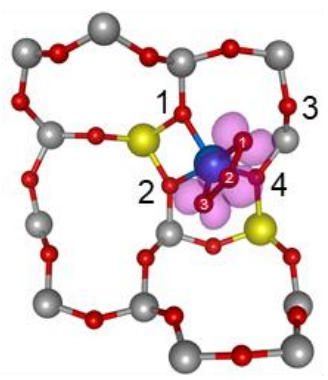

$\mathrm{T} 12 / \mathrm{T} 19$

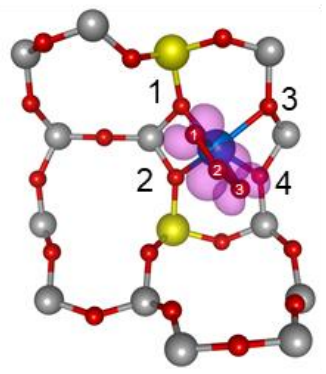

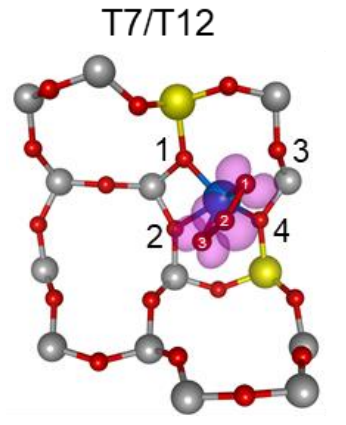

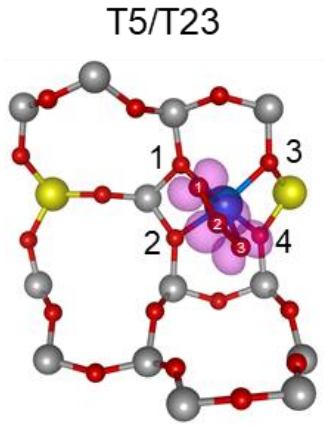

T20/T23

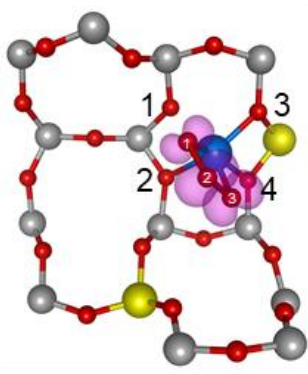

\begin{tabular}{|c|c|c|c|c|c|c|}
\hline $\begin{array}{c}\text { Distance }(\AA), \\
\text { bond angle (deg), } \\
\text { Mulliken spin } \\
\text { density and } \\
\text { natural charge }\end{array}$ & T11/T23 & T7/T11 & T12/T19 & T7/T12 & T5/T23 & T20/T23 \\
\hline $\mathrm{Ga}-1 \mathrm{O}_{\mathrm{t}}$ & 2.043 & 2.070 & 2.064 & 2.022 & 2.054 & 1.971 \\
\hline $\mathrm{Ga}-3 \mathrm{O}_{\mathrm{t}}$ & 2.070 & 1.988 & 2.000 & 2.007 & 2.024 & 2.106 \\
\hline $1 \mathrm{O}_{\mathrm{t}}-2 \mathrm{O}_{\mathrm{t}}$ & 1.346 & 1.332 & 1.332 & 1.310 & 1.340 & 1.372 \\
\hline $2 \mathrm{O}_{t}-3 \mathrm{O}_{\mathrm{t}}$ & 1.340 & 1.360 & 1.357 & 1.351 & 1.347 & 1.319 \\
\hline $1 \mathrm{O}_{\mathrm{t}}-2 \mathrm{O}_{\mathrm{t}}-3 \mathrm{O}_{\mathrm{t}}$ & 107.8 & 108.0 & 107.8 & 107.6 & 107.8 & 107.7 \\
\hline $\mathrm{Ga}-1 \mathrm{O}_{\mathrm{L}}$ & 1.994 & 1.938 & 1.969 & 1.905 & 2.054 & 2.187 \\
\hline $\mathrm{Ga}-2 \mathrm{OL}$ & 2.026 & 1.926 & 1.961 & 2.197 & 2.113 & 2.085 \\
\hline $\mathrm{Ga}-3 \mathrm{O}_{\mathrm{L}}$ & 2.054 & 3.047 & 2.150 & 2.409 & 1.999 & 1.996 \\
\hline $\mathrm{Ga}-4 \mathrm{O}_{\mathrm{L}}$ & 1.979 & 1.897 & 2.098 & 1.889 & 1.953 & 1.929 \\
\hline $\mathrm{Al}-\mathrm{Al}$ & 4.907 & 5.032 & 5.970 & 6.513 & 7.933 & 7.352 \\
\hline Spin $(\mathrm{Ga})$ & 0.00 & 0.00 & 0.01 & 0.01 & 0.01 & 0.01 \\
\hline $\operatorname{Spin}\left(\mathrm{O}_{3}\right)$ & 0.99 & 0.99 & 0.99 & 0.99 & 0.99 & 0.99 \\
\hline Spin (zeolite) & 0.01 & 0.01 & 0.00 & 0.00 & 0.00 & 0.00 \\
\hline Charge $(\mathrm{Ga})$ & 1.72 & 1.78 & 1.72 & 1.75 & 1.73 & 1.73 \\
\hline Charge $\left(1 \mathrm{O}_{\mathrm{t}}\right)$ & -0.38 & -0.34 & -0.32 & -0.35 & -0.38 & -0.44 \\
\hline Charge $\left(2 \mathrm{O}_{\mathrm{t}}\right)$ & 0.23 & 0.24 & 0.24 & 0.25 & 0.24 & 0.25 \\
\hline Charge $\left(3 \mathrm{O}_{\mathrm{t}}\right)$ & -0.37 & -0.40 & -0.41 & -0.39 & -0.36 & -0.30 \\
\hline Charge $\left(1 \mathrm{O}_{\mathrm{L}}\right)$ & -1.31 & -1.30 & -1.29 & -1.29 & -1.27 & -1.26 \\
\hline Charge $\left(2 \mathrm{O}_{\mathrm{L}}\right)$ & -1.30 & -1.32 & -1.29 & -1.27 & -1.26 & -1.26 \\
\hline Charge $\left(3 \mathrm{O}_{\mathrm{L}}\right)$ & -1.29 & -1.27 & -1.25 & -1.26 & -1.30 & -1.30 \\
\hline Charge $\left(4 \mathrm{O}_{\mathrm{L}}\right)$ & -1.31 & -1.29 & -1.27 & -1.29 & -1.32 & -1.32 \\
\hline
\end{tabular}

${ }^{a} \mathrm{O}_{\mathrm{t}}$ means the oxygen atoms in the ozonide ligand; $\mathrm{O}_{\mathrm{L}}$ means the lattice oxygen atoms.

Figure S36. Summary of the geometric features of the $\left[\mathrm{Ga}-\left(\mathrm{O}_{3}\right)\right]^{2+\bullet}$ sites shown in Figures S30-S35. 

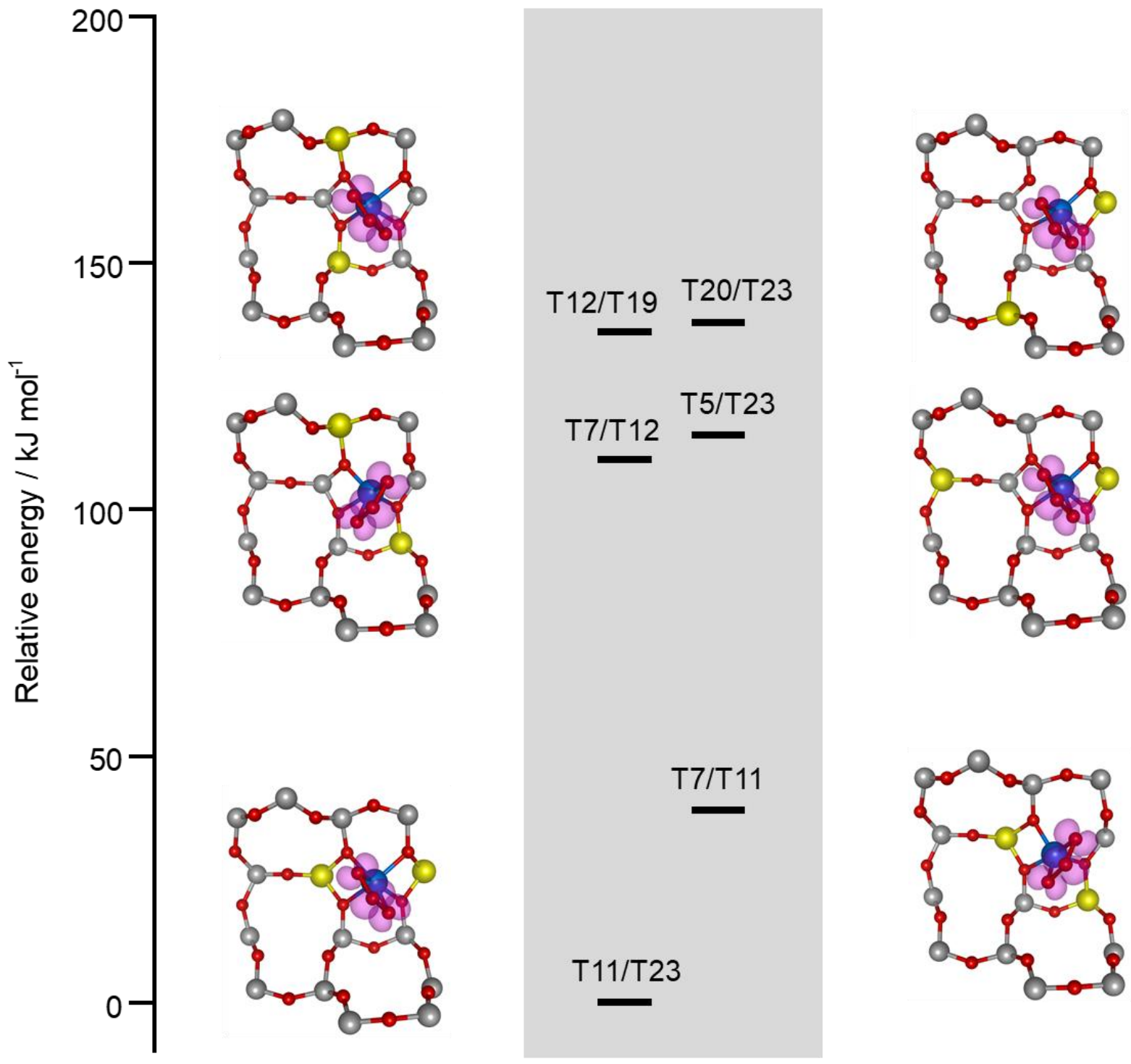

Figure S37. Relative energies of the $\left[\mathrm{Ga}\left(\mathrm{O}_{3}\right)\right]-\mathrm{Al}_{2} \mathrm{Si}_{150} \mathrm{O}_{263} \mathrm{H}_{82}$ geometries shown in Figures S30-S35. For clarity, the local geometries of the $\left[\mathrm{Ga}-\mathrm{O}_{3}\right]^{2+\cdot}$ species were also shown, where the Mulliken spin distributions were also shown as pink surfaces. Legend: blue, Ga; yellow, Al; grey, Si; red, O. 


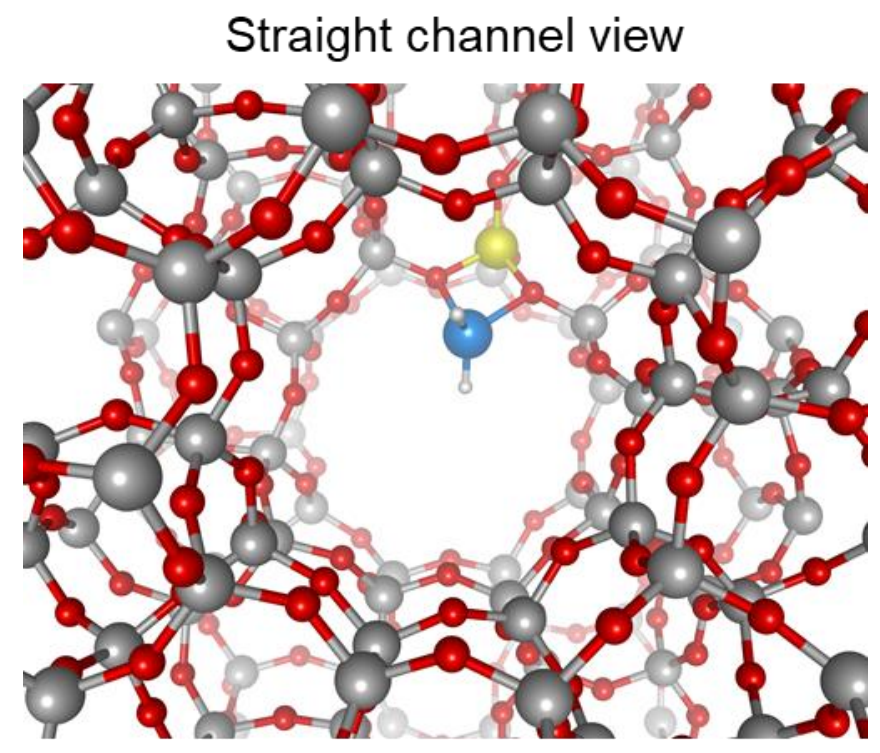

Sinusoidal channel view

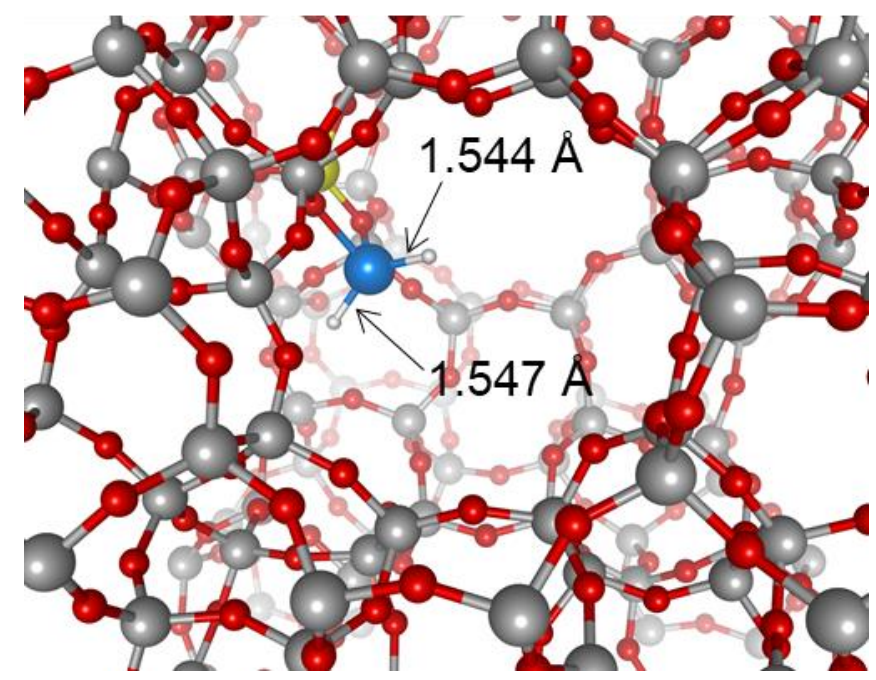

Figure S38. Optimized [ $\left.\mathrm{GaH}_{2}\right]-\mathrm{Al}_{1} \mathrm{Si}_{150} \mathrm{O}_{263} \mathrm{H}_{82}$ geometry representing the $\left[\mathrm{Ga}-(\mathrm{H})_{2}\right]^{+}$species anchored on the 10MR site containing a framework $\mathrm{Al}$ atoms at T5 crystallographic position: (top) straight channel view; (bottom) sinusoidal channel view. Legend: blue, Ga; yellow, Al; grey, Si; red, O. 

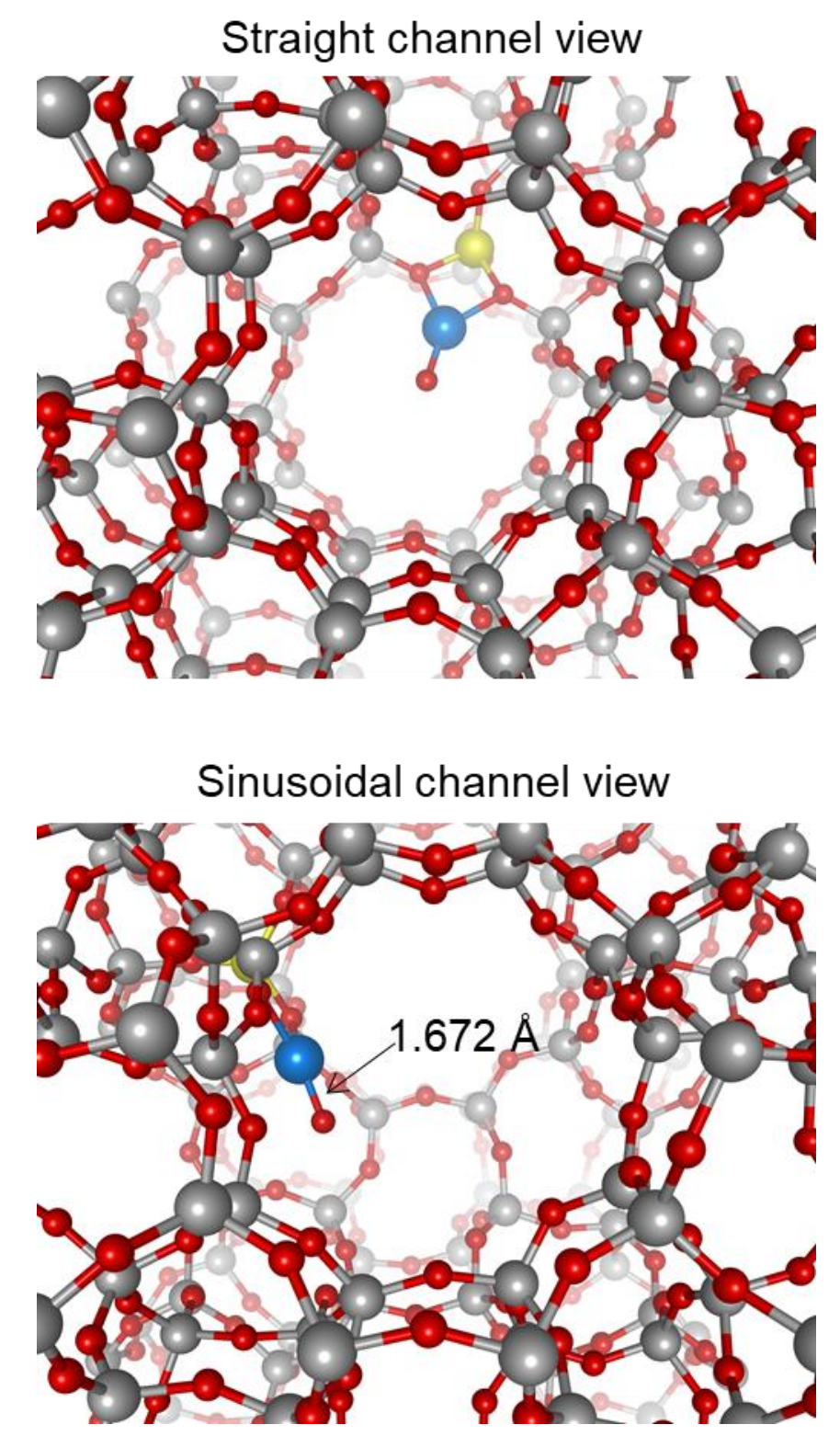

Figure S39. Optimized [ $\mathrm{GaO}]-\mathrm{Al}_{1} \mathrm{Si}_{151} \mathrm{O}_{263} \mathrm{H}_{82}$ geometry representing the $[\mathrm{Ga}=\mathrm{O}]^{+}$species anchored on the $10 \mathrm{MR}$ site containing a framework $\mathrm{Al}$ atom at $\mathrm{T} 5$ crystallographic position: (top) straight channel view; (bottom) sinusoidal channel view. Legend: blue, Ga; yellow, Al; grey, Si; red, O. 


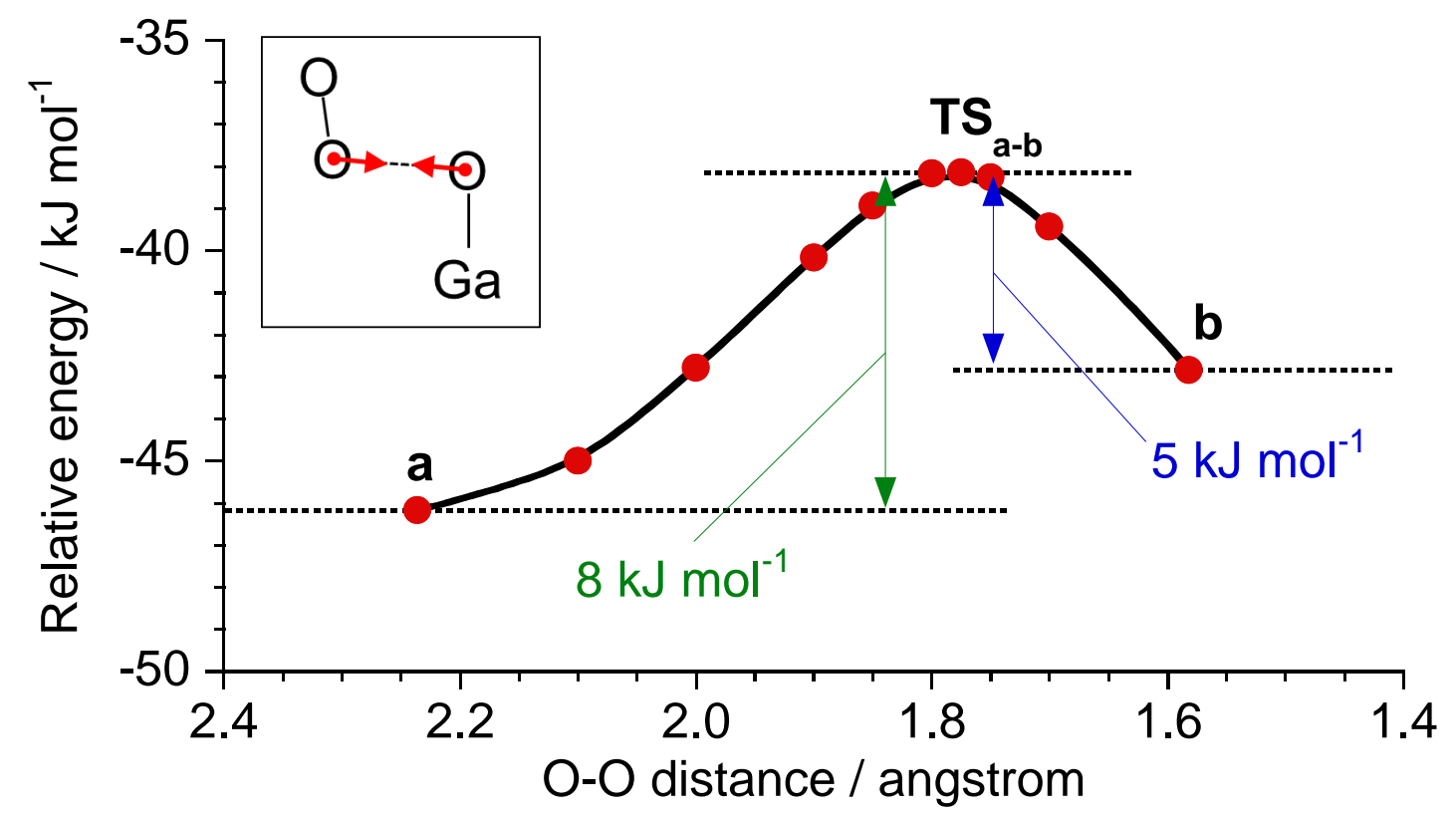

a

$\mathrm{TS}_{\mathrm{a}-\mathrm{b}}$

b
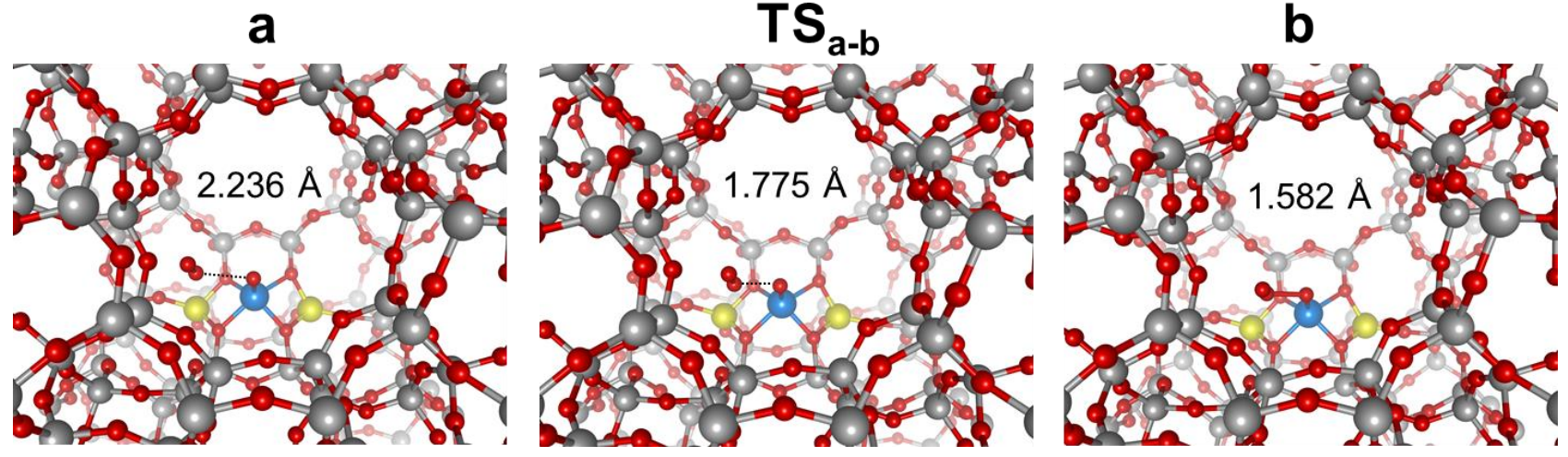

Figure S40. Computed $S=1 / 2$ potential energy surface along the $O-O$ distance between the $[\mathrm{Ga}-\mathrm{O}]^{2+\cdot}$ site $(S=$ $-1 / 2)$ and $\mathrm{O}_{2}$ molecule $(S=1)$ at the B3LYP-D3/6-311++(3df,3pd),6-31G(d)//B3LYP/6-311G(d,p),6-31G(d) level. The selected geometries were also shown below. Legend: blue, Ga; yellow, Al; grey, Si; red, O. 


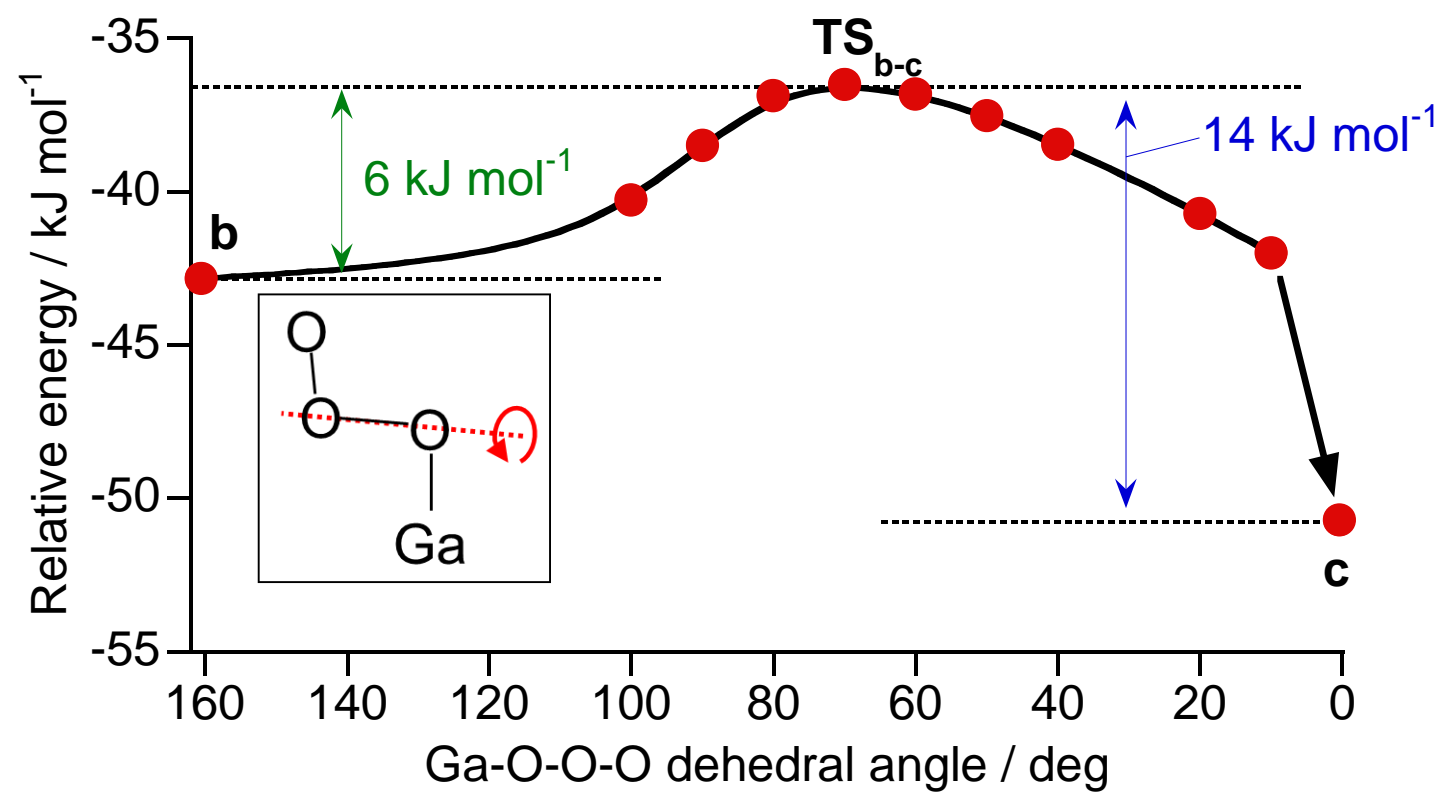

b

$\mathbf{T S}_{\mathrm{b}-\mathrm{c}}$

C

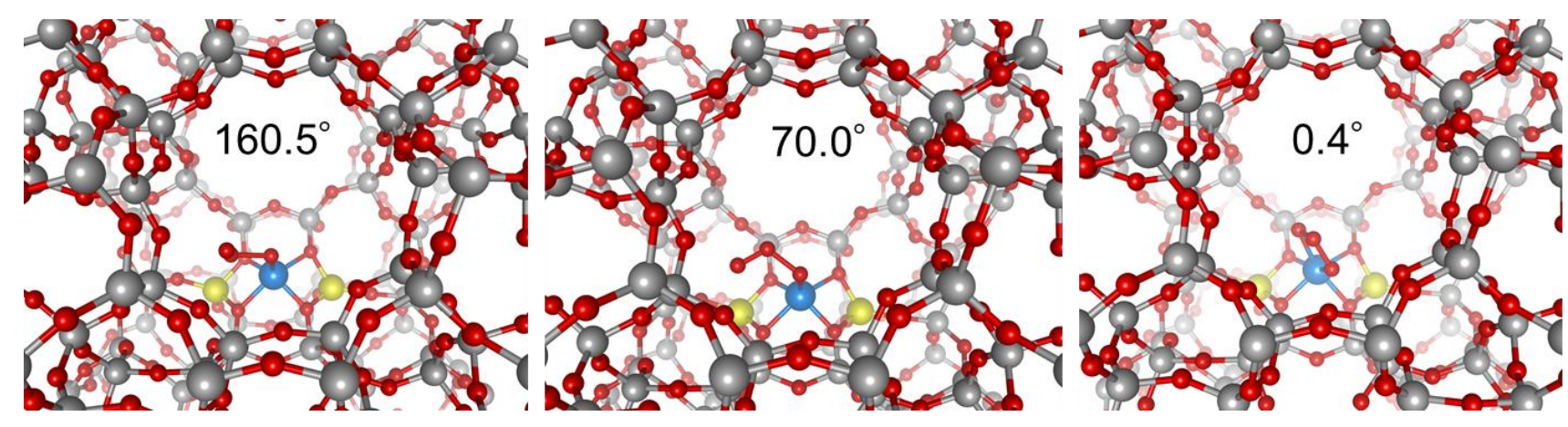

Figure S41. Computed $S=1 / 2$ potential energy surface along the $\mathrm{Ga}-\mathrm{O}-\mathrm{O}-\mathrm{O}$ dihedral angle at the B3LYPD3/6-311++(3df,3pd),6-31G(d)//B3LYP/6-311G(d,p),6-31G(d) level. The selected geometries were also shown below. Legend: blue, $\mathrm{Ga}$; yellow, $\mathrm{Al}$; grey, $\mathrm{Si}$; red, $\mathrm{O}$. 
Fragment orbitals

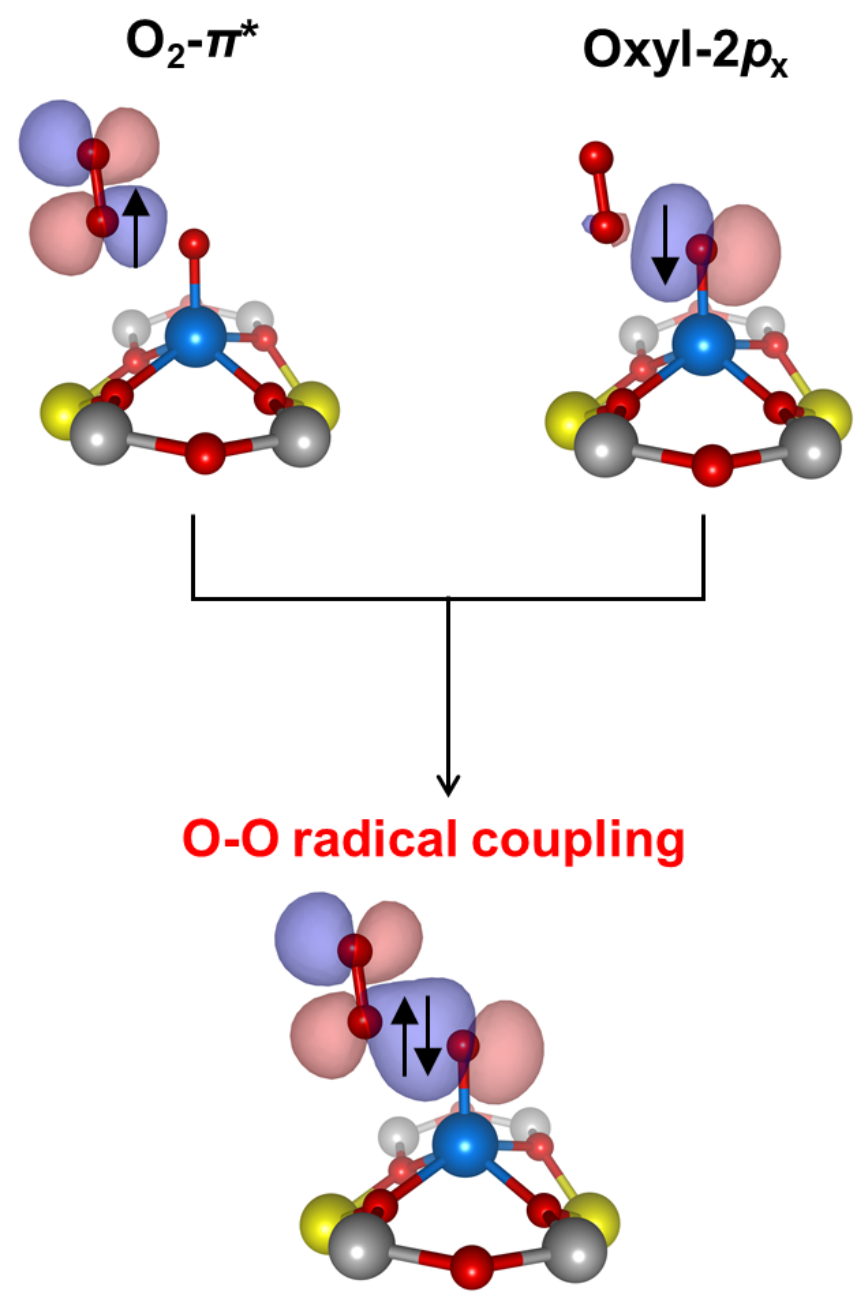

Figure S42. Schematic view of the $\mathrm{O}-\mathrm{O}$ radical coupling between the oxyl and $\mathrm{O}_{2}$.

S48 


\section{Ground state}
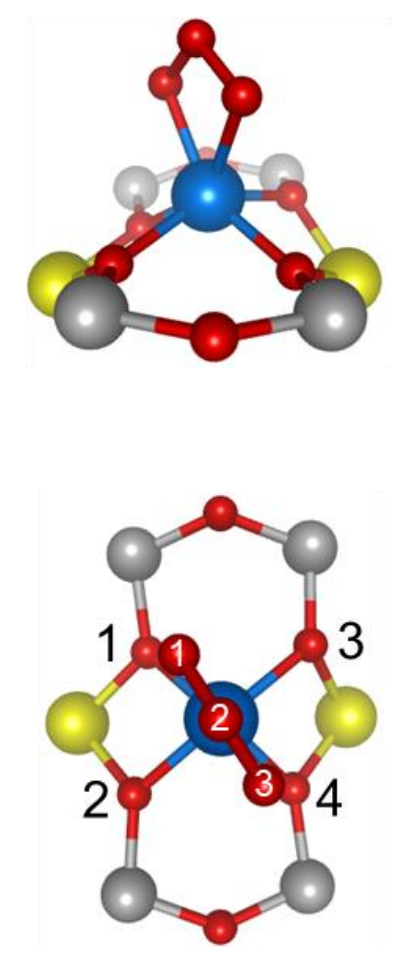

\section{Excited state}
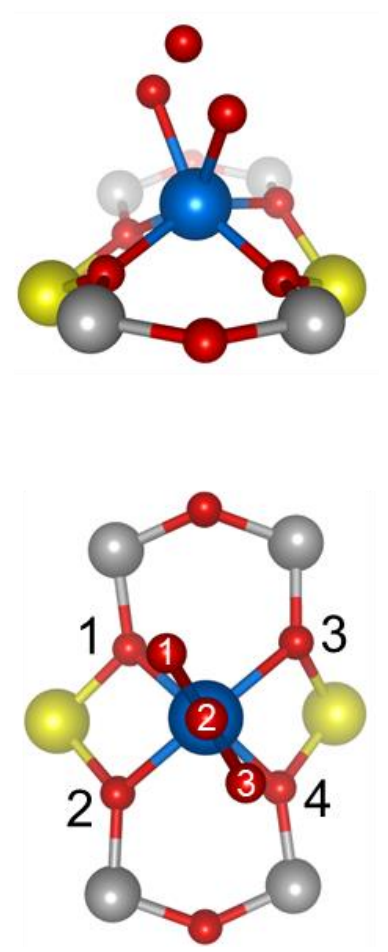

\section{Distance ( $(\AA)$ or bond angle (deg) ${ }^{a}$}

\begin{tabular}{cr}
$\begin{array}{c}\text { angle }(\mathbf{d e g})^{a} \\
\mathrm{Ga}-1 \mathrm{O}_{\mathrm{t}}\end{array}$ & Ground st \\
$\mathrm{Ga}-3 \mathrm{O}_{\mathrm{t}}$ & 2.053 \\
$1 \mathrm{O} \leftarrow 2 \mathrm{O}_{\mathrm{t}}$ & 2.111 \\
$2 \mathrm{O}_{\mathrm{t}}-3 \mathrm{O}_{\mathrm{t}}$ & 1.350 \\
$\angle 1 \mathrm{O}_{\mathrm{t}}-2 \mathrm{O}_{\mathrm{t}}-3 \mathrm{O}_{\mathrm{t}}$ & 1.336 \\
$\mathrm{Ga}-1 \mathrm{O}_{\mathrm{L}}$ & 108.0 \\
$\mathrm{Ga}-2 \mathrm{O}_{\mathrm{L}}$ & 1.976 \\
$\mathrm{Ga}-3 \mathrm{O}_{\mathrm{L}}$ & 2.020 \\
$\mathrm{Ga}-4 \mathrm{O}_{\mathrm{L}}$ & 2.044 \\
$\mathrm{Al}-\mathrm{Al}$ & 1.963 \\
\hline
\end{tabular}

\section{Excited state}

2.072

2.075

1.455

1.448

99.3

1.976

2.027

2.050

1.963

4.912
Change

$+0.019$

$-0.036$

$+0.106$

$+0.113$

$-8.6$

0.000

0.007

$+0.006$

$+0.001$

0.000

${ }^{a} \mathrm{O}_{\mathrm{t}}$ means the oxygen atoms in the ozonide ligand; $\mathrm{O}_{\mathrm{L}}$ means the lattice oxygen atoms.

Figure S43. Optimized electronic-ground and -excited states of the $\left[\mathrm{Ga}-\left(\mathrm{O}_{3}\right)\right]^{2+\bullet}$ species at $6 \mathrm{MR}$ site having T11/T23 configuration, where terminated hydrogen atoms were omitted for clarity. Structural details were summarized in the table. Legend: blue, Ga; yellow, Al; grey, Si; red, O. 


\section{Ground state}
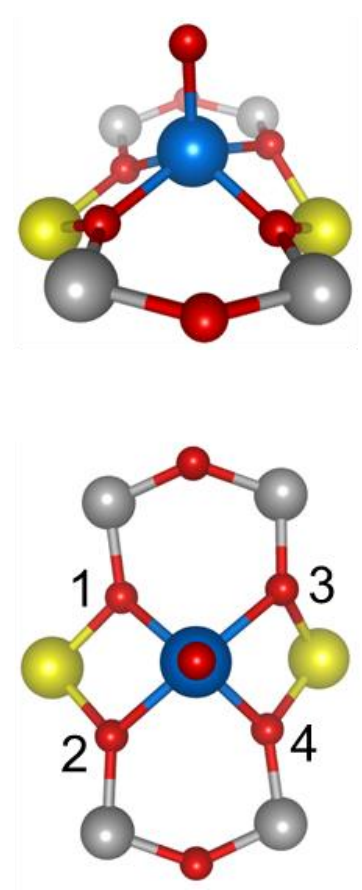

\section{Excited state}
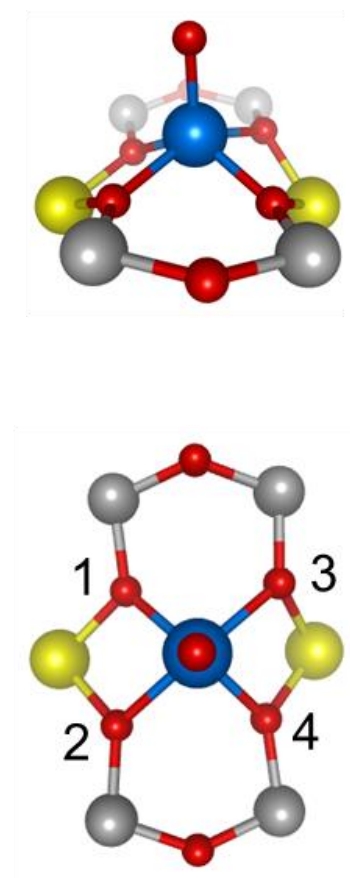

${ }^{a}$ Distance (§̊)

$\mathrm{Ga}-\mathrm{O}_{\mathrm{t}}$

$\mathrm{Ga}-1 \mathrm{O}$

Ga-2OL

Ga-3OL

$\mathrm{Ga}-4 \mathrm{O}_{\mathrm{L}}$

$\mathrm{Al}-\mathrm{Al}$

\section{Ground state}

1.834

1.952

2.029

2.051

1.944

4.926

\section{Excited state}

1.798

1.947

2.027

2.041

1.937

4.931
Change

$-0.036$

$-0.005$

$-0.002$

$-0.010$

$-0.007$

$+0.005$

${ }^{a} \mathrm{O}_{\mathrm{t}}$ means the terminal oxyl bound to gallium; $\mathrm{O}_{\mathrm{L}}$ means the lattice oxygen atoms.

Figure S44. Optimized electronic-ground and -excited states of the $[\mathrm{Ga}-\mathrm{O}]^{2+\bullet}$ species at $6 \mathrm{MR}$ site having T11/T23 configuration, where the terminated hydrogen atoms were omitted for clarity. Structural details were summarized in the table. Legend: blue, Ga; yellow, Al; grey, Si; red, O. 


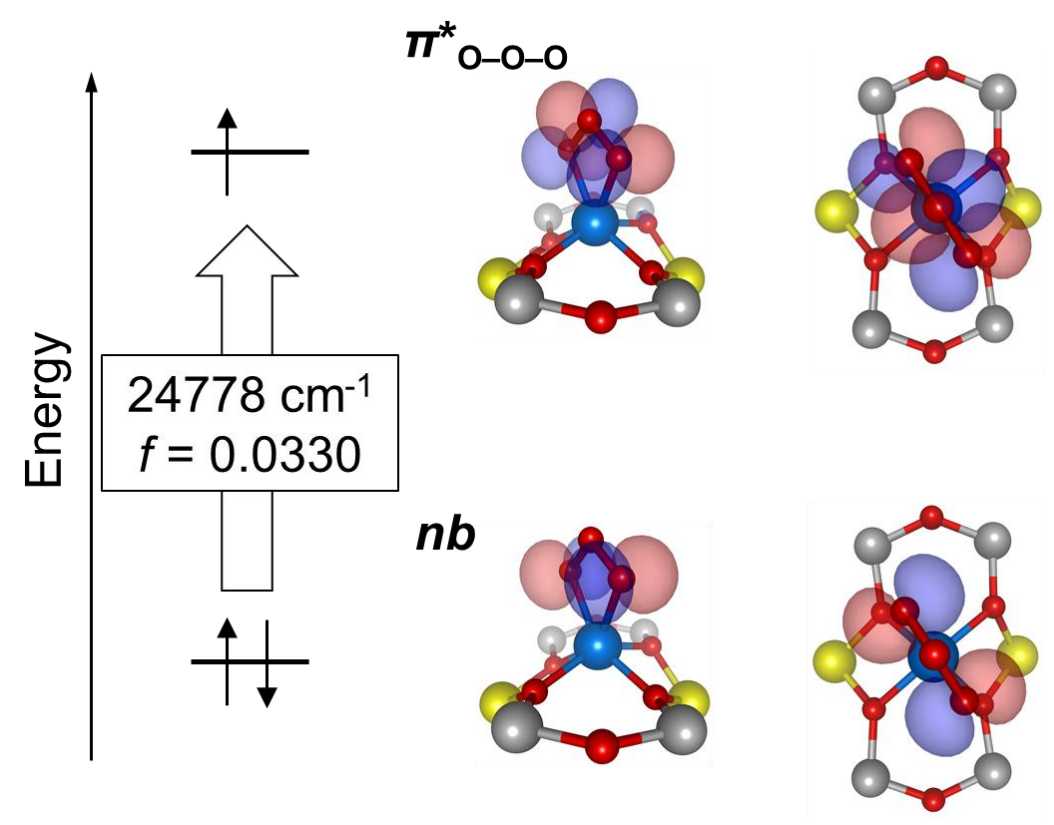

Figure S45. TD-DFT predicted excitation involved in the vibronic progressions of the Gall-ozonide species. The $\boldsymbol{n} \boldsymbol{b} \rightarrow \boldsymbol{\pi}^{*}$ o-o-o excitation is the orbitally allowed transition, as evidenced by $f=0.0330$. Legend: blue, Ga; yellow, Al; grey, Si; red, O.
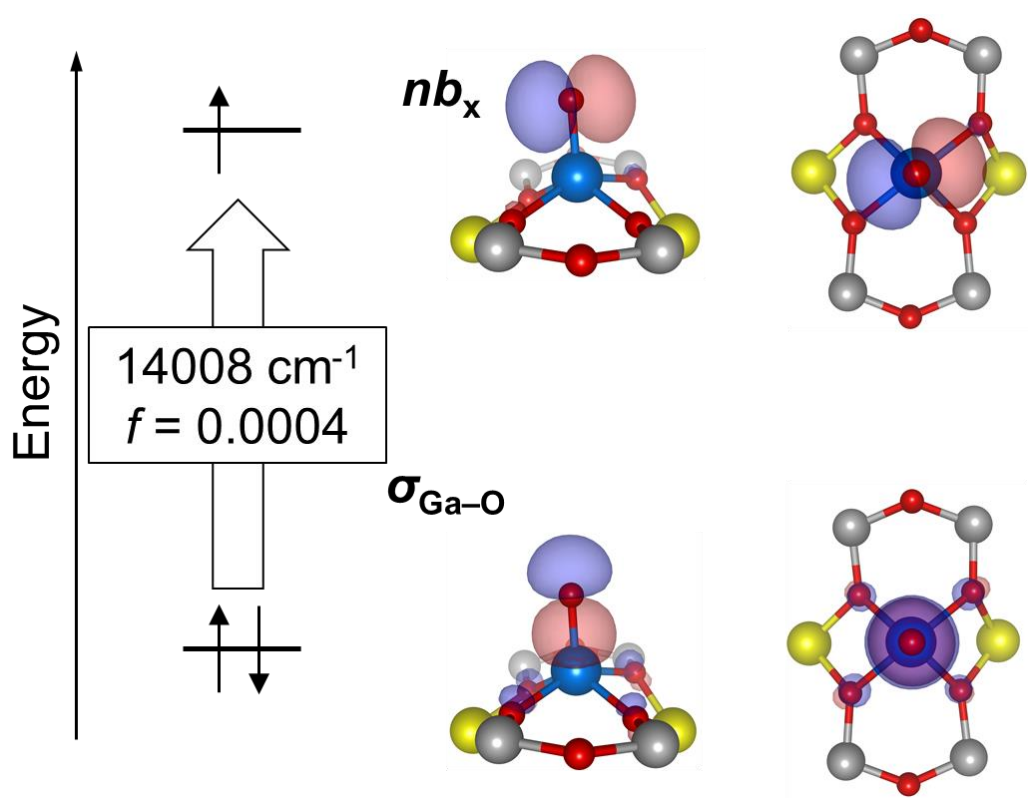

Figure S46. TD-DFT predicted excitation involved in the vibronic progressions of the Ga"ll-oxyl species. the $\boldsymbol{\sigma} \mathrm{Ga}_{\mathrm{O}-\mathrm{O}} \rightarrow \boldsymbol{n} \boldsymbol{b}_{\mathbf{x}}$ excitation of the oxyl is a near-forbidden transition $(f=0.0004)$ because the $\boldsymbol{\sigma} \boldsymbol{G}_{\mathrm{Ga}-\mathrm{O}} \rightarrow \boldsymbol{n} \boldsymbol{b}_{\mathbf{x}}$ transition can be considered as the $\mathbf{2} p_{z} \rightarrow \mathbf{2} p_{x}$ forbidden transition due to the large contributions of the O-2p atomic orbitals to both $\boldsymbol{\sigma}_{\mathrm{Ga}-\mathrm{O}}$ and $\boldsymbol{n} \boldsymbol{b}_{\mathbf{x}}$. Legend: blue, Ga; yellow, Al; grey, Si; red, O. 
A)

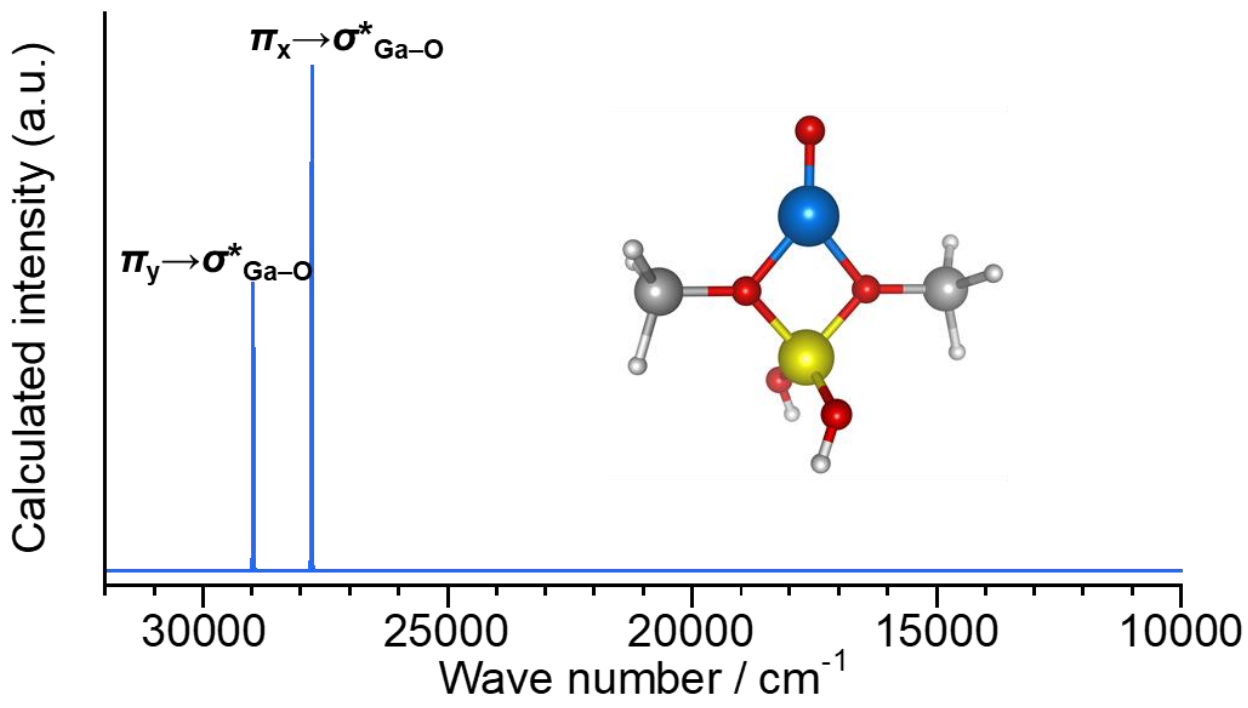

B)
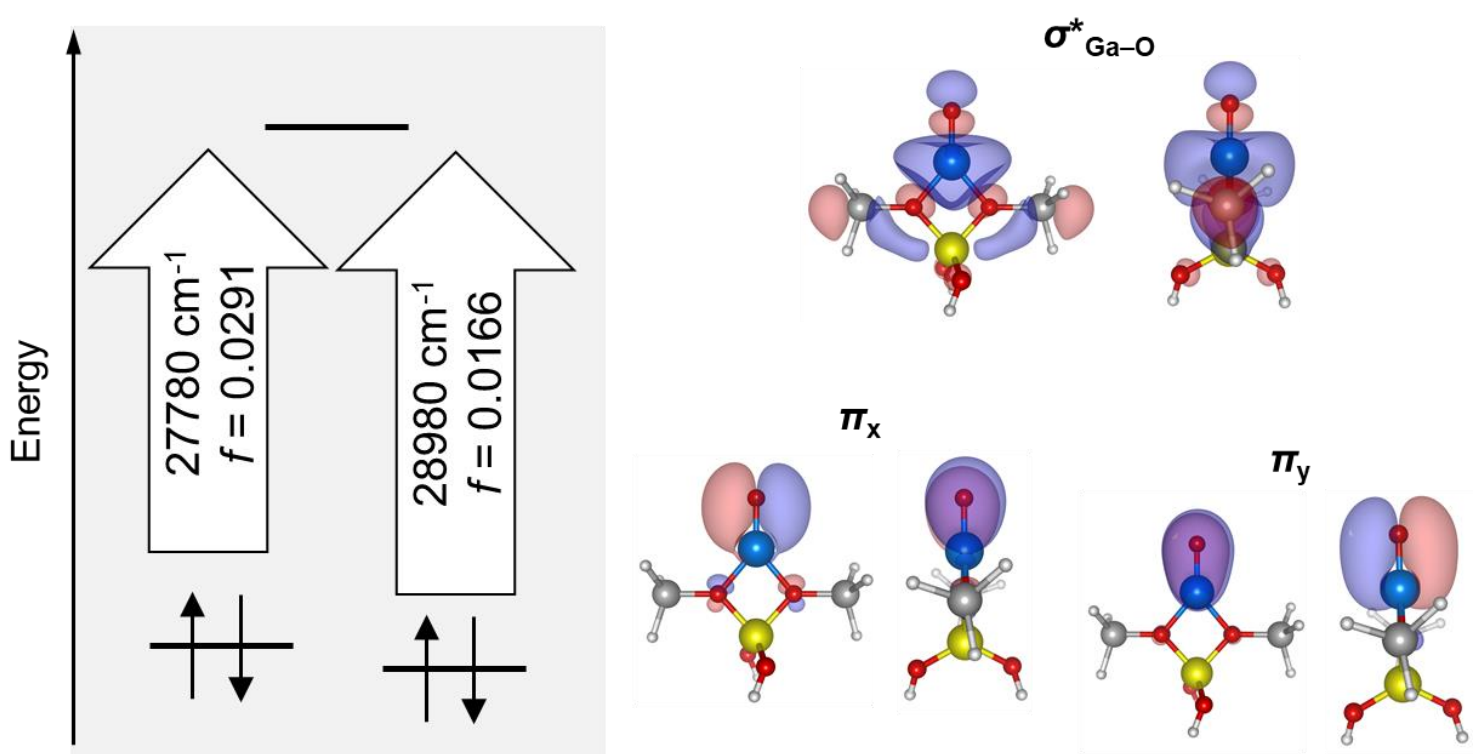

Figure S47. (A) Computed UV-Vis-NIR spectrum of the fully optimized [ $\mathrm{GaO}]-\mathrm{AlSi}_{2} \mathrm{O}_{4} \mathrm{H}_{8}$ geometry $(\mathrm{S}=0$ ). (B) Assignments of two dominant peaks in the UV region; excitation energies, oscillator strengths, and Kohn-Shame orbitals involving in the excitations were summarized. Legend: blue, Ga; yellow, Al; grey, Si; red, O. 


\section{References}

[S1] (a) Kazansky, V.; Subbotina, I.; Van Santen, R.; Hensen, E., DRIFTS study of the chemical state of modifying gallium ions in reduced Ga/ZSM-5 prepared by impregnation: I. Observation of gallium hydrides and application of CO adsorption as a molecular probe for reduced gallium ions. J. Catal. 2004, 227, 263-269; (b) Kazansky, V.; Subbotina, I.; Rane, N.; Van Santen, R.; Hensen, E., On two alternative mechanisms of ethane activation over ZSM-5 zeolite modified by $\mathrm{Zn}^{2+}$ and Ga ${ }^{1+}$ cations. Phys. Chem. Chem. Phys. 2005, 7, 3088-3092; (c) Kazansky, V.; Subbotina, I.; Van Santen, R.; Hensen, E., DRIFTS study of the nature and chemical reactivity of gallium ions in Ga/ZSM-5: II. Oxidation of reduced Ga species in ZSM-5 by nitrous oxide or water. J. Catal. 2005, 233, 351-358; (d) Rane, N.; Overweg, A.; Kazansky, V.; Van Santen, R.; Hensen, E., Characterization and reactivity of $\mathrm{Ga}^{+}$and $\mathrm{GaO}^{+}$cations in zeolite ZSM-5. J. Catal. 2006, 239, 478-485; (e) Gao, P.; Wang, Q.; Xu, J.; Qi, G.; Wang, C.; Zhou, X.; Zhao, X.; Feng, N.; Liu, X.; Deng, F., Brønsted/Lewis acid synergy in methanol-to-aromatics conversion on Ga-modified ZSM-5 zeolites, as studied by solid-state NMR spectroscopy. ACS Catal. 2018, 8 , 69-74; (f) Gao, P.; Xu, J.; Qi, G.; Wang, C.; Wang, Q.; Zhao, Y.; Zhang, Y.; Feng, N.; Zhao, X.; Li, J.; et al. A mechanistic study of methanol-to-aromatics reaction over Ga-modified ZSM-5 zeolites: understanding the dehydrogenation process. ACS Catal. 2018, 8, 9809-9820; (g) Phadke, N. M.; Van der Mynsbrugge, J.; Mansoor, E.; Getsoian, A. B.; Head-Gordon, M.; Bell, A. T., Characterization of isolated Ga ${ }^{3+}$ cations in Ga/H-MFI prepared by vapor-phase exchange of $\mathrm{H}-\mathrm{MFI}$ zeolite with $\mathrm{GaCl}_{3}$. ACS Catal. 2018, 8, 6106-6126; (h) Phadke, N. M.; Mansoor, E.; Bondil, M.; Head-Gordon, M.; Bell, A. T., Mechanism and Kinetics of Propane Dehydrogenation and Cracking over Ga/H-MFI Prepared via Vapor-Phase Exchange of H-MFI with $\mathrm{GaCl}_{3}$. J. Am. Chem. Soc. 2018, 141, 1614-1627; (i) Schreiber, M. W.; Plaisance, C. P.; Baumgärtl, M.; Reuter, K.; Jentys, A.; Bermejo-Deval, R.; Lercher, J. A., Lewis-Brønsted acid pairs in Ga/H-ZSM-5 to catalyze dehydrogenation of light alkanes. J. Am. Chem. Soc. 2018, 140, 4849-4859; (j) Yasumura, S.; Huang, M.; Wu, X.; Liu, C.; Toyao, T.; Maeno, Z.; Shimizu, K., A CHA zeolite supported Ga-oxo cluster for partial oxidation of $\mathrm{CH}_{4}$ at room temperature. Catal. Today 2020, $352,118-126$.

[S2] Van Koningsveld, H.; Jansen, J.; Van Bekkum, H., The monoclinic framework structure of zeolite H-ZSM-5. Comparison with the orthorhombic framework of as-synthesized ZSM-5. Zeolites 1990, 10, 235-242.

Oda, A.; Ohkubo, T.; Yumura, T.; Kobayashi, H.; Kuroda, Y., Identification of a Stable Zn ${ }^{\text {II }-O x y l ~ S p e c i e s ~}$ Produced in an MFI Zeolite and Its Reversible Reactivity with $\mathrm{O}_{2}$ at Room Temperature. Angew. Chem. Int. Ed. 2017, 56, 9715-9718.

[S4] Oda, A.; Ohkubo, T.; Yumura, T.; Kobayashi, H.; Kuroda, Y., Room-Temperature Activation of the C-H Bond in Methane over Terminal $\mathrm{Zn}^{\mathrm{II}}-\mathrm{Oxyl}$ Species in an MFI Zeolite: A Combined Spectroscopic and Computational Study of the Reactive Frontier Molecular Orbitals and Their Origins. Inorg. Chem. 2019, 58, 327-338

[S5] Oda, A.; Nanjo, T.; Ohkubo, T.; Kuroda, Y., Experimental Description of Biomimetic Ni ${ }^{\mathrm{II}}-\mathrm{Superoxo} \delta$-Bond: Franck-Condon Analyses on Its Vibronically-Resolved Spectrum. J. Phys. Chem. C 2020, 11544-11557.

[S6] Oda, A.; Mamenari, Y.; Ohkubo, T.; Kuroda, Y., Spectroscopic Determination of the Site in MFI Zeolite where Cobalt(I) Performs Two-Electron Reduction of $\mathrm{O}_{2}$ at Room Temperature. J. Phys. Chem. C 2019, 123, 17842 17854.

[S7] (a) Tian, Y.; Li, G.-D.; Chen, J.-S., Chemical formation of mononuclear univalent zinc in a microporous crystalline silicoaluminophosphate. J. Am. Chem. Soc. 2003, 125, 6622-6623; (b) Li, L.; Li, G. D.; Yan, C.; Mu, X. Y.; Pan, X. L.; Zou, X. X.; Wang, K. X.; Chen, J. S., Efficient sunlight-driven dehydrogenative coupling 
of methane to ethane over a $\mathrm{Zn}^{+}$-modified zeolite. Angew. Chem. Int. Ed. 2011, 50, 8299-8303; (c) Xu, J.; Zheng, A.; Wang, X.; Qi, G.; Su, J.; Du, J.; Gan, Z.; Wu, J.; Wang, W.; Deng, F., Room temperature activation of methane over Zn modified H-ZSM-5 zeolites: Insight from solid-state NMR and theoretical calculations. Chem. Sci. 2012, 3, 2932-2940; (d) Qi, G.; Xu, J.; Su, J.; Chen, J.; Wang, X.; Deng, F., Low-temperature reactivity of $\mathrm{Zn}^{+}$ions confined in ZSM-5 zeolite toward carbon monoxide oxidation: insight from in situ DRIFT and ESR spectroscopy. J. Am. Chem. Soc. 2013, 135, 6762-6765; (e) Oda, A.; Ohkubo, T.; Yumura, T.; Kobayashi, H.; Kuroda, Y., Synthesis of an unexpected $\left[\mathrm{Zn}_{2}\right]^{2+}$ species utilizing an MFI-type zeolite as a nano-reaction pot and its manipulation with light and heat. Dalton Trans. 2015, 44, 10038-10047; (f) Morra, E.; Berlier, G.; Borfecchia, E.; Bordiga, S.; Beato, P.; Chiesa, M., Electronic and Geometrical Structure of $\mathrm{Zn}^{+}$Ions Stabilized in the Porous Structure of Zn-Loaded Zeolite H-ZSM-5: A Multifrequency CW and Pulse EPR Study. J. Phys. Chem. C 2017, 121, 14238-14245; (g) Shah, M. A.; Raynes, S.; Apperley, D. C.; Taylor, R. A., Framework Effects on Activation and Functionalisation of Methane in Zinc-Exchanged Zeolites. ChemPhysChem 2020, 21, 673-679.

[S8] Serykh, A. I., On photoluminescence properties of gallium-exchanged ZSM-5 zeolite. Chem. Phys. Lett. 2012, $554,159-162$.

[S9] Xiao, Z.; Hauge, R.; Margrave, J., Cryogenic reactions of gallium with molecular hydrogen and methane. Inorg. Chem. 1993, 32, 642-646.

[S10] Pidko, E. A.; Hensen, E. J.; van Santen, R. A., Dehydrogenation of light alkanes over isolated gallyl ions in Ga/ZSM-5 zeolites. J. Phys. Chem. C 2007, 111, 13068-13075.

[S11] (a) Snyder, B. E.; Vanelderen, P.; Bols, M. L.; Hallaert, S. D.; Böttger, L. H.; Ungur, L.; Pierloot, K.; Schoonheydt, R. A.; Sels, B. F.; Solomon, E. I., The active site of low-temperature methane hydroxylation in iron-containing zeolites. Nature 2016, 536, 317-321; (b) Snyder, B. E.; Böttger, L. H.; Bols, M. L.; Yan, J. J.; Rhoda, H. M.; Jacobs, A. B.; Hu, M. Y.; Zhao, J.; Alp, E. E.; Hedman, B. et al. Structural characterization of a non-heme iron active site in zeolites that hydroxylates methane. Proc. Natl. Acad. Sci. U. S. A. 2018, 115, 4565-4570; (c) Bols, M. L.; Hallaert, S. D.; Snyder, B. E.; Devos, J.; Plessers, D.; Rhoda, H. M.; Dusselier, M.; Schoonheydt, R. A.; Pierloot, K.; Solomon, E. I.; et al. Spectroscopic Identification of the $\alpha-\mathrm{Fe} / \alpha-\mathrm{O}$ Active Site in Fe-CHA Zeolite for the Low-Temperature Activation of the Methane C-H Bond. J. Am. Chem. Soc. 2018, 140, 12021-12032.

[S12] Oda, A.; Torigoe, H.; Itadani, A.; Ohkubo, T.; Yumura, T.; Kobayashi, H.; Kuroda, Y., Unprecedented reversible redox process in the $\mathrm{ZnMFI-H} 2$ system involving formation of stable atomic $\mathrm{Zn}^{0}$. Angew. Chem. Int. Ed. 2012, 51, 7719-7723.

[S13] Jansen, M.; Nuss, H., Ionic ozonides. Z. Anorg. Allg. Chem. 2007, 633, 1307-1315. 